\title{
Stream water quality and benthic macroinvertebrate ecology in a coal-mining, acid-sensitive region
}

George T. Merovich Jr.

West Virginia University

Follow this and additional works at: https://researchrepository.wvu.edu/etd

\section{Recommended Citation}

Merovich, George T. Jr., "Stream water quality and benthic macroinvertebrate ecology in a coal-mining, acid-sensitive region" (2007). Graduate Theses, Dissertations, and Problem Reports. 2594.

https://researchrepository.wvu.edu/etd/2594

This Dissertation is protected by copyright and/or related rights. It has been brought to you by the The Research Repository @ WVU with permission from the rights-holder(s). You are free to use this Dissertation in any way that is permitted by the copyright and related rights legislation that applies to your use. For other uses you must obtain permission from the rights-holder(s) directly, unless additional rights are indicated by a Creative Commons license in the record and/ or on the work itself. This Dissertation has been accepted for inclusion in WVU Graduate Theses, Dissertations, and Problem Reports collection by an authorized administrator of The Research Repository @ WVU.

For more information, please contact researchrepository@mail.wvu.edu. 


\title{
STREAM WATER QUALITY AND BENTHIC MACROINVERTEBRATE ECOLOGY IN A COAL-MINING, ACID-SENSITIVE REGION
}

\author{
George T. Merovich, Jr.
}

\author{
Dissertation submitted to the \\ Davis College of Agriculture, Forestry, and Consumer Sciences \\ at West Virginia University \\ in partial fulfillment of the requirements \\ for the degree of
}

Doctor of Philosophy

in

Forestry and Natural Resources

Dr. J. Todd Petty, Committee Chairperson

Dr. Kyle J. Hartman

Dr. Stuart A. Welsh

Dr. Jeffrey G. Skousen

Dr. Paul F. Ziemkiewicz

Wildlife and Fisheries Resources Program

Morgantown, West Virginia

2007

Keywords: acid precipitation, acid mine drainage (AMD), aquatic geochemistry, benthic macroinvertebrates, community structure, diagnosing stressors, indicator species, multiple stressors, thermal pollution, multivariate analysis, stream classification, stream ecosystem integrity, watershed restoration, water quality

Copyright 2007 George T. Merovich, Jr. 


\section{ABSTRACT \\ Stream Water Quality and Benthic Macroinvertebrate Ecology in a Coal-Mining, Acid-Sensitive Region}

\section{George T. Merovich, Jr.}

Acid mine drainage (AMD) and acid rain are important sources of impairment to streams in the Tygart Valley and Cheat River basins in north central West Virginia, USA. Due to a network of abandoned mined lands and bond forfeiture sites in this coal-mining region, AMD represents severe, but rather localized impacts to water quality. AMD is a consequence of the chemical oxidation of reduced geological minerals (sulfides) usually associated with coal during mining operations. The reactions produce aqueous solutions high in sulfates and dissolved metals when the minerals are exposed to the oxic environment through land disturbance. In addition, the weakly buffered and mostly acid producing to circum-neutral mineral geology of this region makes surface waters susceptible to the chemical consequences of acid rain. Acid rain forms when gaseous compounds of nitrogen and sulfur from fossil fuel combustion react with atmospheric moisture.

I tested a classification system based on water chemistry in streams of these two basins. Streams of the region ranged from very good water quality (reference type) to increasingly impaired by AMD (moderate to severe AMD types). Streams with soft water had characteristics associated with the impacts from acid rain, and streams with hard water were either natural occurrences or were influenced by alkaline materials injected into water to treat acid sources. A transitional water quality type was recognized, which was very difficult to characterize because of its gradation in chemistry across the spectrum from reference and hard water types to waters increasingly influenced by AMD.

It is commonly observed that benthic macroinvertebrates in streams from unpolluted waters are distributed continuously without being organized into discrete communities. The discreteness of water quality observed in this research, however, suggests that benthic macroinvertebrates ought not to be distributed continuously, but rather should correspond discretely to water quality types as distinct communities. Therefore, I tested the expectation that macroinvertebrate communities should be distributed in concordance with water quality types in the Cheat River basin. Multivariate models suggested that water quality types significantly structured macroinvertebrates. Measures of classification strength by water quality on community composition were weak, but significant. Indicator species analysis found several important macroinvertebrate genera that were linked especially to reference and soft water quality types.

In the Cheat River mainstem, benthic macroinvertebrate communities and a measure of stream ecosystem health were highly correlated to spatial and temporal inputs of AMD and thermal effluent. However, when these stressors occurred simultaneously, stream health and community structure did not recover with downstream improvements in water quality as they did when stressors occurred singly. In the Cheat River mainstem overall, AMD was responsible for most degradation, but AMD in combination with thermal effluent was also responsible for extensive loss of ecological integrity in the Cheat Canyon region. Consequently, local water chemistry accounts for the distributions of benthic macroinvertebrates in the Cheat basin. Therefore, macroinvertebrates may respond in predictable ways to restoration efforts that reduce 
harmful chemical constituents associated with acidic impacts. Large, watershed-scale attributes may be needed to explain variation in benthic macroinvertebrate communities not captured by local water quality types. 


\section{Acknowledgements}

I'm indebted to many folks that have made this dissertation possible. Our lab, not just me, was instrumental in collecting much of the data contained herein. Donna Hartman identified many of the bug samples and Jered Studinski often helped ID problematic specimens. The expression has been said many times by others, but it is worth saying here...if it wasn't for Donna's help I would still be identifying bugs. But, identifying the scores of bugs would not have been possible either if it was not for numerous undergraduate wildlife and fisheries students who labored over sieves and picked out bugs with forceps from a bunch of sticks, leaves, and mud-for hours on end. I thank Tony Grubb, John Bruning, Sarah Bitter, Jason Clingerman, Mathias Hickman, Eric Gladwell, Dustin Smith, and Chris Harvey. Jennifer Fulton collected most of the water quality data, often by herself. Brock Reggi, Jennifer Fulton, Zach Liller, Jason Clingerman, and Tony Grubb helped collect benthic samples in the field. I also thank Dr. Steven Kohler and Craig Mains for discussion on bug ID and sampling / sub-sampling strategies. I have learned that analytical prowess, I believe, is key to knowing how to proceed in research after a ruthless knowledge of the literature suggests the appropriate questions to pursue. I thank more people than I can list here...Roy Martin, Dr. Jason Freund, Zina Hense, Jason Clingerman, Zach Liller, Dr. Jim Stiles, Sarah McClurg, Walt Veselka, Holly Henderson, Jered Studinski, and Jason Stolarski for statistical discussions. Even though you guys often ask me for my help, I have learned much trying to answer your questions. I hope I succeeded somewhat. There is often no better way to learn than to try to explain things to others, and I thank you all for that opportunity. I thank my committee members Dr. Stuart Welsh, Dr. Kyle Hartman, Dr. Jeff Skousen, Dr. Paul Ziemkiewicz, and Dr. Todd Petty. I appreciate your willingness to train me as scientist and share your enthusiasm for research and teaching. I especially thank Todd Petty for his unremitting efforts to support me in everything I have encountered here at WVU, reminding me tacitly about being practical, and guiding me through this journey. I hope we continue to share our interest for streams and, if you see fit, to collaborate after my stay at WVU has expired. Finally, my endeavors would not have been possible without the universal and unconditional support of my parents, Vicky and George Merovich (Sr.), and my wife Cathy and daughter Emily. Thanks for your inspiration and endurance. 


\section{Table of Contents}

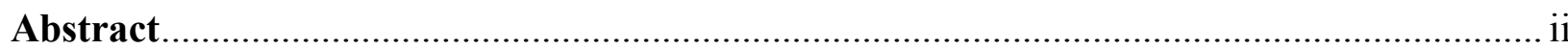

Acknowledgements ................................................................................................. iv

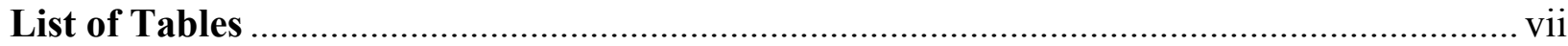

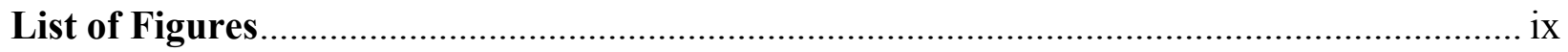

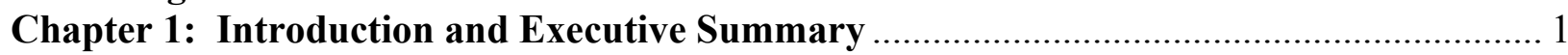

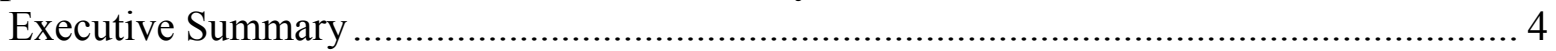

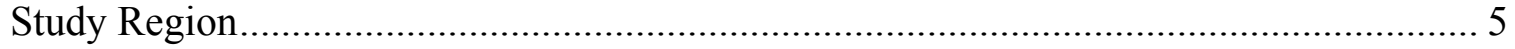

Summary of Research Objectives and Results ……………..................................... 8

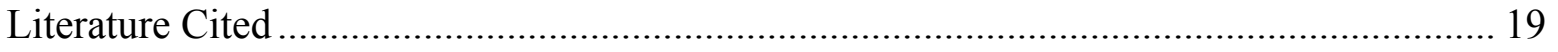

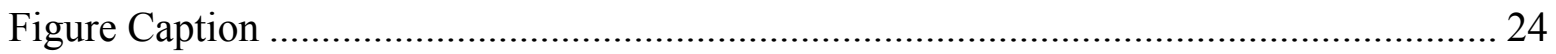

Chapter 2: Water Chemistry Based Classification of Streams and Implications for

Restoring Mined Appalachian Watersheds......................................................................... 26

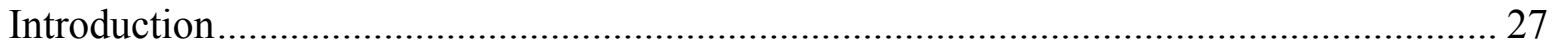

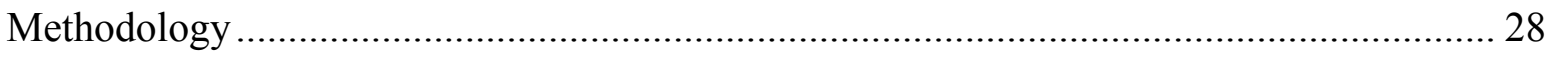

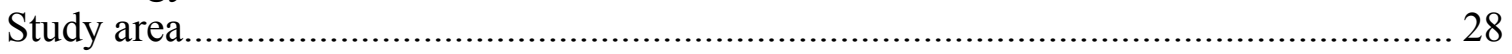

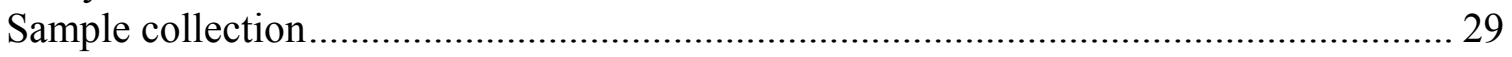

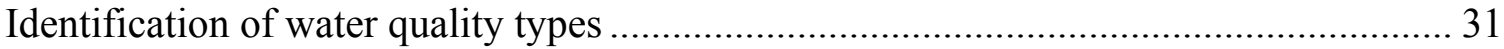

Verification and chemical description of water quality clusters...................................... 32

Temporal variation in water quality clusters and impairment criteria............................... 33

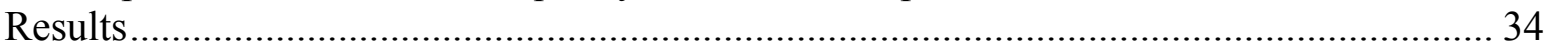

Identification and verification of water quality types .................................................... 34

Chemical description of water quality types.................................................................. 36

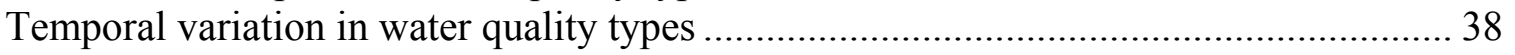

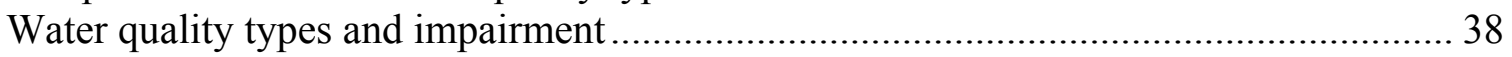

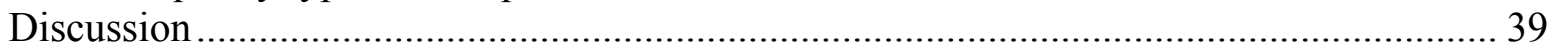

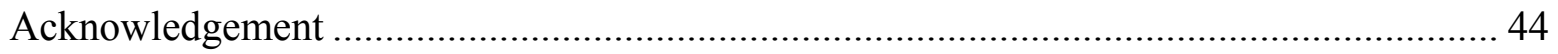

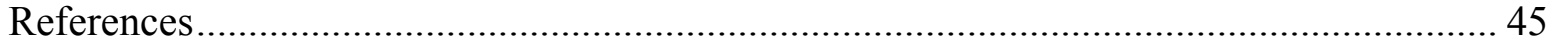

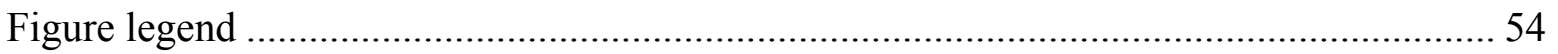

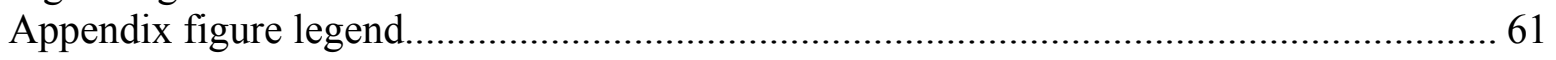

Chapter 3: Correspondence between Stream Macroinvertebrates and a Discrete

Disturbance Gradient: Consequences for Diagnosing Stressors ...........................................6 63

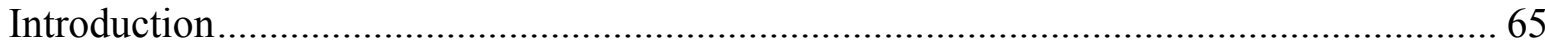

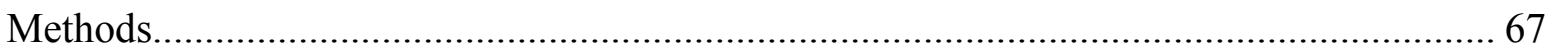

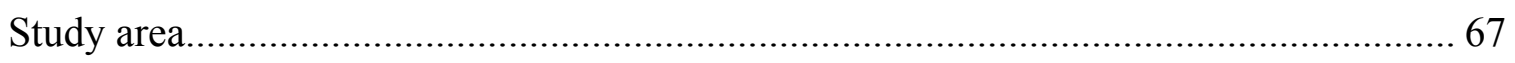

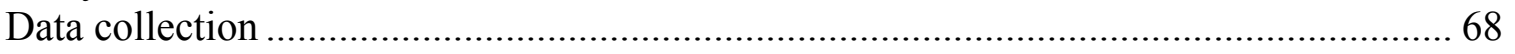

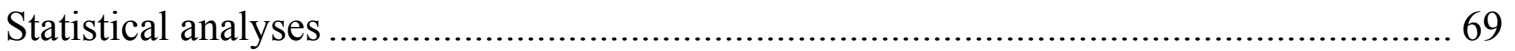

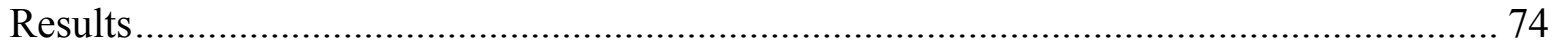

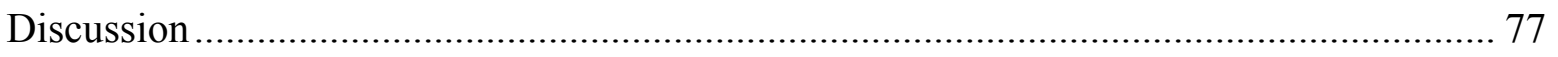

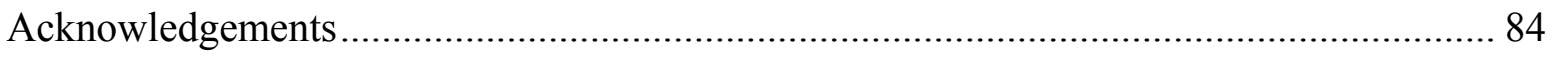

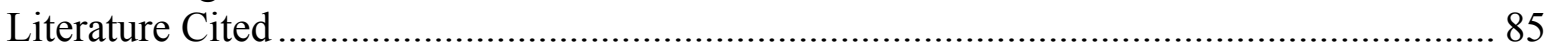

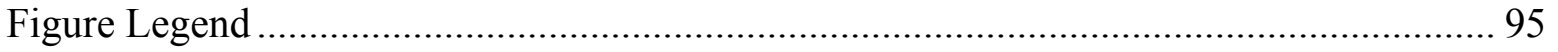


Chapter 4: Interactive Effects of Multiple Stressors and Restoration Priorities in a Mined

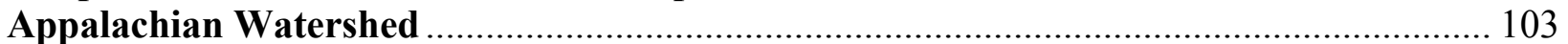

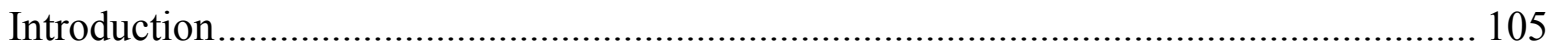

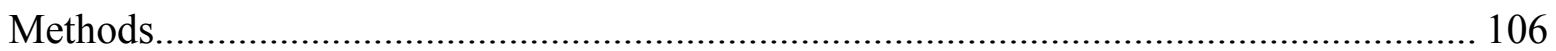

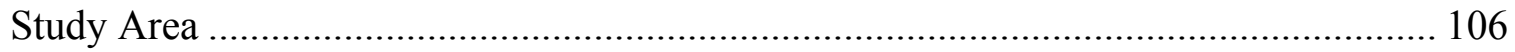

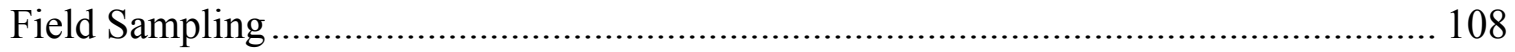

Water Chemistry and Temperature ........................................................................ 108

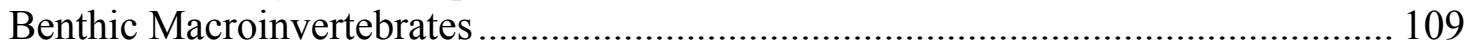

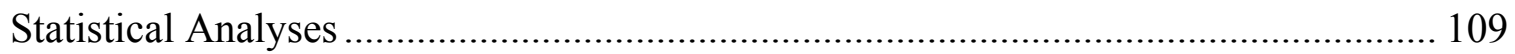

Water Chemistry and Temperature ......................................................................... 109

Ecological Condition and Invertebrate Community Similarity ................................... 110

Assigning Levels of Ecological Impairment to Each Stressor and Identifying

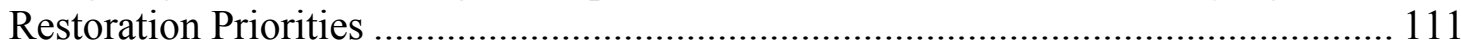

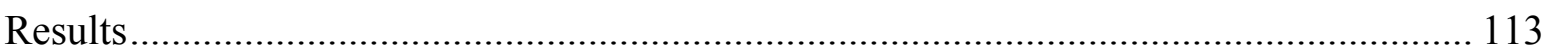

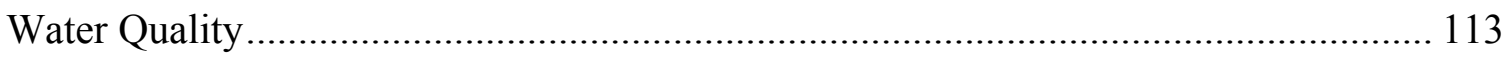

Ecological Condition Based on WVSCI............................................................... 114

Macroinvertebrate Community Similarity .................................................................. 116

Assigning Levels of Ecological Impairment to Each Stressor and Identifying Restoration

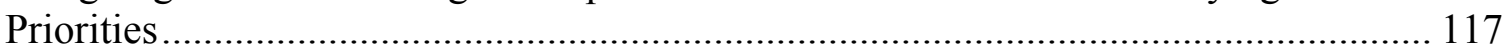

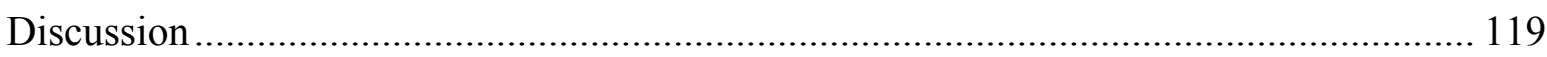

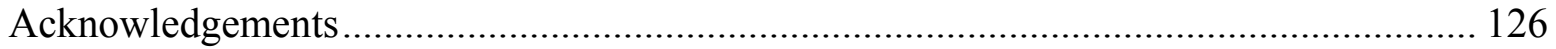

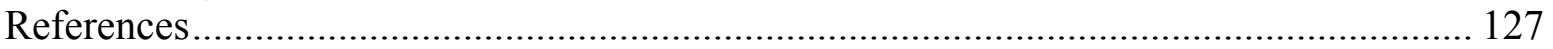

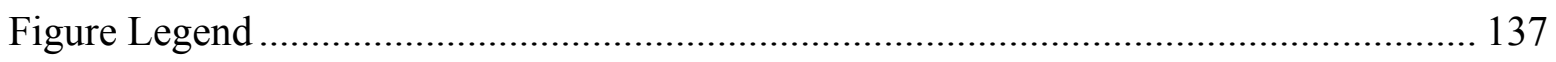

Appendix 1: Submission of Chapter 2 to Environmental Toxicology and Chemistry-

Submission Cover Letters, Reviewers' Comments, and Response to Comments ............... 144

Appendix 2: Submission of Chapter 4 to Hydrobiologia- Submission Cover Letter,

Reviewers' Comments, and Response to Comments ....................................................... 158

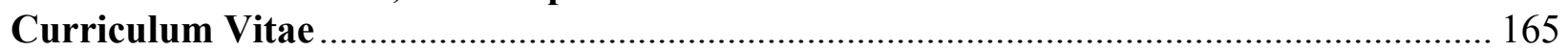




\section{List of Tables}

\section{Chapter 2}

Table 1. Means (and standard deviations) of water quality constituents, and principal component (PC) 1 and PC 2 scores for each water quality type (number in parenthesis is number of samples classifying into that type). For PC 1 and PC 2, means with different letters are statistically different from one another $(p<0.05$; analysis of variance (ANOVA)/Tukey post test). Means are reported in $\mathrm{mg} / \mathrm{L}$ except where indicated. Conductivity (Cond) is reported in $\mu \mathrm{S} / \mathrm{cm}$ and alkalinity (Alk) is reported in $\mathrm{mg} / \mathrm{L} \mathrm{CaCO} 3$ equivalents. AMD $=$ acid mine drainage.

Table 2. Temporal patterns in water chemistry type. Values along the diagonal represent the number $(\%)$ of sites that maintained a constant water quality type from season to season. Off diagonals represent the tendency for the initial water quality type (First Season Type) to change type in subsequent samples (Sub-Season Type). For example, $82 \%$ of the severe acid mine drainage (AMD) samples remained severe AMD type in subsequent samples, whereas $14 \%$ shifted from severe AMD to moderate AMD type in subsequent samples.... 52

Table 3. Number of samples (and \%) within cluster types exceeding specific water quality criteria applicable to West Virginia, USA $(\mathrm{pH}<6.0 ; \mathrm{Fe}>0.5 \mathrm{mg} / \mathrm{L} ; \mathrm{Al}>0.75 \mathrm{mg} / \mathrm{L}$; and $\mathrm{Mn}>1.0 \mathrm{mg} / \mathrm{L})^{\mathrm{a}}$. The number of water samples classified into each water cluster type is also given.

Appendix Table 1. Method detection limits (MDLs) of analytical methods used to determined concentrations of water chemistry parameters in water samples. ICP = inductively coupled plasma-atomic emission spectrometry; IC = ion chromatography. The U.S. Environmental Protection Agency (EPA) method source is also given.

Appendix Table 2. The factor pattern (i.e., loadings) and eigenvalue magnitude for the first four principle components (PC) identified by principal components analysis.

\section{Chapter 3}

Table 1. Results from analysis of similarity (ANOSIM), including all pair wise comparisons. The asterisk indicates statistical difference evaluated at the 0.005 level of significance (Bonferroni adjusted).

Table 2. Water chemistry parameters studied and related to NMDS ordination of macroinvertebrate genera in two dimensions by vector fitting (linear model) and surface fitting (non-linear general additive model) using thin plate splines. Corresponding $R^{2}$ and $p$ values are given.

Table 3. Significant indicator genera (29 of 95 total) sorted by descending indicator value for water quality types determined from dominant water chemistry profile. $P$-values are estimated from 1000 randomizations of the data (sum of all probabilities $=27.7$ ). Relative

frequency and abundance is for genera for their indictor group. 


\section{Chapter 4}

Table 1. Sample sites and locations within major regions defined by stressor type in the Cheat River, WV. Region 2 was the AMD region. Sites in Region 2 containing no dominant stressor were on the side of the river opposite the tributary source of AMD. Upstream distance to the source of the dominant stressor is also listed. DS = Downstream; RR = River Right; $\mathrm{RL}=$ River Left; $\mathrm{A}=\mathrm{AMD} ; \mathrm{H}=$ heat; APS = Albright Power Station.

Table 2. Mean and standard error of water chemistry parameters measured over the study period at sampling sites. Site No. as in Table 1. NA = Not Available

Table 3. Estimates of EUs and EU loss from each of AMD alone, heat alone, and AMD $\mathrm{x}$ heat interaction for Fall 2002 and Spring 2003 across regions of the Cheat River. Estimates for the river overall in both seasons and for the annualized period are also presented. In the fall AMD $x$ heat region where we estimated minimum and maximum loss from each stressor (see Methods), we report the average of those estimates here.

Table 4. Annualized estimates of EUs recoverable (Gain) in Regions 1 - 4 and river-wide (Annual Total) from AMD treatment vs. heat removal. Annualized estimates of total EU loss are also listed. In Region 4 of fall 2002 where we estimated minimum and maximum gain from stressor mitigation (see Methods), we report the average of those estimates. ... 136 


\section{List of Figures}

\section{Chapter 1}

Figure 1. Map of the study area with major rivers labeled. The shaded area of the state of West Virginia inset indicates the location of the Tygart Valley and Cheat river basins.

\section{Chapter 2}

Figure 1. Upper part of the dendrogram from cluster analysis. The portion of the dendrogram with a semi-partial R2 $<0.4$ was not displayed. Labels at the bottom identify discrete water quality clusters (Types 1-6) identified by cluster analysis. 55

Figure 2. Bivariate scatter plot of principal component (PC) 1 and 2 scores for each water chemistry sample. Samples are identified by cluster type assigned by cluster analysis and are descriptively labeled as $\mathrm{A}=$ severe acid mine drainage (AMD), $\mathrm{M}=$ moderate $\mathrm{AMD}, \mathrm{S}$ $=$ soft, $\mathrm{H}=$ hard, $\mathrm{T}=$ transitional, and $\mathrm{R}=$ reference water quality types. Chemical variables with high $(>|0.5|)$ factor loadings on each PC are shown on the corresponding axis. SO4 = sulfate; Cond $=$ conductivity.

Figure 3. Classification tree on water types derived from cluster analysis. The top of each leaf in the tree is labeled with its a priori assigned cluster type (Sev AMD = severe acid mine drainage and Mod AMD = moderate AMD). Also listed is the number of samples per leaf $(\mathrm{N})$ and the predicted distribution of the samples (\#OBS) among the available cluster types where $\mathrm{A}=$ severe $\mathrm{AMD}, \mathrm{M}=$ moderate $\mathrm{AMD}, \mathrm{S}=$ soft, $\mathrm{H}=$ hard, $\mathrm{T}=$ transitional, and $\mathrm{R}=$ reference water quality types. For example, leaf type $\mathrm{Sev}$ AMD had $\mathrm{N}=38$ water samples assigned to it by classification and regression tree (CART) analysis. Only two of the 38 samples actually belonged to another cluster ( $\mathrm{M}$, in this case). MCR is the misclassification rate for a terminal leaf. The misclassification rate for the full tree model was $12 \%$, compared to $64 \%$ for the null model (majority rule). SO $4=$ sulfate.

Appendix Figure 1. Locations of water samples taken within the Tygart Valley and Cheat river basins, West Virginia. Geographic Information System data layers from Natural Resource

Analysis Center, West Virginia University [18].

\section{Chapter 3}

Figure 1. Sample locations within the Cheat River basin, WV (inset), USA.

Figure 2. Cluster dendrogram from agglomerative nesting cluster analysis on Bray-Curtis distance coefficient using flexible beta $($ beta $=-0.5)$ linkage method. Macroinvertebrate communities are labeled by dominant water quality type of the sites from which they were sampled $(\mathrm{A}=$ acid mine drainage; $\mathrm{T}=$ transitional; $\mathrm{S}=$ soft $\mathrm{H}=$ hard; $\mathrm{R}=$ reference $) .. . .98$

Figure 3. Non-metric multidimensional scaling ordination of benthic macroinvertebrate samples (Bray-Curtis distance coefficient) in two dimensions. Stress $=16.0$ in three dimensional 
solution. Two convergent solutions were found after 15 runs. The plot is rotated so axis one contains the largest variance in site scores, and is scaled in half-change units so change in one unit halves community similarity. Sites are labeled as in Figure 2.

Figure 4. Mean similarity dendrogram for benthic macroinvertebrate communities grouped by dominant water quality type. The vertical line is plotted at the overall between-group mean similarity and the horizontal branches extend out to the within-group mean similarity for that group. The name of each dominant water quality type is given at the end of each horizontal branch. The number in parenthesis is number of sites classifying into the group. AMD has 9 sites, because 2 sites with no individuals were deleted from the analysis. The overall within-group mean similarity (Wbar) is also plotted, and it can be interpreted as the center of mass of the plot.

Figure 5. Maximally packed matrix from Nestedness Calculator. The x-axis is taxa and the yaxis is sites labeled by dominant water quality type. Dark blocks represent taxa presences, whereas clear blocks represent taxa absences. Dark blocks to the right of the line are unexpected presences, and clear blocks left of the curved line are unexpected absences assuming a nested pattern.

Figure 6. The NMDS solution from Figure 3 fitted to vectors (Linear) and smooth surfaces (Surf) for water chemistry parameter studied (excluding $\mathrm{Ba}, \mathrm{Cl}$, and $\mathrm{Na}$ ). The R-sq (R2) value for each model is at the top.

\section{Chapter 4}

Figure 1. Study area of the Cheat River, WV. Asterisks and numbers indicate sampling sites (Table 1). The bar on the left of the figure delineates assigned regions along the river. APS $=$ Albright Power Station. GIS database source: NRAC (2001). 138

Figure 2. Temperature and discharge data for the Cheat River. a) Seven-day moving average of the daily average temperature $\left({ }^{\circ} \mathrm{C}\right)$ at selected sites from May-Oct 2002 and 2003. Error bars represent mean daily temperature range. The data points in Region 1 were from a temperature logger deployed at a site $2 \mathrm{~km}$ upstream of site 2 . Of eight loggers deployed during each season, only two were recovered in 2002 and six were recovered in 2003. b) Average daily and overall mean discharge (Q cms) of the Cheat River (5/1/2002 10/13/2003) $2 \mathrm{~km}$ upstream of site 2 (USGS 03069870) in relation to the maximum daily temperature $\left({ }^{\circ} \mathrm{C}\right)$ profile at site 9 just downstream of the Albright Power Station (DS APS) in 2002 and 2003 and at two sites upstream of the Albright Power Station (US APS) with continuous temperature data. In 2002, the US APS temperature site was approximately 2 $\mathrm{km}$ upstream of site 2. In 2003, the US APS site was at sites 5 and 7. The record period for temperature extended from mid May to mid September (2002) — mid October (2003), but ended approximately one month earlier at sites upstream of APS.

Figure 3. West Virginia Stream Condition Index (WVSCI) scores at study sites in fall 2002 and spring 2003. Stream rating categories are indicated by horizontal lines. WVSCI scores at sites 12 and 13 were unavailable in fall 2002. 
Figure 4. Pair-wise similarity (Bray-Curtis index) comparisons in fall 2002 and spring 2003. In each panel, the focal site for comparisons is the site where similarity is 1.0. Invertebrate data at sites 12 and 13 were unavailable in fall 2002.

Figure 5. Non-metric multidimensional scaling (NMDS) ordination of sites on invertebrate data from fall 2002 and spring 2003. The minimum number of dimensions (axes) that best represented the data was 6 (stress $=3.9 \%$ ). NMDS scores from Axis 1 (x-axis) and Axis 2 (y-axis) are plotted. Taxa abundances and invertebrate community metrics with high Spearman Rank correlations $(p<0.05)$ with the axes are listed; arrows indicate their direction of increase. Percent tolerant metric is the percentage of individuals in the sample with tolerance values $\geq 7$ (Gerritsen et al., 2000). Invertebrate data at sites 12 and 13 were unavailable in fall 2002.

Figure 6. Cumulative EU loss (ha) (0.5 km segment scale) along the Cheat River in the downstream direction from Site 1 to the bottom of the study area. 


\section{Chapter 1: Introduction and Executive Summary- Stream Water Quality and Benthic Macroinvertebrate Ecology in a Coal-Mining, Acid-Sensitive Region}

Three themes emerge in this document. The broad theme of my dissertation research is stream ecological integrity - the idea that healthy streams maintain ecosystem structural and functional attributes (physical, chemical, and biological) consistent with those found in undisturbed systems (Barbour et al. 1999, Simon 1999, Hawkins 2006). Stream and riverine ecosystems that are ecologically healthy should not only maintain ecosystem functions, but also should provide sustainable aquatic resources. Structured beneath this broad theme is the theme of classification and association, which recognizes the age-old ecological axiom that organisms are not haphazardly distributed among habitats, but rather there is some non-random, albeit heterogeneous, order. This concept appears in my research where I tests links between benthic macroinvertebrate communities and stream water quality types in an acid polluted region.

Finally, because so many streams are impaired by acid rain and acid mine drainage (AMD) in the study region, and because of the desire to clean them up, prioritizing stream restorationprotection efforts and predicting biotic response to mitigation activities are consistent elements of discussion.

Streams and rivers, from a purely natural science perspective, are incredibly complex and fascinating. They epitomize the hierarchical patch dynamic paradigm that is ensconced in current ecological research (Wu and Loucks 1995). Their heterogeneous, patchy nature is not just a local phenomenon. The heterogeneity is hierarchically arranged in a watershed network (Leibold et al. 2004), where all parts of the riverine system are connected, not only to upstream and downstream structural and functional attributes (Pringle 1997, Freeman et al. 2007), but also to terrestrial processes through organic matter and energy inputs (Hynes 1975). Ward (1989) 
recognized a four-dimensional nature of lotic systems that encompasses this hierarchical organization and spatial interaction. The longitudinal organization of riverine systems, first recognized in the River Continuum Concept of Vannote et al. (1980), is the upstreamdownstream dimension. The lateral dimension includes not only the active channel but also the influence of the floodplain to river ecology documented first in the flood-pulse concept and augmented later in the flow-pulse concept (Tockner et al. 2000). The vertical dimension connects the aquifer and hyporheos to the atmosphere through the stream's surface waters. Time represents the fourth dimension as the stream cycles through seasonal changes. It seems that a fifth dimension would be useful to recognize flow variation from headwaters to the sea because flow is not equivalent to the time or the longitudinal dimension. Perhaps this fifth flow dimension explicitly recognizes the interaction of all dimensions, so that it is apparent, for example, that downstream processes influence upstream structure and function even though flow is unidirectional (Pringle 1997), and that stream hydrographs (flow dimension) vary with the interaction between basin area (longitudinal dimension) and season (time dimension). Many studies have demonstrated that riverine biota and biotic interactions are mediated at multiple scales from the patch to the watershed level (e.g., Palmer et al. 2000), and that downstream processes influence ecological structure and function of upstream reaches (Pringle 1997). Unfortunately, however, stream ecosystems are being altered and destroyed in all dimensions and across all levels of biological organization despite the fact that they carry and deliver an essential component of life - water (Allan 2004, Poff et al. 2006, Le Maitre et al. 2007). Streams are altered or destroyed physically by roads, bridges, culverts, valley-fill mining, and dredging/channelization (Freeman et al. 2007). Biotic pollution (i.e., introduced species) alters or removes native stream communities (Ross 1991, Gray et al. 2005). Pollution from 
chemicals and thermal discharge directly threatens water quality and organisms, and may indirectly affect abundance and distribution of organisms by altering habitat conditions (e.g., Wellborn and Robinson 1996). For example, chemical precipitates from acid mine drainage bury and cement stream bottom habitats, effectively eliminating places for insects and fish to live (DeNicola and Stapleton 2002). It is generally recognized that downstream locations are degraded from the accumulation of upstream impacts (Freeman et al. 2007). But, downstream alteration to stream ecosystems also influences upstream ecology as well (Pringle 1997).

Legally, the Clean Water Act (CWA) mandates that our water resources support healthy aquatic life (Barbour et al. 1999). The rationale for this legal document is self-evident. However, we should all desire a healthy aquatic resource independent of legal considerations, and abstain from degrading it, because we depend on it for our own health and survival. This statement is part and parcel to the general fact that humans require earth's resources and services to survive. These ecosystem services are provided to us for free. With the increasing size of our population, humans will impart even more demand on nature for these services. This increased demand without cognizance of sustainability or impacts jeopardizes the health of ecosystems. We must recognize that we exist because of the services provided to us by nature, and if we squander them we jeopardize our own health. Therefore, my interest with stream ecosystems is not only in their natural structure and function, but also in how stream health and biological communities respond to pollution. Currently, my specific research involves how lotic communities in a coal-mining dominated landscape respond to stressors related to acid impairment. If we understand this link then we can better assess stream ecosystem health and possibly predict how degraded streams may respond to remediation. This knowledge is critical 
because if stream ecosystems cannot support healthy aquatic communities, then we jeopardize our benefits from the resource.

Consequently, my research in stream ecosystem health has an outcome with direct societal benefits. From an anthropocentric point of view, a healthy stream ecosystem indicates a safe, useable resource. From a biocentric perspective, and just as importantly, healthy stream reaches keep the river network intact from headwaters to the ocean, and they keep the river continuum fully linked to terrestrial processes. The overriding goal of my research is to understand the relationships between ecological components that define stream ecosystem health and stressors imposed on the ecosystem from pollution. Results derived from this basic science are important because they provide insight needed to assess and protect our stream water resources.

\section{Executive Summary}

I studied stream ecosystems in the north-central region of West Virginia where impacts from AMD and acid rain often severely degrade ecological condition and water quality. A network of abandoned mined lands and bond forfeiture sites in this coal-mining region are responsible for the severe but rather localized impacts of AMD. Acid mine drainage forms when reduced geological minerals (sulfides) usually associated with coal are exposed to oxidizing conditions during mining operations. The reduced minerals react with water and oxygen in a series of oxidation-reduction reactions to produce aqueous solutions high in sulfates, dissolved metals, and acidity. In addition, the weakly buffered and mostly acid producing to circumneutral mineral geology of this region makes surface waters susceptible to the chemical consequences of acid rain. Acid rain forms when gaseous compounds of nitrogen and sulfur 
from fossil fuel combustion react with moisture in the atmosphere. The chemical reactions produce precipitation with a $\mathrm{pH}$ less than 5.6 , which is the $\mathrm{pH}$ of natural rain fall.

The overriding goal of my research was to understand patterns in benthic macroinvertebrate communities across the range of impairment from these pollution types and their associated stressors, and to link macroinvertebrate communities to specific water chemistry signatures. I had 3 broad research objectives, and each of these make up a published or publishable element of my dissertation. My first objective was to establish a classification system for water quality in streams located in this coal mining-influenced region where AMD and acid rain chemically alter and degrade stream water chemistry. My second objective was to test a priori expectations about community organization of benthic macroinvertebrates in relation to these water quality types. This research draws links between macroinvertebrate communities and water chemistry characteristics and facilitates the identification of specific abiotic (water chemistry) stressors to communities. It also identifies macroinvertebrate taxa that are indicative of specific water quality types. This research has implication for stressor diagnosis, which is currently an active area of research in pollution ecology. My last objective was to distinguish and quantify impairment from individual stressors when multiple stressors interact. In this research I used similarity analysis to examine the extent to which total ecological impairment can be partitioned into impairment from AMD and from thermal pollution when these stressors co-occur. The information is then used to inform restoration priorities.

\section{Study Region}

The location for my dissertation research is the Cheat and Tygart Valley river basins in north-central West Virginia (Fig. 1). Many streams in this region are in excellent ecological 
condition, residing peacefully in the mountains. However, many other streams are impaired by AMD and acid rain (Williams et al. 1999), both of which impart chemical characteristics to surface waters that are incompatible with a diverse and productive ecosystem and severely compromise biotic integrity. Therefore, the region is ideal for studying novel stream classification schemes based on water chemistry, and for testing ecological expectations about how stream biota should relate to these discrete conditions. In addition, the unique combination of AMD and thermal pollution in the Cheat River mainstem presents the opportunity to study how multiple interacting stressors affect riverine communities. This is an area of field ecology that deserves more attention given that multiple stressors are common in aquatic ecosystems.

The Cheat and Tygart Valley rivers are major tributaries to the Monongahela River. Both rivers have their headwaters, in surprisingly close proximity, in high elevation mountains of Pocahontas County and flow northward (Fig. 1). The Tygart Valley River joins the West Fork River near Fairmont, WV to form the Monongahela River, while Shavers and Black Fork rivers join at Parsons, WV to form the Cheat River, which enters the Monongahela in Point Marion, PA, just north of the West Virginia state line. The Central Appalachian and Ridge and Valley physiographic provinces occupy a large portion of each basin, however, the lower portion of the Tygart Valley basin drains significantly more of the Western Allegheny Plateau than does the lower Cheat. Both basins consist of highly variable terrain, soil, and hydrogeology (Yildiz 2004). The entire area is characterized by rounded, parallel upland ridges, which are dissected by numerous valleys, with relief being greatest in the southern portions (McAuley 1995, Yildiz 2004).

Land cover in both basins is over $70 \%$ diverse mesophytic and mountain hardwood forest, of which oak forests dominate. Pasturelands and grasslands, which comprise nearly all of 
the agricultural land use, make up about $18 \%$ of the basins. Urban use including roads, and construction, mining, and related activities each make up about $1 \frac{1}{2} \%$ of land use. Consequently, both the Tygart Valley and Cheat basin are largely rural. The U.S. Census Bureau (2000) estimated that the largest population centers in the Cheat basin support less than 3000 people. In fact, almost the entire southern portion of the Cheat basin is located in the Monongahela National Forest. However, the region was heavily logged at the turn of the $20^{\text {th }}$ century.

The geology of the basins consists of Pennsylvanian-, Mississippian-, and Devonian-aged sedimentary rocks, which have been extensively fractured and folded (McAuley 1995). Above 400-500 $\mathrm{m}$ in elevation, highly dissected bedrock consists of sandstone and other sedimentary rocks, with thin, nutrient-poor, slightly acidic soil layers above (Schwartz and Meredith 1962, Anderson et al. 2000). Other dominant sedimentary rocks are shale, coal, and some limestone. Shaver Fork is underlain by Pennsylvanian shales and sandstone, and some Devonian shale. Devonian shales and sandstone also underlie most of the Cheat River. Greenbrier limestone is locally dominant especially in the southern part of the Cheat and Tygart basins (Randolph and Pocahontas counties) (Schwartz and Meredith 1962).

Coal deposits in the basins are found only in Pennsylvanian strata, which dominate the Tygart Valley river basin and occur mainly in the northern (lower) one-half to one-third of the Cheat basin. Of these deposits, the Allegheny formation containing Kittanning and Freeport coals and the Conomaugh formation containing Bakerstown coal are widespread in the Tygart Valley, but are more characteristic of the lower portions of the Cheat basin (NRAC 2001). They are important in the Blackwater and Red Creek areas of the Cheat also (Schwartz and Meredith 1962, NRAC 2001). The Monongahela formation containing Pittsburgh and Waynesburg coals, among others, makes up only a small portion of the deposits and is mostly found in the 
northwestern part of the Cheat basin and the western portion of the Tygart Valley basin (NRAC 2001). Most coal in the region has been mined from the Allegheny formation, which contains little capacity to neutralize acidity produced from its moderate to high sulfur materials (West Virginia Geologic and Economic Survey 2002, Demchak et al. 2004). Consequently, riverine systems impacted by acidic coal-mine drainages occur more in the lower portion of the Cheat and are more widely distributed, but less abundant, in the Tygart Valley (NRAC 2001).

\section{Summary of Research Objectives and Results}

The overriding goal of my dissertation research is to develop a classification system for stream water quality in this coal-mining region that is sensitive to acidic pollution, and then test the association of benthic macroinvertebrates to these environmental conditions. Because so many streams are chemically impaired by AMD and acid rain, a water quality classification scheme would aid water quality management and restoration efforts. Rosgen (1994) and Montgomery and Buffington (1997) have produced stream classifications based on physical stream attributes. Dodds et al. (1998) have produced a classification of stream water chemistry based on nutrient levels. Each of these classification systems has proven useful, especially that of Rosgen (1994) in applicability to natural stream channel design and restoration. Therefore, it seems logical that a stream classification system based on AMD and acid rain chemistry would benefit efforts to restore impaired streams in the region. For example, the classification could provide statistics on numbers of streams impaired and the chemical constituents responsible for impairment. These data could be used to facilitate identifying groups of streams requiring similar treatment strategies, rather than designing strategies on a case-by-case basis, and this approach would simplify cost estimates. Furthermore, the data could be used to identify 
priorities for management so that highly valuable streams vulnerable to future impacts are protected, and so that easily recoverable streams are returned to productive systems quickly in the efforts to restore the most stream miles and return watershed connectivity (e.g., Freeman et al. 2007).

Stream biota have been used as indicators of stream health for over a century (Williams and Feltmate 1992, Simon 1999). Benthic macroinvertebrates are especially well suited to assessing local stream conditions (Resh et al. 1996). They are ubiquitous and extremely evolutionarily and ecologically diverse (Hauer and Resh 1996). Some taxa are sensitive to pollution sources while others are tolerant. Because they are relatively sedentary compared to other steam biota (e.g., fish), they integrate local environmental conditions over time, and therefore are better indicators of long-term site conditions, whereas water quality monitoring represents conditions only at the time of water sampling (Resh et al. 1996). Consequently, it seems logical that benthic macroinvertebrates at both the organismic and community levels of biological organization should be linked to, and structured by, different water quality types. Most evidence suggests that benthic macroinvertebrate communities are organized along continuous gradients (e.g., McIntosh 1995, Heino 2005) so that distinct community types do not exist or, at best, are inconspicuous. But, because of the severe impacts to water chemistry from AMD and acid rain in the study region, the putative water quality classification scheme suggests that stream macroinvertebrates should be structured in relation to these discrete environmental conditions. Therefore, I test this a priori expectation of discrete community organization and I test for indicator taxa for these conditions.

The use of stream biota as environmental indicators and to diagnose stressors is currently an active areas of research in steam ecosystem health and assessment, in part because 
instantaneous water quality monitoring alone has been realized to be a tenuous surrogate for biological integrity of surface waters (Yoder and Rankin 1998). Hopefully, my research contributes to this broad knowledge base. Furthermore, if benthic macroinvertebrates signify water quality types in this coal-mining region then perhaps they may respond to restoration activity designed to improve water quality and they can be used to assess restoration success. Thus, attainment of and compliance with water quality standards can be evaluated with biological endpoints, the aquatic life use goal that the clean Water Act specifies for surface waters. This would supplement water quality monitoring, which has predominated methods by state and federal agencies to assess biological integrity (Yoder and Rankin 1998).

Because benthic macroinvertebrates are excellent indicators of local stream ecosystem integrity, attributes of their community composition are often used to generate an index of biotic integrity (IBI). An IBI is a multimetric index that combines various community level metrics (e.g., taxon richness, \% dominance) into one score designed to reflect the health or condition of the community and thus the integrity of the ecosystem (see Barbour et al. 1999). In my final major research objective, I used this concept to develop ecological units, a currency representing ecological value that weights the ecological condition of a stream by some dimension, either length or area of stream. I then applied this ecological currency concept with similarity analysis to examine the effects of multiple interacting stressors on stream health, and to calculate specific restoration priorities for treating AMD and managing thermal effluent in the Cheat River.

In the following sections, I highlight the important findings and conclusions of each of the above research topics. Each represents a subsequent chapter in this document, and is published (Chapter 2 and 4) or soon to be submitted for publication (Chapter 3). Style has been formatted as per journal requirements. The subheadings below represent the running head in the 
respective publication. Because these documents were ultimately collaborative, the perspective in each subsequent chapter is therefore in the first person plural.

\section{Water Quality Classification of Streams in a Mined Watershed-Chapter 2 (Merovich et al. 2007).}

Principal component analysis (PCA) identified two important gradients in water chemistry data from the Cheat and Tygart Valley River basins. The strongest trend was an acidity / AMD gradient where water chemistry contained high levels of dissolved metals and sulfates and low $\mathrm{pH}$ at one end of the spectrum, and circum-neutral $\mathrm{pH}$ and low levels of dissolved metals and sulfates at the other end. The other significant trend was a hardness-salinity gradient where water samples varied most importantly in $\mathrm{pH}$, alkalinity, hardness, sodium, and chloride.

Cluster analysis found six distinct water quality groups based on the chemical composition of water samples. When these group assignments from cluster analysis were overlaid on a scatter plot of the first two derived axes from PCA, significant distinction between the identified types was apparent in this multivariate space. The emergence of this pattern along with the significant gradients identified by PCA suggested following nomenclature for the six identified types: Type $1=$ Reference; Type $2=$ Soft; Type $3=$ Transitional; Type $4=$ Hard; Type 5 = Moderate AMD; and Type $6=$ Severe AMD. Analysis of variance on principal component 1 and 2 scores determined that these water quality types were statistically different from one another in terms of their significant overall chemical trends. Classification tree analysis confirmed this distinction, with only a $12 \%$ overall misclassification rate of water quality types based on the total water chemistry dataset. Classification tree analysis found that manganese, sulfate, aluminum, calcium, and zinc concentrations and alkalinity were useful 
chemical variables that distinguished the water quality types identified by cluster analysis and described by PCA.

The water quality types had the following chemical characteristics. The reference type had circum-neutral $\mathrm{pH}$ and low dissolved metal concentrations. The soft water type had low $\mathrm{pH}$, $\mathrm{Ca}, \mathrm{Mg}$, and alkalinity, but had low conductivity, sulfates, and Mn, too. Hard waters contained circum-neutral $\mathrm{pH}$ and elevated conductivity, alkalinity, $\mathrm{Ca}, \mathrm{Cl}, \mathrm{Mg}, \mathrm{Mn}, \mathrm{Na}$, and sulfate, but dissolved metal concentration remained low. The transitional water type was highly variable and probably represented a transition between moderate AMD type and reference type water, because $\mathrm{Mn}$ and $\mathrm{Al}$ were elevated. The moderate $\mathrm{AMD}$ and severe $\mathrm{AMD}$ water types had deceasing $\mathrm{pH}$ and increasing conductivity, dissolved metals, and sulfates.

Water samples were collected during 3 different times (spring 2004-fall 2004-spring 2005) for this study. The general trend in water chemistry for the water quality types was for the initial water type at a site to remain constant from sample to subsequent sample. However, samples that were initially transitional, moderate AMD, or reference type did have some tendency to shift to another water type in subsequent samples. For example, sites with samples initially classifying as moderate AMD type had a tendency to shift to transitional type in subsequent samples. Reference types tended to shift in the same direction also.

The frequency of legal chemical impairment of water varied among the identified water quality types. The severe AMD type had a very high percentage of samples being impaired for $\mathrm{pH}, \mathrm{Al}, \mathrm{Fe}$, and $\mathrm{Mn}$. The moderate AMD type was legally impaired mostly by $\mathrm{pH}$ and $\mathrm{Al}$. The soft water type had a high percentage of samples being impaired, but the reason was for low $\mathrm{pH}$ only. Very few reference type waters had $\mathrm{pH}$ values in the impairment range $(<6.0)$. 
These results suggest that distinct water quality types exist in the Cheat and Tygart Valley river basins where AMD and acid rain are significant sources of chemical impairment. Precipitation and these acid sources interact with basin geology (such as mineral composition of bedrock and soil attributes) to produce either reference, soft, transitional, hard, moderately impacted AMD, or severely impacted AMD water types. The existence of water quality groups we identified by cluster analysis, along with the latent chemical trends revealed by PCA and the specific components responsible for types determined by classification tree analysis, represents a beginning for making monitoring and remediation of impaired waters more efficient. These findings provide an objective decision-making opportunity to prioritize restoration efforts and to implement the appropriate restoration strategies for a given impairment type. For example, a relatively short list of chemical constituents can be used to identify (impaired) water quality types. Also, the existence of water quality types can be used to identify sites requiring the same remediation technologies. Finally, the rates of impairment of the identified water types can be used to prioritize efforts to recover the greatest amount of lost chemical and biological integrity in a watershed.

\section{Macroinvertebrates from Distinct Water Quality Types-Chapter 3 (Merovich and Petty In Prep -- to be submitted to Ecological Applications).}

Cluster analysis showed weak clustering of sites based on macroinvertebrate abundance data from Cheat River tributaries. But, when macroinvertebrate cluster groups were labeled by site water quality types, cluster groups generally contained the same water quality type. For example, macroinvertebrate samples from AMD, soft, and reference streams grouped together, but samples from transitional and hard stream types were widely scattered. In non-metric multidimensional scaling (NMDS) ordination space, benthic macroinvertebrate communities 
broadly corresponded to, but were highly variable within and among, dominant water quality types. However, the water quality classification was a statistically significant grouping of community types. Fourteen water chemistry parameters studied were significantly correlated with the NMDS ordination. All dissolved metals, conductivity, and sulfate increased quickest toward communities from AMD streams. Non-parametric smooth surface models (thin-plate splines) for conductivity, $\mathrm{Al}, \mathrm{Cr}, \mathrm{Cu}, \mathrm{Fe}, \mathrm{Mn}, \mathrm{Ni}, \mathrm{Zn}$, and sulfate improved over the respective linear correlative models. These isosurfaces curved toward AMD sites, suggesting strong nonlinear relationships between communities and especially conductivity, $\mathrm{Al}, \mathrm{Cu}, \mathrm{Fe}, \mathrm{Mn}, \mathrm{Ni}, \mathrm{Zn}$, and sulfate.

Nestedness was a dominant pattern in the macroinvertebrate data, but this was expected because nestedness is a common attribute of ecological communities. The nestedness pattern in macroinvertebrate communities, however, was weakly related to the dominant water quality classification of streams. Results of analysis of similarity showed that communities were more different in composition between the dominant water quality types than expected by chance, and mean similarity analysis indicated that dominant water quality was a significant classification for benthic macroinvertebrate communities. However, both of these tests produced rather weak statistical indexes indicating much variation among groups. Finally, indicator species analysis found 29 indicator genera out of a total of 95 taxa observed. Indicator genera occurred most frequently for reference and soft stream types, and indicator values were very high in these cases. Mayfly genera were the best indicators for reference streams. Black flies and a Leuctrid stonefly were the best indicators for soft streams.

Thus, despite the variability, macroinvertebrate communities had significant discrete association with dominant water quality types found in the Cheat basin. Macroinvertebrate 
communities did not trend very strongly with individual water chemistry parameters. Smooth non-parametric surface models explained more of the variation and demonstrated complex, but still tractable, relationships between macroinvertebrate communities and local water chemistry that were not evident with linear models.

Surprisingly, there were relatively few indicator genera for the water quality classification. The presence of few indicator taxa is consistent with a continuous community model. However, several taxa were very strong indictors for reference and soft stream types, which suggests some discrete community organization. The lack of indicator taxa for transitional streams is not surprising, given the tremendous variation in chemistry and community composition. Therefore, it will continue to be difficult to diagnose the condition of streams in this transitional zone, which is unfortunate because treatment of AMD or acid rain streams with alkaline materials could shift stream chemistry in this direction. In contrast, if stream chemistry shifted to the hard chemistry type, then diagnosis may be possible because a few taxa were significant indicators of this condition in the data set.

Consequently, the multivariate models of benthic macroinvertebrates in this study suggest that variation in community structure can be explained by local water quality type. Additionally, the analyses demonstrate that benthic macroinvertebrates can diagnosis stressors successfully at least at the broad categorical level (e.g., water quality type). It therefore may be possible to predict to some extent the response of benthic macroinvertebrate communities to reclamation efforts aimed to recover streams from AMD or acid rain influence. Likewise, these findings provide evidence that benthic macroinvertebrate communities can serve as proxies to water chemistry monitoring to ensure watershed reclamation projects can assess goals of meeting aquatic life uses of water resources stipulated by the Clean Water Act. 
3. Interactive Effects of Multiple Stressors-Chapter 4 (Merovich and Petty 2007).

In the Cheat River, water quality was severely degraded immediately downstream of tributary inputs of AMD, but recovered quickly further downstream. The effect of thermal effluent from a coal-fired power plant on river water temperatures was observed in summer, but not in spring time. River water temperatures spiked immediately below the input of thermal effluent, but also quickly moderated with distance downstream. However, elevated water temperatures were observed as far as $19 \mathrm{~km}$ downstream.

Variation in ecological condition was strongly correlated to variation in water quality when AMD and heat stress occurred in isolation. Acute inputs of AMD or heat caused predictable reductions in the West Virginia Stream Condition (WV SCI), a benthic macroinvertebrate index of stream biotic integrity, followed by rapid recovery downstream. However, benthic communities failed to recover from combined inputs of heat and AMD even when these stressors occurred at relatively low levels.

Results of similarity analysis were consistent with the response of WV SCI. In both fall 2002 and spring 2003, NMDS ordination of macroinvertebrate data showed that sites upstream of any inputs of AMD or heat tended to group together (were very similar in community composition). These sites contained diverse assemblages of macroinvertebrates known to be associated with unpolluted, reference-quality sites. Sites immediately below AMD or heat inputs were highly displaced from reference sites in NMDS space, especially in spring time. With increasing distance from AMD or heat inputs, sites increasingly became more similar to unimpacted sites in terms of community structure, except when AMD and elevated temperatures co-occurred (fall time) even at dilute levels. 
In fall 2002, $19 \%$ of the total expected ecological units (EUs) were lost as a result of AMD and heat-related stress. Loss in EUs accumulated more rapidly downstream of the thermal effluent and into the region containing both elevated temperatures and AMD. The greatest region-specific loss occurred where AMD and elevated temperatures were combined (62\%). The interaction of heat and AMD (rather than each stressor considered separately) accounted for most of this loss $(47 \%)$. Of the total ecological loss in the river in fall, $17 \%$ occurred where thermal effluent existed alone. In addition, approximately $18 \%$ of the total ecological loss in the river in fall could be attributed directly to AMD, $29 \%$ was attributed to heat, and the remaining $53 \%$ was attributed to the interactive effects of AMD and heat.

In spring 2003, EU loss occurred at a lower rate (10\%). Much of the improvements could be attributed to a lack of a heat impact. In addition, AMD was a significantly more important stressor in spring than fall. Total EU loss attributable to AMD river-wide increased from $18 \%$ in fall to $94 \%$ in spring.

Annualized over the entire river-year, the Cheat River lost $15 \%$ of its EUs that were expected in the absence of heat or AMD-related stress. Heat accounted for $20 \%$ of the loss, AMD accounted for $43 \%$, and the remaining $37 \%$ was attributed to their interaction. Finally, over the annualized period, the region of the river where AMD and heat co-occurred had significantly greater loss of EUs than in regions where these stressors occurred alone, and therefore the region with multiple stressors would recover more lost EUs from stressor mitigation. Where stressors co-occurred, reduction of heat would return more EUs than AMD treatment. Conversely, AMD treatment river-wide would return slightly more EUs lost (49\%) than heat reduction over the annual period. 
Thus, in the region of the river where AMD and heat co-occurred, most of the ecological loss could be attributed to the interaction of these stressors rather than from each individual stressor acting as the dominant limiting factor, even when these stressors where in dilute levels. This is the first field study to find evidence of the interactive effects of multiple stressors on biological communities in a mined watershed. Given that multiple stressors are common in aquatic ecosystems additional studies are needed to better understand the combined role of these anthropocentric impacts on riverine communities. Dilute levels of multiple interacting stressors may be more ecologically damaging than acute inputs of individual stressors.

The ecological currency concept developed for the Cheat River, in combination with similarity analysis allowed the diagnosis each stressor's responsibility for specific levels of biological impairment when stressors co-occurred. This analytical approach provided the following important conclusion for restoring the river. First, AMD is the dominant factor limiting ecological health. Second, heat in combination with AMD produced extensive ecological loss in the lower portion of the river. Consequently, AMD should be the primary target for restoration, but full restoration of the river will require management of both AMD and heat. Finally, this approach to partitioning impairment among stressors and for prioritizing restoration efforts may be valuable to other watersheds with similar management challenges. 


\section{Literature Cited}

Allan, J. D. 2004. Landscapes and riverscapes: the influence of land use on stream ecosystems. Annual Review of Ecology, Evolution, and Systematics 35:257-284.

Anderson, R. M., K. M. Beer, T. F. Buckwalter, M. E. Clark, S. D. McAuley, I. Sams, J. I., and D. R. Williams. 2000. Water quality in the Allegheny and Monongahela River Basins, Pennsylvania, West Virginia, New York, and Maryland, 1996-98. U.S. Geological Survey Circular 1202, U.S. Department of the Interior; U.S. Geological Survey.

Barbour, M. T., J. Gerritsen, B. D. Snyder, and J. B. Stribling. 1999. Rapid bioassessment protocols for use in streams and wadeable rivers: periphyton, benthic macroinvertebrates, and fish. Second Edition. EPA 841-B-99-022, U.S. Environmental Protection Agency; Office of Water, Washington, D.C.

Demchak, J., J. Skousen, and L. M. McDonald. 2004. Longevity of acid discharges from underground mines located above the regional water table. Journal of Environmental Quality 33:656-668.

DeNicola, D. M., and M. G. Stapleton. 2002. Impact of acid mine drainage on benthic communities in streams: the relative roles of substratum vs. aqueous effects. Environmental Pollution 119:303-315.

Dodds, W. K., J. R. Jones, and E. B. Welch. 1998. Suggested classification of stream trophic state: distributions of temperate stream types by chlorophyll, total nitrogen, and phosphorus. Water Research 32:1455-1462.

Freeman, M. C., C. M. Pringle, and C. R. Jackson. 2007. Hydrologic connectivity and the contribution of stream headwaters to ecological integrity at regional scales. Journal of the American Water Resources Association 43:5-14. 
Gray, E. V. S., K. A. Kellogg, and J. R. Stauffer, Jr. 2005. Habitat shift of a native darter Etheostoma olmstedi (Teleostei: Percidae) in sympatry with a non-native darter Etheostoma zonale. American Midland Naturalist 154:166-177.

Hauer, F. R., and V. H. Resh. 1996. Benthic macroinvertebrates. Pages 339-369 in F. R. Hauer and G. A. Lamberti (editors). Methods in Stream Ecology. Academic Press, San Diego, CA, USA.

Hawkins, C. P. 2006. Quantifying biological integrity by taxonomic completeness: its utility in regional and global assessments. Ecological Applications 16:1277-1294.

Heino, J. 2005. Metacommunity patterns of highly diverse stream midges: gradients, chequerboards, and nestedness, or is there only randomness? Ecological Entomology 30:590-599.

Hynes, H. B. N. 1975. The stream and its valley. Verhandlungen der Internationalen Vereinigung fur theoretische und angewandte Limnologie 19:1-15.

Le Maitre, D. C., S. J. Milton, C. Jarmain, C. A. Colvin, I. Saayman, and J. H. J. Vlok. 2007. Linking ecosystem services and water resources: landscape-scale hydrology of the Little Karoo. Frontiers in Ecology and the Environment 5:261-270.

Leibold, M. A., M. Holyoak, N. Mouquet, P. Amarasekare, J. M. Chase, M. F. Hoopes, R. D. Holt, J. B. Shurin, R. Law, D. Tilman, M. Loreau, and A. Gonzalez. 2004. The metacommunity concept: a framework for multi-scale community ecology. Ecology Letters 7:601-613.

McAuley, S. D. 1995. National water-quality assessment program: the Allegheny-Monongahela River basin. NAWQA Fact Sheet, FS-137-95, U. S. Geological Survey. 
McIntosh, R. P. 1995. H. A. Gleason's 'individualistic concept' and theory of animal communities: a continuing controversy. Biological Reviews 70:317-357.

Merovich, G. T., Jr., and J. T. Petty. 2007. Interactive effects of multiple stressors and restoration priorities in a mined Appalachian watershed. Hydrobiologia 575:13-31.

Merovich, G. T., Jr., and J. T. Petty. In Prep. Patterns in macroinvertebrate community structure and correspondence with distinct water quality types in a mined Appalachian watershed: consequences for diagnosing stressors. Ecological Applications.

Merovich, G. T., Jr., J. M. Stiles, J. T. Petty, J. Fulton, and P. F. Ziemkiewicz. 2007. Water chemistry based classification of streams and implications for restoring mined Appalachian watersheds. Environmental Toxicology and Chemistry 26:1361-1369.

Montgomery, D. R., and J. M. Buffington. 1997. Channel-reach morphology in mountain drainage basins. Geological Society of America Bulletin 109:596-611.

NRAC. 2001. Watershed characterization and modeling system version 2.8. Natural Resource Analysis Center, Division of Resource Management. West Virginia University, Morgantown, WV.

Palmer, M. A., C. M. Swam, K. Nelson, P. Silver, and R. Alvestad. 2000. Streambed landscapes: evidence that stream invertebrates respond to the type and spatial arrangement of patches. Landscape Ecology 15:563-576.

Poff, N. L., B. P. Bledsoe, and C. O. Cuhaciyan. 2006. Hydrologic variation with land use across the contiguous United States: geomorphic and ecological consequences for stream ecosystems. Geomorphology 79:264-285.

Pringle, C. M. 1997. Exploring how disturbance is transmitted upstream: going against the flow. Journal of the North American Benthological Society 16:425-438. 
Resh, V. H., M. J. Meyers, and M. J. Hannaford. 1996. Macroinvertebrates as biotic indicators of environmental quality. Pages 647-667 in F. R. Hauer and G. A. Lamberti (editors). Methods in Stream Ecology. Academic Press, San Diego, CA, USA.

Rosgen, D. L. 1994. A classification of natural rivers. Catena 22:169-199.

Ross, S. T. 1991. Mechanisms structuring stream fish assemblages: are there lessons form introduced species. Environmental Biology of Fishes 30:359-368.

Schwartz, F. J., and W. G. Meredith. 1962. Crayfishes of the Cheat River watershed in West Virginia and Pennsylvania. Part II. Observations upon ecological factors relating to distribution. The Ohio Journal of Science 62:260-273.

Simon, T. P. 1999. Introduction: Biological integrity and use of ecological health concepts for application to water resource characterization. Pages 3-16 in T. P. Simon (editor). Assessing the sustainability and biological integrity of water resources using fish communities. CRC Press, New York.

Tockner, K., F. Malard, and J. V. Ward. 2000. An extension of the flood pulse concept. Hydrological Processes 14:2861-2883.

U.S. Census Bureau. 2000. American FactFinder. http://factfinder.census.gov.

Vannote, R. L., G. W. Minshall, K. W. Cummins, J. R. Sedell, and C. E. Cushing. 1980. The river continuum concept. Canadian Journal of Fisheries and Aquatic Sciences 37:130137.

Ward, J. V. 1989. The four-dimensional nature of lotic ecosystems. Journal of the North American Benthological Society 8:2-8.

Wellborn, G. A., and J. V. Robinson. 1996. Effects of a thermal effluent on macroinvertebrates in a central Texas reservoir. The American Midland Naturalist 136:110-120. 
West Virginia Geologic and Economic Survey. 2002. Trace elements in West Virginia Coals. http://www.wvgs.wvnet.edu/www/datastat/te/index.htm.

Williams, D. D., and W. B. Feltmate. 1992. Aquatic insects. Cab International, Oxon.

Williams, D. R., M. E. Clark, and J. B. Brown. 1999. Stream water quality in coal mined areas of the lower Cheat River basin, West Virginia and Pennsylvania, during low-flow conditions, July 1997. Water-Resources Investigations Report 98-4258, U. S. Geological Survey.

Wu, J., and O. L. Loucks. 1995. From balance of nature to hierarchical patch dynamics: a paradigm shift in ecology. Quarterly Review of Biology 70:439-466.

Yildiz, O. 2004. An investigation of the effect of drainage density on hydrologic response. Turkish Journal of Engineering and Environmental Sciences 28:85-94.

Yoder, C. O., and E. T. Rankin. 1998. The role of biological indicators in a state water quality management process. Environmental Monitoring and Assessment 51:61-88. 


\section{Figure Caption}

Figure 1. Map of the study area with major rivers labeled. The shaded area of the state of West Virginia inset indicates the location of the Tygart Valley and Cheat river basins. 


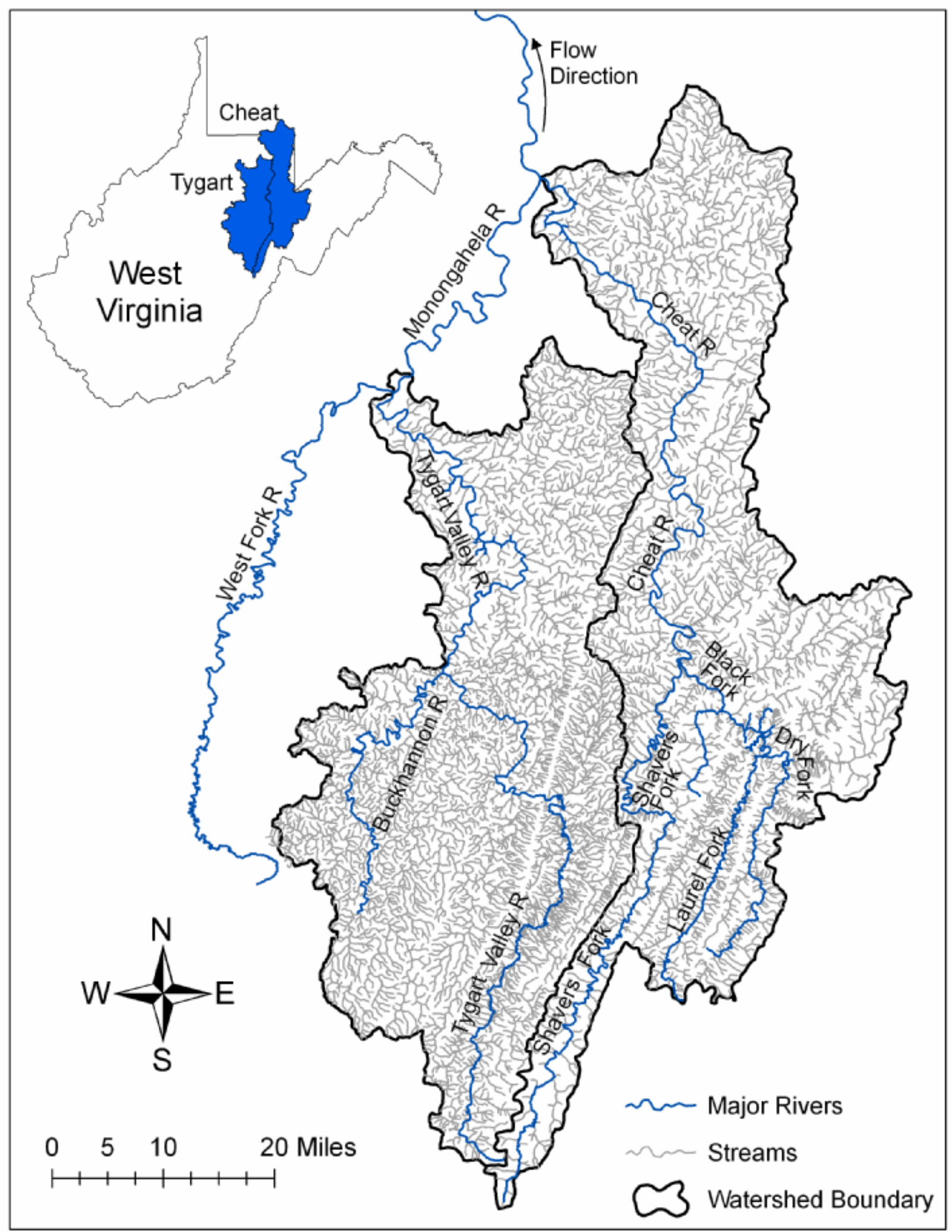

Figure 1. 


\title{
Chapter 2: Water Chemistry Based Classification of Streams and Implications for Restoring Mined Appalachian Watersheds
}

\begin{abstract}
We analyzed seasonal water samples from the Cheat and Tygart Valley river basins, West Virginia, USA, in an attempt to classify streams based on water chemistry in this coalmining region. We also examined temporal variability among water samples. Principal component analysis identified two important dimensions of variation in water chemistry. This variation was largely determined by mining related factors (elevated metals, sulfates, and conductivity) and an alkalinity-hardness gradient. Cluster analysis grouped water samples into six types that we described as Reference, Soft, Hard, Transitional, Moderate acid mine drainage, and Severe acid mine drainage. These types were statistically distinguishable in
\end{abstract} multidimensional space. Classification tree analysis confirmed that chemical constituents related to acid mine drainage and acid rain distinguished these six groups. Hard-, soft-, and severe acid mine drainage type streams were temporally constant compared to streams identified as reference-, transitional-, and moderate acid mine drainage type, which had a greater tendency to shift to a different water type between seasons. Our research is the first to establish a statistically supported stream classification system in mined watersheds. The results suggest that human related stressors superimposed on geology are responsible for producing distinct water quality types in this region as opposed to more continuous variation in chemistry that would be expected in an un-impacted setting. These findings provide a basis for simplifying stream monitoring efforts, developing generalized remediation strategies, and identifying specific remediation priorities in mined Appalachian watersheds.

Keywords - Acid mine drainage; Acid precipitation; Aquatic geochemistry; Stream classification; Watershed restoration 


\section{Introduction}

Coal has been extensively mined in the central Appalachian Mountains for almost 200 years and impacts to water quality from acid mine drainage have been a persistent environmental problem in this region. Acid mine drainage (AMD) forms when pyritic minerals in coal and overburden materials are exposed to water and oxygen $[1,2]$. The result is highly acidic, sulfaterich stream water with high concentrations of total dissolved solids [2]. Acid precipitation has been another significant environmental problem in this region since the mid 1900s [3-5].

Burning fossil fuels releases sulfur dioxide and nitrogen oxides, which react with water, oxygen, and other chemicals in the atmosphere to form various acidic compounds. As a result, precipitation is a solution of dilute sulfuric and nitric acid, which leaches cations (e.g., $\mathrm{Ca}^{2+}$ and $\mathrm{Mg}^{2+}$ ) and metals from the surrounding soils and causes reduced productivity and biodiversity in surface waters [3]. Acid rain and AMD are such extensive problems in the central Appalachians that more than $25 \%$ of streams are negatively affected in West Virginia (WV) alone [6-8]. Given the extent of the acidification problem, integrated watershed restoration programs are needed in this region [7]. However, restoration efforts in the central Appalachians are hindered by the fact that so many streams are impaired. Remediation of AMD is technically difficult and extremely expensive [2]. The overwhelming expense of acid stream restoration stems from the need to access numerous remote locations and the need for continued remediation over time [7]. Consequently, for restoration programs to be successful we need procedures that can be used to identify restoration priorities and effective remediation actions.

Stream classification on the basis of water chemistry may provide an important step towards simplifying water quality management in mined watersheds. Streams with similar water quality would be expected to have similar ecological conditions and require similar remediation 
prescriptions. Instead of designing a remediation plan for each individual stream, remediation plans could be designed for groups of streams of the same water quality type. Stream classification systems on the basis of size [9] and channel morphology [10, 11] have proven to be quite powerful. In addition, Dodds et al. [12] produced an initial classification based on nutrients and chlorophyll to assess trophic status of streams. However, to our knowledge, there have been no attempts to categorize streams in mined watersheds on the basis of water chemistry.

The constituents that define water quality of surface waters are highly variable both spatially and temporally [13-15]. Because of this variation, one would expect that stream water quality would also vary continuously. However, Stiles et al. [16] found several discrete water quality types draining from completely and partially flooded underground mines in the Pittsburgh coal basin. This finding suggests that a water quality based classification of streams draining mined watersheds of this region may be possible.

Given the value of a stream classification system and the lack of such efforts in the central Appalachians, we conducted a watershed-scale survey of water chemistry in streams of the Cheat and Tygart Valley river basins, two intensively mined basins in northeastern WV. Our specific objectives were to use cluster analysis to group water samples from stream reaches into discrete categories based on water chemistry, determine if the water chemistry clusters were statistically distinguishable by describing the chemical characteristics of clusters, and finally quantify seasonal variability in cluster assignment of water samples from the same location.

\section{Methodology}

Study area

The Cheat and Tygart Valley rivers (Appendix Figure 1) are major tributaries to the Monongahela River. Both rivers flow northward from their headwaters located in the mountains 
of Pocahontas County, WV. The Central Appalachian and Ridge and Valley physiographic provinces dominate each basin. Both basins consist of highly variable terrain, soil, and hydrogeology. The entire area is characterized by rounded, parallel upland ridges, which are dissected by numerous valleys, with the relief being greatest in the southern portions [17]. Land cover in both basins is over $70 \%$ diverse mesophytic and mountain hardwood forest, of which oak forests dominate. Pasturelands and grasslands, which comprise nearly all of the agricultural land use, make up about $18 \%$ of the basins. Urban land use activities affect less than $1 \%$ of these watersheds [18].

Geology of the basins consists of Pennsylvanian, Mississippian, and Devonian aged sedimentary rocks, mostly sandstones and shales with thin, nutrient-poor, slightly acidic soil layers above $[19,20]$. Coal deposits are found only in Pennsylvanian strata. Kittanning and Freeport coals within the Allegheny formation, and Bakerstown coal within the Conemaugh formation, are widespread throughout the Cheat and Tygart Valley river basins. Pittsburgh and Waynesburg coals within the Monongahela formation makes up only a small portion of coal deposits [18]. Most coal in the region has been mined from the Allegheny formation, which contains little capacity to neutralize acidity produced from the moderate to high sulfur materials [8].

\section{Sample collection}

Water quality samples were collected at 123 sites distributed throughout the Cheat and Tygart Valley river basins (Appendix Figure 1). Study sites were distributed across a range of stream sizes, elevations, bedrock geology (e.g., sandstone, shale, or limestone), coal geology (e.g., Freeport, Kittanning, or Pittsburgh seams), and relative mining intensity (from un-mined to intensively mined). Sites were spread across the two basins as much as possible to minimize 
interdependency among sites and to capture a wide range of water quality conditions. We know from other studies in this region that water chemistry is influenced predominantly by acidic precipitation and acid mine drainage from abandoned mine lands $[6,7,21]$.

Following suggestions of Petty and Barker [6], three seasonal water samples were obtained at each location, two during early spring (April 2004 and 2005) and another in early autumn (October 2004). Water samples in spring were timed to capture relatively high base flow conditions, whereas the autumn sample was conducted during low base flow conditions. Water samples and direct field measurements were collected in accordance with standard operating procedures of the WV Department of Environmental Protection, with duplicate samples taken at $2.5 \%$ of all sampling locations. Temperature $\left({ }^{\circ} \mathrm{C}\right), \mathrm{pH}$, specific conductivity $(\mu \mathrm{S} / \mathrm{cm})$, dissolved oxygen $(\mathrm{mg} / \mathrm{L})$, and total dissolved solids $(\mathrm{g} / \mathrm{L})$ were measured in the field with a multiparameter YSI 650 unit fitted with a 600XL sonde (Yellow Springs Instruments, Yellow Springs, OH, USA). The YSI probe was calibrated before each use. Average current velocity was measured with a digital Marsh-McBirney flow meter, and discharge $\left(\mathrm{m}^{3} / \mathrm{s}\right)$ was calculated using area-velocity techniques.

Two water samples were collected at each site during each of the three site visits. First, a filtered $250 \mathrm{~mL}$ sample was collected with a pre-rinsed Nalgene polysulfone filter holder and receiver fitted with mixed cellulose ester membrane discs $(0.45 \mu \mathrm{m}$ pore size $)$. Filtered samples were immediately treated with $5 \mathrm{~mL}$ 1:1 nitric acid to maintain dissolved metals in solution. Filtered samples were analyzed within six months for the following dissolved parameters. Aluminum, barium, cobalt, copper, iron, manganese, nickel, cadmium, chromium, calcium, magnesium, sodium, and zinc were analyzed using inductively coupled plasma-atomic emission spectrometry, and chloride was analyzed with ion chromatography. Second, an unfiltered 500 
$\mathrm{mL}$ sample was collected and kept at $4^{\circ} \mathrm{C}$. These samples were analyzed for alkalinity and acidity within $14 \mathrm{~d}$ of collection using an automatic titrator. Sulfate was determined within $28 \mathrm{~d}$ using flow injection analysis. Method detection limits (MDL) and sources of analytical methods are listed in Appendix Table 1. One-half of the value of a method's detection limit for a particular chemical constituent was substituted into the dataset whenever concentrations were less than detection limits. All samples were analyzed at the National Research Center for Coal and Energy at West Virginia University. Quality control and assurance procedures were followed in accordance with standard methods [22].

\section{Identification of water quality types}

We used a combination of principal components analysis (PCA) and cluster analysis (CA) to examine the possibility of discrete water quality types within the water chemistry data. Principal components analysis reduces the dimensionality of a large multivariate data set to a smaller number of newly derived orthogonal variables called principal components (PCs). Principal components are ordered by proportion of variance explained by each [23]. Prior to analysis, all variables except $\mathrm{pH}$ were normalized with the natural logarithm function because PCA assumes variables have a normal distribution. Alkalinity was normalized after adding 1 $\mathrm{mg} / \mathrm{L} \mathrm{CaCO}_{3}$ equivalents to its value because alkalinity can have valid zero values. Total acidity was not included in the analysis because of its strong dependence on other included constituents.

The SAS (SAS Institute, Cary, NC, USA) procedure FACTOR was used with the PRINCIPAL method option to perform PCA, and the procedure SCORE was employed to calculate factor scores for each sample [24]. The constituents included in PCA were pH, specific conductivity, total alkalinity, aluminum, barium, calcium, chloride, cadmium, cobalt, chromium, copper, iron, magnesium, manganese, sodium, nickel, zinc, and sulfate. Principal components 
with eigenvalues $>1.5$ were considered significant. Water chemistry parameters were considered significant components of a PC if their factor loadings had an absolute value $>0.5$ [23].

Cluster analysis was performed with the SAS procedure CLUSTER to identify particular water types in the dataset based on water chemistry parameters that were significant components in PCA [24]. Ward's minimum-variance method was employed with the square of the Euclidean distance measure to define clusters. Because the normalized dataset did not possess any outliers, no trimming algorithms were employed with the Ward method. This analysis was performed on all water samples. However, because $\mathrm{Ba}, \mathrm{Cd}$, and $\mathrm{Cr}$ did not contribute significantly to any of the PCs defined by PCA, these constituents were removed from CA.

\section{Verification and chemical description of water quality clusters}

Our second objective was to determine if the water quality types identified by CA were statistically distinguishable from one another or if sample-to-sample variation in water chemistry was best described continuously. To meet this objective, we used a combination of analysis of variance (ANOVA) and classification and regression tree (CART) analysis. The chemical characteristics of the water types were examined with basic statistics on the water quality constituents of the samples within each type. Basic statistics calculated for each raw water quality constituent and PC score included maximum, minimum, median, mean, and standard deviation. We used ANOVA with post hoc Tukey tests to test for statistical differences in mean PC 1 and 2 scores among the water types. An a priori alpha level was set at 0.05 for this test. Our underlying null hypothesis was that there were no differences in water chemistry as described by the PCs among water types identified by CA.

We used CART analysis to examine the relationship between water quality variables and water quality types derived from CA and to quantify the relative classification strength of the 
types. Classification and regression tree analysis partitions variation in a categorical or continuous response variable by recursively splitting the response variable into groups defined by combinations of explanatory variables that minimize within group variation [25].

Classification and regression tree analysis is a non-parametric statistical technique, and therefore its strength is its ability to find relationships within complex datasets containing multiple variables that may each have different patterns of variance (i.e., lack multivariate normality) [26]. Results of CART are contained in decision trees showing splitting levels of explanatory variables that partition groups. Tree nodes represent splitting levels of explanatory variables that define groups, and tree leaves represent terminal groups, which can be described with summary statistics [25].

Interpretation of CART results is simple and achieved by following the splitting decisions down to terminal leaves. When the response variable is categorical (i.e., classification) the strength of the CART (i.e., classification tree) model can be evaluated by how many observations were misclassified [25]. We implemented the CART algorithm with the $\mathrm{R}$ language and environment for statistical commuting version 2.2.0 [27], which follows Breiman et al.[28]. Group membership defined by CA on water chemistry data (i.e., water type) was the response variable, and the un-transformed water chemistry parameters were the explanatory variables. This analysis allowed us to identify the most important water chemistry predictors of cluster membership and to examine the repeatability of water quality cluster assignment.

\section{Temporal variation in water quality clusters and impairment criteria}

Our final objective was to quantify the extent to which water quality types varied at a given site from season to season. To measure this tendency, we simply tallied the number of times the water type of all sites shifted to another type or stayed the same from sample to 
subsequent sample. The initial cluster type for a site was that observed in spring 2004 when the first water samples were taken. Subsequent water types for a site were those observed during subsequent sampling dates (i.e., fall 2004 then spring 2005).

Finally, water samples were considered in need of treatment (i.e., were impaired) if at least one of $\mathrm{pH}$, aluminum, iron, or manganese did not meet water quality standards. These impairment criteria are in U. S. Environmental Protection Agency [29] and are established for aquatic life and human health use categories. The impairment criterion for iron was considered at chronic doses for trout water use designation $(>0.5 \mathrm{mg} / \mathrm{L})$. Impairment due to aluminum was considered at acute doses for trout waters $(>0.75 \mathrm{mg} / \mathrm{L})$. Manganese and $\mathrm{pH}$ impairment were defined by standards of the human health use category $(>1.0 \mathrm{mg} / \mathrm{L}$ and $<6.0$, respectively).

\section{Results}

Identification and verification of water quality types

We observed high levels of variability in water chemistry among samples distributed across the Cheat and Tygart Valley river basins (Table 1). Principal components analysis reduced this variation to four important components with eigenvalues $>1.0$, but only PC 1 and PC 2 were interpreted (i.e., eigenvalue >1.5) (Appendix Table 2). Combined, PC 1 and PC 2 explained $63 \%$ of the total variance in the water chemistry dataset. Principal component 1 represented a gradient of AMD chemistry where large positive values indicated streams with decreasing $\mathrm{pH}$, high conductivity, and high concentrations of sulfate and dissolved metals (Appendix Table 2). In contrast, PC 2 represented a hardness - salinity gradient. High positive values on PC 2 were characterized by increasing $\mathrm{pH}$, alkalinity, hardness, sodium, and chloride (Appendix Table 2). 
Cluster analysis identified six water chemistry clusters within three hierarchical levels (Figure 1). At the first level, cluster 6 was highly differentiated from the remaining five clusters. At the second level, cluster 1 was differentiated from the remaining four clusters. Finally, clusters 2 and 3 were differentiated from clusters 4 and 5 (Figure 1). A bivariate plot of sites from each cluster in PC 1 and PC 2 space illustrates the general differences in water chemistry among the types identified (Figure 2). This plot suggested that water quality types

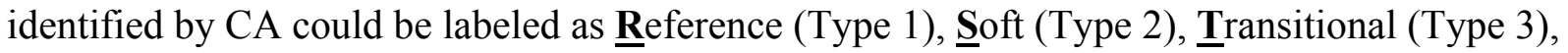
Hard (Type 4), Moderate AMD (Type 5), and Severe $\underline{A} M D$ (Type 6). Figure 2 reflects this labeling convention, as do categories in subsequent tables and figures. Differentiation among Type 1, Types 2-4 as a group, and Types 5 and 6 was predominantly influenced by AMD chemistry as described by PC 1 . In contrast, differentiation among Types $2-4$ was predominantly influenced by alkalinity, water hardness, and salinity as described by PC 2 (Figure 2).

Analysis of variance on mean PC 1 and PC 2 scores indicated a significant level of differentiation among the water quality types identified by CA (Table 1). Analysis of variance detected statistical differences among water quality types on both $\mathrm{PC} 1(\mathrm{~F}=393$; d.f. $=5,369 ; \mathrm{p}$ $<0.0001)$ and PC $2(\mathrm{~F}=126$; d.f. $=5,369 ; \mathrm{p}<0.0001)$ (Table 1). Along PC 1 , all water quality clusters, except the soft water type (i.e., Type 2), differed significantly from the reference type (Table 1; Figure 2). Only the moderate AMD type (i.e., Type 5) was statistically equivalent to the reference type along PC 2 (Table 1; Figure 2).

Classification tree analysis further supported a high level of differentiation among the six water quality types identified by CA (Figure 3). Overall, CART analysis produced a classification tree with a $12 \%$ misclassification rate, meaning that CART correctly classified 
$88 \%$ of the water samples into the water quality type to which they were previously assigned by CA. Manganese, sulfate, aluminum, calcium, and zinc concentrations and alkalinity were all useful variables in distinguishing among the six clusters (Figure 3). Consistent with the results of CA and ANOVA, CART analysis indicated that the reference cluster and the severe AMD cluster were the most highly differentiated groups, with an overall misclassification rate of $3 \%$ for reference and 5\% for severe AMD. Although higher, the misclassification rates of the remaining clusters also were quite low. Soft water type samples were misclassified as transitional types $11 \%$ of the time (Figure 3). Hard water types were misclassified either as transitional or moderate AMD types $10 \%$ of the time. Transitional samples were misclassified at a rate of $17 \%$ and were most often misclassified as reference samples (13 of 26 total misclassifications). The highest rate of misclassification was observed in the moderate AMD type (18\%), which was most often misclassified as a transitional type (Figure 3). The overall low rates of misclassification suggest that the six water chemistry clusters identified by CA may be appropriately considered discrete water quality types.

\section{Chemical description of water quality types}

In combination, our analyses enabled us to describe specific chemical characteristics of the six water quality types identified by CA and verified by ANOVA and CART analysis (Table 1, Figures 2 and 3).

The reference cluster represented water samples characterized by circum-neutral $\mathrm{pH}$, low conductivity, low calcium, chloride, cobalt, magnesium, sodium, nickel, zinc, and sulfate concentrations, and very low aluminum, iron, and manganese concentrations (Table 1, Figure 2 and 3). Streams of this type probably drain un-mined watersheds that contain geological 
attributes that buffer receiving streams from acid precipitation (e.g., higher proportions of shale and limestone).

The soft water cluster possessed highly reduced $\mathrm{pH}$, alkalinity, calcium, and magnesium, low conductivity, and low concentrations of sulfate and manganese (Table 1, Figure 2 and 3). This chemical signature probably is typical of streams draining un-mined watersheds influenced by high acid precipitation rates and low buffering capacity in surrounding soils.

The hard water cluster was characterized by circum-neutral $\mathrm{pH}$ and significantly elevated levels of conductivity, alkalinity, calcium, chloride, magnesium, manganese, sodium, and sulfate (Table 1, Figure 2 and 3). However, concentrations of aluminum, iron, and other metals (e.g., nickel and zinc) remained low. This chemical profile is representative of saline mine drainage characteristic of streams draining mined watersheds where AMD is being actively treated or the surrounding overburden possesses naturally high buffering capacity.

The transitional water cluster possessed highly variable chemistry (Table 1, Figure 2), and consequently, is difficult to describe in a general sense. This cluster is best described as a transitional type between the reference and moderate AMD type. The presence of slightly elevated manganese and aluminum concentrations relative to reference samples suggests that this type is characteristic of highly dilute AMD chemistry (Table 1, Figure 2 and 3).

The moderate AMD cluster was characterized by low to moderate $\mathrm{pH}$ and significantly elevated concentrations of aluminum, iron, manganese, nickel, zinc, and sulfate. Streams of this type probably drain watersheds that have been mined at a moderate level of intensity. In addition, AMD inputs probably are not being actively treated nor are there natural sources of alkalinity in the surrounding overburden. 
The severe AMD cluster possessed extremely low $\mathrm{pH}$, extremely high conductivity, and extremely high concentrations of dissolved metals and sulfate. Streams classifying into this type probably drain intensively mined watersheds abundant in acid-producing minerals with little chemical treatment or geological potential for acid neutralization.

\section{Temporal variation in water quality types}

The general trend in water chemistry over our sampling period was for water types to remain constant from season to season (Table 2). Constancy ranged from 63-95\% depending on water quality type. Water samples classifying as hard were most stable ( $95 \%$ constancy) followed by the severe AMD type ( $82 \%$ constancy) and the soft water type ( $79 \%$ constancy). In contrast, transitional, moderate AMD, and reference types were more likely to shift from one type to another over time $(63 \%, 65 \%$, and $69 \%$ constancy, respectively) (Table 2). Several important patterns of shift from initial water type emerged from our analysis. The reference type always varied in the direction of transitional type, and this occurred $31 \%$ of the time over our sampling period (Table 2). Likewise, the transitional type usually varied in the direction of reference type, and this occurred $18 \%$ of the time (Table 2). The transitional type also had some tendency to move to the hard water type (12\% of the time) and the moderate AMD type ( $6 \%$ of the time) over the sampling period (Table 2). Finally, soft water and moderate AMD types tended to vary toward the transitional type $17 \%$ and $35 \%$ of the time, respectively (Table 2 ).

\section{Water quality types and impairment}

The percentage of samples within a given cluster that possessed legally impaired water quality varied from a low of $8 \%$ in the reference cluster to a high of $100 \%$ in the severe AMD cluster (Table 3). The soft water cluster experienced an impairment rate of $81 \%$, all resulting 
from low pH (Table 3). The moderate AMD cluster had a similar impairment rate of $84 \%$.

However, impairment of this water quality type was a combination of depressed $\mathrm{pH}$ and elevated dissolved metals (Table 3). Transitional and hard water types experienced low to moderate rates of impairment (19\% and 14\%, respectively) but for very different reasons. The transitional type tended to experience depressed $\mathrm{pH}$, whereas the hard water type was most often impaired by elevated iron and manganese (Table 3).

\section{Discussion}

Although stream chemistry was highly variable across sites, the results of our analyses support the existence of discrete water chemistry types within the Cheat and Tygart Valley river basins. The six stream types that we identified by cluster analysis were significantly different from one another and chemically interpretable in multivariate space. Furthermore, CART produced a classification tree model with a low error rate that was consistent with the patterns extracted from PCA. Interpretation of our combined analyses identified water quality in streams of the Cheat and Tygart Valley river basins as Reference, Soft, Hard, Transitional, Moderate AMD, and Severe AMD types.

Other studies that have attempted to identify and classify water chemistry types have had mixed success. For example, Abollino et al. [13] attempted to classify waters from Antarctic lakes and found that samples did not group neatly in multidimensional space constructed from a suite of selected elements. However, samples from the same lakes tended to group together. Papatheodorou et al. [15] examined ten years of water chemistry data from a shallow, eutrophic Greek lake to determine the dominant factors related to temporal sources of variation in water quality and to classify water samples. They found six principle factors describing variation in the data, but did not find distinct water type clusters. 
In contrast, there have been numerous successful attempts to classify water types in highly impacted water bodies [5, 14, 30-33]. For example, Kowalkowski et al. [30] identified four natural cluster types of water chemistry and were able to distinguish and characterize polluted samples of water from clean samples taken along the Brda River in Poland. McNeil et al. [14] used a similar approach to classify a large, broad-scale water chemistry dataset from Queensland, Australia. Their analysis found nine water types, which subsequently allowed for the designation of provinces characterized by similar water chemistry. Likewise, Lent et al. [31] found good support that a large basin used for drinking water supply in central MA, USA could be classified into three sub-basins based on water chemistry data.

Given findings from studies in other regions where chemical pollution is prevalent, we were not surprised to find discrete water quality types in the Cheat and Tygart Valley basins. However, the occurrence of discrete types does not mean that water chemistry was not highly variable or that it did not vary continuously across samples. In fact, the water quality types we identified varied continuously across the two dominant gradients extracted by PCA (Figure 2). The water type we identified as transitional was notoriously variable. We believe this variability warrants class designation because this type would not exist in the absence of acid inputs from human activity. Other studies using similar analytical approaches as ours have also found highly and continuously variable water chemistry across sites $[5,13-15,31,32]$. Continuous variation in surface water chemistry is common feature of aquatic ecosystems probably because the host of underlying processes also vary continuously [32].

Many natural processes determine surface water chemistry, potential water types, and the accompanying spatial and temporal variability. Especially important factors are basin and aquifer geology, climate, and topography [32]. In our study region, the preponderance of 
sandstone and shale geology favors stream water that is naturally circum-neutral to slightly acidic with low total dissolved solid concentrations and conductivity. Surface waters influenced by limestone occur but are uncommon. Given the natural geochemistry of this region, we would expect un-impacted watersheds to possess a relatively low degree of variability in water chemistry among streams and little if any evidence for discrete water types.

However, our results indicate that acid precipitation and AMD punctuate the range of expected variation in water chemistry and produce discrete water types. This occurs via two mechanisms. First, acidic precipitation produces streams with extremely low conductivity, low buffering capacity, and low $\mathrm{pH}$, as acidic rain and snowfall strip buffering capacity from soils in the surrounding landscape [34]. The soft water type that results is distinct from reference streams where buffering capacity remains intact. Second, mining produces streams with varying degrees of AMD, which along with surrounding geology, results in four additional water types. If the surrounding geology does not possess significant buffering capacity and AMD is dilute, then the transitional type is produced. The moderate and severe AMD types are the result of increasing levels of AMD production from increasingly intensive mining. Finally, the hard water type results when AMD from mining is either treated with calcium and sodium hydroxide, or interacts with high buffering capacity geology.

Although we chose sites to minimize their interdependence, variation in our water chemistry data may have resulted at least in part from spatial autocorrelation even at scales larger than watershed boundaries [35]. Any similarity in chemical composition of sites resulting simply from their location, however, is still variation that warrants inclusion into a classification algorithm for categorization. Overall, our analyses found that definable water types exist in this region where severe anthropocentric stressors (i.e., acid precipitation and AMD) are common. 
These stressors interacting with geologic mechanisms and site location appear to produce distinct water quality types in contrast to more continuous variation in chemistry that would be expected in an un-impacted setting.

Temporal variability in water quality types observed at a given sample location also was an important component in our water chemistry data. Overall, reference, transitional, and moderate AMD types tended to be the most variable streams. This result is consistent with the findings of Petty and Barker [6], who found a high degree of temporal variability in water chemistry of moderately impaired streams. In contrast, the severe AMD, hard, and soft water types were extremely stable. This suggests that increasing pollutant levels tend to produce extreme, but relatively stable chemical conditions.

The modeling and classification success we had in defining water types in this region is valuable because it potentially simplifies decisions needed to restore and protect water quality in mined watersheds. First, our results indicate that a relatively short list of chemical constituents is needed to classify a given water body (i.e., stream or river) into a particular water quality type. These constituents included alkalinity and manganese, aluminum, sulfate, calcium, and zinc concentrations (Figure 3). We also found that a given stream could be consistently classified with two or three samples collected each year across a range of base flow conditions. Consequently, this study makes clear how to efficiently characterize the chemical conditions of streams in mined watersheds.

Second, the existence of meaningful water types translates into groups of streams that could be efficiently restored using similar remediation technologies. For example, streams classifying into transitional or soft water types could be targeted for limestone sand addition, whereas full remediation of the severe AMD streams would require a combination of alkaline 
injection to increase $\mathrm{pH}$ and precipitate metals and anaerobic wetland systems to reduce sulfate concentrations.

Finally, identification of discrete water types along with their relative rates of impairment (Table 3) provides a basis for setting objective restoration priorities in these intensively mined watersheds. For example, our analysis identified soft water types that are highly vulnerable to acidification from acid precipitation. These types of streams should receive the highest priority in a stream restoration program because this type of impairment is so common and because this type is relatively easy to reclaim with processed limestone amendments [36]. This approach would also effectively restore many transitional and moderate AMD streams and quickly recover ecological productivity to many stream miles. In contrast, severe AMD and hard water type streams would receive lower restoration priorities, because reduction of dissolved metal and sulfate concentrations is a very difficult and complex process $[2,8]$. However, these streams should receive long term attention and effort in an ecologically based framework to identify which streams, if restored, would translate into the greatest chemical and ecological benefit to the watershed as a whole [7].

Several important questions extend from this study. It is uncertain whether or not the water quality types that we identified in the Cheat and Tygart Valley basins can be consistently reproduced in other mining regions of Appalachia. If the classification system is reproducible, then it would be possible to develop region-wide, rather than watershed specific, remediation strategies. We also would be interested to know whether or not the water quality types that we identified can be predicted from mapped watershed characteristics (e.g., elevation, geology, drainage area, land cover). If so, then it would be possible to generate continuous maps of expected water quality conditions without having to obtain water chemistry samples from all 
streams in a watershed. Finally, it is unclear whether or not biological communities respond in a predictable manner to the water quality types. Our hypothesis is that such discrete water types should produce discrete community types by punctuating gradual change in community composition [37]. If such relationships exist, then it would be possible to predict community response to remediation actions designed to improve water quality and this would greatly improve our ability to set meaningful restoration priorities.

\section{Acknowledgement}

We thank Jason Freund, Michael Strager, Richard Herd, and Kenneth Stewart for their ideas and contributions to this study. Comments from two anonymous reviewers improved the original version of the manuscript. This paper was prepared with support of a grant from the U.S. Environmental Protection Agency to JTP, PFZ, and JMS under Contract Agreement No. RD83136401-0. Any opinions, findings, conclusions, or recommendations expressed herein are those of the authors and do not reflect the views of the U.S. Environmental Protection Agency. 


\section{References}

1. Stumm W, Morgan JJ. 1996. Aquatic chemistry: chemical equilibria and rates in natural waters. John Wiley \& Sons, Inc., New York.

2. Skousen JG, Sexstone A, Ziemkiewicz PF. 2000. Acid mine drainage control and treatment. In Barnhisel RI, Darmody RG, Daniels WL, eds, Reclamation of drastically disturbed lands, 2nd ed. Agronomy No. 41. American Society of Agronomy and American Society for Surface Mining and Reclamation. Madison, WI., Madison, WI, pp 131-168.

3. Driscoll CT, Lawrence GB, Bulger AJ, Butler TJ, Cronan CS, Eagar C, Lambert KF, Likens GE, Stoddard JL, Weathers KC. 2001. Acidic deposition in the Northeastern United States: Sources and inputs, ecosystem effects, and management strategies. BioScience 51: 180-198.

4. Haines TA. 1981. Acidic precipitation and its consequences for aquatic ecosystems: A review. Trans Am Fish Soc 110: 669-707.

5. Kaufmann PR, Herlihy AT, Baker LA. 1992. Sources of acidity in lakes and streams of the United States. Environ Pollut 77: 115-122.

6. Petty JT, Barker J. 2004. Water quality variability in tributaries of the Cheat River, a mined Appalachian watershed. Presented at 2004 National Meeting of the American Society of Mining and Reclamation and the 25th West Virginia Surface Mine Drainage Task Force, Morgantown, WV.

7. Petty JT, Thorne D. 2005. An ecologically based approach to identifying restoration priorities in an acid-impacted watershed. Restor Ecol 13: 348-357. 
8. Demchak J, Skousen J, McDonald LM. 2004. Longevity of acid discharges from underground mines located above the regional water table. J Environ Qual 33: 656-668.

9. Strahler AN. 1952. Dynamic basis of geomorphology. Geol Soc Am Bull 63: 923-938.

10. Rosgen DL. 1994. A classification of natural rivers. Catena 22: 169-199.

11. Montgomery DR, Buffington JM. 1997. Channel-reach morphology in mountain drainage basins. Geol Soc Am Bull 109: 596-611.

12. Dodds WK, Jones JR, Welch EB. 1998. Suggested classification of stream trophic state: distributions of temperate stream types by chlorophyll, total nitrogen, and phosphorus. Water Res 32: 1455-1462.

13. Abollino O, Aceto M, Buoso S, Gasparon M, Green WJ, Malandrino M, Mentasti E. 2004. Distribution of major, minor and trace elements in lake environments of Antarctica. Antarct Sci 16: 277-291.

14. McNeil VH, Cox ME, Preda M. 2005. Assessment of chemical water types and their spatial variation using multi-stage cluster analysis, Queensland, Australia. J Hydrol 310: 181-200.

15. Papatheodorou G, Demopoulou G, Lambrakis N. 2006. A long-term study of temporal hydrochemical data in a shallow lake using multivariate statistical techniques. Ecol Model 193: 759-776.

16. Stiles JM, Donovan JJ, Dzombak DA, Capo RC, Cook L. 2004. Geochemical cluster analysis of mine water quality within the Monongahela basin. Presented at Proceedings of the 2004 National Meeting of the American Society of Mining and Reclamation and the $25^{\text {th }}$ West Virginia Surface Mine Drainage Task Force, Lexington, KY, USA. 
17. Yildiz O. 2004. An investigation of the effect of drainage density on hydrologic response. Turkish J Eng Env Sci 28: 85-94.

18. NRAC. 2001. Watershed characterization and modeling system version 2.8. Natural Resource Analysis Center, Division of Resource Management. West Virginia University, Morgantown, WV.

19. Anderson RM, Beer KM, Buckwalter TF, Clark ME, McAuley SD, Sams I, J. I., Williams DR. 2000. Water quality in the Allegheny and Monongahela River Basins, Pennsylvania, West Virginia, New York, and Maryland, 1996-98. Rep. U.S. Geological Survey Circular 1202, U.S. Department of the Interior; U.S. Geological Survey.

20. Schwartz FJ, Meredith WG. 1962. Crayfishes of the Cheat River watershed in West Virginia and Pennsylvania. Part II. Observations upon ecological factors relating to distribution. Ohio J Sci 62: 260-273.

21. Merovich GT, Jr., Petty JT. 2007. Interactive effects of multiple stressors and restoration priorities in a mined Appalachian watershed. Hydrobiologia 575: 13-31.

22. Clesceri LS, Greenberg AE, Eaton AD. 1998. Standard methods for the examination of water and wastewater. American Public Health Association, Washington, DC.

23. Hair JF, Jr., Anderson RE, Tatham RL, Black WC. 1995. Multivariate data analysis with readings. Prentice Hall, Upper Saddle River, NJ.

24. SAS Institute. 2003. SAS. SAS Institute Inc. Cary, NC, USA.

25. De'ath G, Fabricius KE. 2000. Classification and regression trees: A powerful yet simple technique for ecological data analysis. Ecology 81: 3178-3192.

26. Raymond B, Watts DJ, Burton H, Bonnice J. 2005. Data mining and scientific data. Arct Antarct Alp Res 37: 348-357. 
27. R Development Core Team. 2005. $R$ : A language and environment for statistical computing. R Foundation for Statistical Computing, Vienna, Austria.

28. Breiman L, Friedman JH, Olshen RA, Stone CG. 1984. Classification and regression trees. Wadsworth International Group, Belmont, CA, USA.

29. U.S. Environmental Protection Agency. 2001. Metals and pH TMDLs for the Cheat River watershed, West Virginia, U.S. Environmental Protection Agency Region 3, Philadelphia, PA.

30. Kowalkowski T, Zbytniewski R, Szpejna J, Buszewski B. 2006. Application of chemometrics in river water classification. Water Res 40: 744-752.

31. Lent RM, Waldron MC, Rader JC. 1998. Multivariate classification of small order watersheds in the Quabbin Reservoir Basin, Massachusetts. J Am Water Resour As 34: 439-450.

32. Guler C, Thyne GD, MCCray JE, Turner AK. 2002. Evaluation of graphical and multivariate statistical methods for classification of water chemistry data. Hydrogeol $J$ 10: $455-474$.

33. Dorval E, Jones CM, Hannigan R. 2005. Chemistry of surface waters: Distinguishing fine-scale differences in sea grass habitats of Chesapeake Bay. Limnol Oceanogr 50: 1073-1083.

34. Wigington PJ, Jr., DeWalle DR, Murdoch PS, Kretser WA, Simonin HA, Van Sickle J, Baker JP. 1996. Episodic acidification of small streams in the Northeastern United States: Ionic controls of episodes. Ecol Appl 6: 389-407.

35. Peterson EE, Merton AA, Theobald DM, Urquhart NS. 2006. Patterns of spatial autocorrelation in stream water chemistry. Environ Monit Assess 121: 571-596. 
36. Hudy M, Downey DM, Bowman DW. 2000. Successful restoration of an acidic native Brook trout stream through mitigation with limestone sand. North Am J Fish Manage 20: 453-466.

37. Heino J. 2005. Metacommunity patterns of highly diverse stream midges: gradients, chequerboards, and nestedness, or is there only randomness? Ecol Entomol 30: 590-599.

38. U. S. Environmental Protection Agency. 1983. Methods for chemical analysis of water and wastes, Environmental Monitoring Systems Support Laboratory, Office of Research and Development, US Environmental Protection Agency, Cincinnati, OH. 


\section{Tables and Figures}

\section{Tables}

Table 1. Means (and standard deviations) of water quality constituents, and principal component (PC) 1 and PC 2 scores for each water quality type (number in parenthesis is number of samples classifying into that type). For PC 1 and PC 2, means with different letters are statistically different from one another $(\mathrm{p}<0.05$; analysis of variance (ANOVA)/Tukey post test). Means are reported in $\mathrm{mg} / \mathrm{L}$ except where indicated. Conductivity (Cond) is reported in $\mu \mathrm{S} / \mathrm{cm}$ and alkalinity (Alk) is reported in $\mathrm{mg} / \mathrm{L} \mathrm{CaCO}_{3}$ equivalents. $\mathrm{AMD}=$ acid mine drainage.

\begin{tabular}{lllllll}
\hline & Reference & Soft (32) & Hard (42) & Moderate & Transitional & Severe \\
& $(98)$ & & AMD (32) & $(134)$ & AMD (37) \\
\hline $\mathrm{pH}$ & $6.9(0.5)$ & $5.0(0.8)$ & $7.1(0.5)$ & $6.0(1.0)$ & $6.8(0.7)$ & $3.5(0.7)$ \\
$\mathrm{Cond}$ & $94(80)$ & $74(96)$ & $591(543)$ & $171(103)$ & $125(130)$ & $703(455)$ \\
$\mathrm{Alk}$ & $21.3(18.8)$ & $2.3(2.9)$ & 82.4 & $25.4(55.9)$ & $22.9(21.3)$ & $0.5(1.6)$ \\
$\mathrm{Al}$ & $0.01(0.01)$ & $0.21(0.14)$ & $0.04(0.05)$ & $0.43(0.97)$ & $0.06(0.08)$ & $9.72(9.37)$ \\
$\mathrm{Ba}$ & $0.03(0.01)$ & $0.03(0.01)$ & $0.04(0.01)$ & $0.04(0.03)$ & $0.04(0.01)$ & $0.03(0.01)$ \\
$\mathrm{Ca}$ & $9.8(9.4)$ & $1.9(1.3)$ & $58.3(33.9)$ & $16.9(12.1)$ & $11.0(7.6)$ & $51.0(45.3)$ \\
$\mathrm{Cd}^{\mathrm{a}}$ & $3.0(0.3)$ & $3.0(0.0)$ & $3.2(8.9)$ & $4.0(2.2)$ & $3.9(1.8)$ & $3.5(1.5)$ \\
$\mathrm{Cl}$ & $1.7(1.5)$ & $1.5(2.2)$ & $48.5(252.3)$ & $3.8(4.4)$ & $6.4(7.6)$ & $3.9(3.1)$ \\
$\mathrm{Co}^{\mathrm{a}}$ & $1.5(1.1)$ & $1.9(1.3)$ & $2.6(2.2)$ & $19.7(95.9)$ & $1.6(3.5)$ & $57.4(47.8)$ \\
$\mathrm{Cr}^{\mathrm{a}}$ & $2.2(1.4)$ & $1.9(1.1)$ & $2.3(1.3)$ & $2.2(1.1)$ & $2.2(1.2)$ & $4.9(3.0)$ \\
$\mathrm{Cu}$ & $1.6(1.5)$ & $2.0(3.1)$ & $2.2(3.2)$ & $2.0(3.1)$ & $1.7(2.4)$ & $15.9(13.4)$ \\
& $0.03(0.03)$ & $0.09(0.1)$ & $0.13(0.33)$ & $0.17(0.13)$ & $0.14(0.11)$ & 12.23
\end{tabular}




\begin{tabular}{|c|c|c|c|c|c|c|}
\hline & $\begin{array}{l}\text { Reference } \\
(98)\end{array}$ & Soft (32) & Hard (42) & $\begin{array}{l}\text { Moderate } \\
\text { AMD (32) }\end{array}$ & $\begin{array}{l}\text { Transitional } \\
\text { (134) }\end{array}$ & $\begin{array}{l}\text { Severe } \\
\text { AMD (37) }\end{array}$ \\
\hline & & & & & & (19.91) \\
\hline $\mathrm{Mg}$ & $1.7(1.6)$ & $0.6(0.4)$ & $15.7(11.0)$ & $4.7(3.6)$ & $2.2(1.2)$ & $18.7(21.6)$ \\
\hline $\mathrm{Mn}$ & $0.01(0.01)$ & $0.07(0.05)$ & $0.35(0.31)$ & $0.38(0.37)$ & $0.10(0.16)$ & $1.85(2.50)$ \\
\hline $\mathrm{Na}$ & $1.6(1.7)$ & $0.7(1.4)$ & $\begin{array}{l}43.6 \\
(124.4)\end{array}$ & $2.9(3.4)$ & $4.8(5.5)$ & $3.9(2.9)$ \\
\hline $\mathrm{Ni}^{\mathrm{a}}$ & $2.4(1.9)$ & $3.1(1.6)$ & $5.3(4.8)$ & $18.5(13.2)$ & $2.4(1.4)$ & $87.9(62.9)$ \\
\hline $\mathrm{Zn}^{\mathrm{a}}$ & $2.9(3.4)$ & $17.5(50.2)$ & $5.2(5.6)$ & $23.3(27.3)$ & $2.3(2.0)$ & $\begin{array}{l}173.6 \\
(121.8)\end{array}$ \\
\hline $\mathrm{SO}_{4}$ & $9.6(11.4)$ & $7.7(3.4)$ & $\begin{array}{l}198.9 \\
(201.2)\end{array}$ & $44.5(47.2)$ & $14.6(8.0)$ & $\begin{array}{l}266.2 \\
(210.1)\end{array}$ \\
\hline PC 1 & $-0.87^{\mathrm{A}}$ & $-0.66^{\mathrm{A}}$ & $0.40^{\mathrm{B}}$ & $-0.18^{\mathrm{C}}$ & $0.94^{\mathrm{D}}$ & $2.25^{\mathrm{E}}$ \\
\hline & $(0.30)$ & $(0.45)$ & $(0.29)$ & $(0.43)$ & $(0.34)$ & $(0.60)$ \\
\hline PC 2 & $-0.00^{\mathrm{A}}$ & $-1.68^{\mathrm{B}}$ & $1.56^{\mathrm{C}}$ & $0.25^{\mathrm{A}}$ & $-0.37^{\mathrm{D}}$ & $-0.90^{\mathrm{E}}$ \\
\hline & $(0.56)$ & $(0.51)$ & $(0.78)$ & $(0.64)$ & $(0.71)$ & $(0.39)$ \\
\hline
\end{tabular}


Table 2. Temporal patterns in water chemistry type. Values along the diagonal represent the number $(\%)$ of sites that maintained a constant water quality type from season to season. Off diagonals represent the tendency for the initial water quality type (First Season Type) to change type in subsequent samples (Sub-Season Type). For example, $82 \%$ of the severe acid mine drainage (AMD) samples remained severe AMD type in subsequent samples, whereas $14 \%$ shifted from severe AMD to moderate AMD type in subsequent samples.

\begin{tabular}{|c|c|c|c|c|c|c|}
\hline Sub-Season & & & Firs & son Type & & \\
\hline Type & & & & & & \\
\hline & Reference & Soft & Hard & Transitional & Moderate & Severe \\
\hline & & & & & AMD & AMD \\
\hline Reference & 47 (69) & $1(4)$ & & $16(18)$ & & \\
\hline Soft & & $19(79)$ & & $1(1)$ & & \\
\hline Hard & & & $21(95)$ & $10(12)$ & & \\
\hline Transitional & $21(31)$ & $4(17)$ & $1(5)$ & $55(63)$ & $7(35)$ & $1(4)$ \\
\hline Moderate & & & & $5(6)$ & $13(65)$ & $4(14)$ \\
\hline AMD & & & & & & \\
\hline Severe AMD & & & & & & $23(82)$ \\
\hline Total & 68 & 24 & 22 & 87 & 20 & 28 \\
\hline Observations & & & & & & \\
\hline
\end{tabular}


Table 3. Number of samples (and \%) within cluster types exceeding specific water quality criteria applicable to West Virginia, USA $(\mathrm{pH}<6.0 ; \mathrm{Fe}>0.5 \mathrm{mg} / \mathrm{L} ; \mathrm{Al}>0.75 \mathrm{mg} / \mathrm{L} ; \text { and } \mathrm{Mn}>1.0 \mathrm{mg} / \mathrm{L})^{\mathrm{a}}$. The number of water samples classified into each water cluster type is also given.

\begin{tabular}{|c|c|c|c|c|c|c|}
\hline \multirow[t]{2}{*}{ Cluster Type } & \multirow{2}{*}{$\begin{array}{l}\text { Number of Samples per } \\
\text { Cluster Type }\end{array}$} & \multirow{2}{*}{$\begin{array}{l}\text { Number of Samples (\%) } \\
\text { Requiring Treatment }\end{array}$} & \multicolumn{4}{|c|}{ Number of Samples Requiring Treatment for: } \\
\hline & & & $\mathrm{pH}$ & $\mathrm{Al}$ & $\mathrm{Fe}$ & $\mathrm{Mn}$ \\
\hline Reference & 98 & $8(8)$ & $8(8)$ & $0(0)$ & $0(0)$ & $0(0)$ \\
\hline Soft & 32 & $26(81)$ & $26(81)$ & $0(0)$ & $0(0)$ & $0(0)$ \\
\hline Hard & 42 & $6(14)$ & $1(2)$ & $0(0)$ & $2(5)$ & $3(7)$ \\
\hline Transitional & 134 & $25(19)$ & $23(17)$ & $0(0)$ & $1(1)$ & $1(1)$ \\
\hline Moderate AMD & 32 & $27(84)$ & $26(81)$ & $17(53)$ & $2(6)$ & $4(13)$ \\
\hline Severe AMD & 37 & $37(100)$ & $37(100)$ & $37(100)$ & $33(89)$ & $22(59)$ \\
\hline
\end{tabular}

\footnotetext{
${ }^{\mathrm{a}} \mathrm{Mn}$ criterion is public water supply standard. The Fe criterion is designated specifically for trout waters in WV and is evaluated at chronic standards; $\mathrm{Al}$ is also designated specifically for trout waters and aquatic life use in general, but is evaluated at acute standards
} [29]. 


\section{Figure legend}

Figure 1. Upper part of the dendrogram from cluster analysis. The portion of the dendrogram with a semi-partial $\mathrm{R}^{2}<0.04$ was not displayed. Labels at the bottom identify discrete water quality clusters (Types 1-6) identified by cluster analysis.

Figure 2. Bivariate scatter plot of principal component (PC) 1 and 2 scores for each water chemistry sample. Samples are identified by cluster type assigned by cluster analysis and are descriptively labeled as $\mathrm{A}=$ severe acid mine drainage (AMD), $\mathrm{M}=$ moderate $\mathrm{AMD}, \mathrm{S}=$ soft, $\mathrm{H}$ $=$ hard, $\mathrm{T}=$ transitional, and $\mathrm{R}=$ reference water quality types. Chemical variables with high $(>|0.5|)$ factor loadings on each $\mathrm{PC}$ are shown on the corresponding axis. $\mathrm{SO} 4=$ sulfate; Cond $=$ conductivity.

Figure 3. Classification tree on water types derived from cluster analysis. The top of each leaf in the tree is labeled with its a priori assigned cluster type ( $\mathrm{Sev} \mathrm{AMD}=$ severe acid mine drainage and Mod AMD = moderate AMD). Also listed is the number of samples per leaf $(\mathrm{N})$ and the predicted distribution of the samples (\#OBS) among the available cluster types where A $=$ severe $\mathrm{AMD}, \mathrm{M}=$ moderate $\mathrm{AMD}, \mathrm{S}=$ soft, $\mathrm{H}=$ hard, $\mathrm{T}=$ transitional, and $\mathrm{R}=$ reference water quality types. For example, leaf type $\mathrm{Sev}$ AMD had N=38 water samples assigned to it by classification and regression tree (CART) analysis. Only two of the 38 samples actually belonged to another cluster ( $\mathrm{M}$, in this case). $\mathrm{MCR}$ is the misclassification rate for a terminal leaf. The misclassification rate for the full tree model was $12 \%$, compared to $64 \%$ for the null model (majority rule). SO4 = sulfate. 
Figure 1.

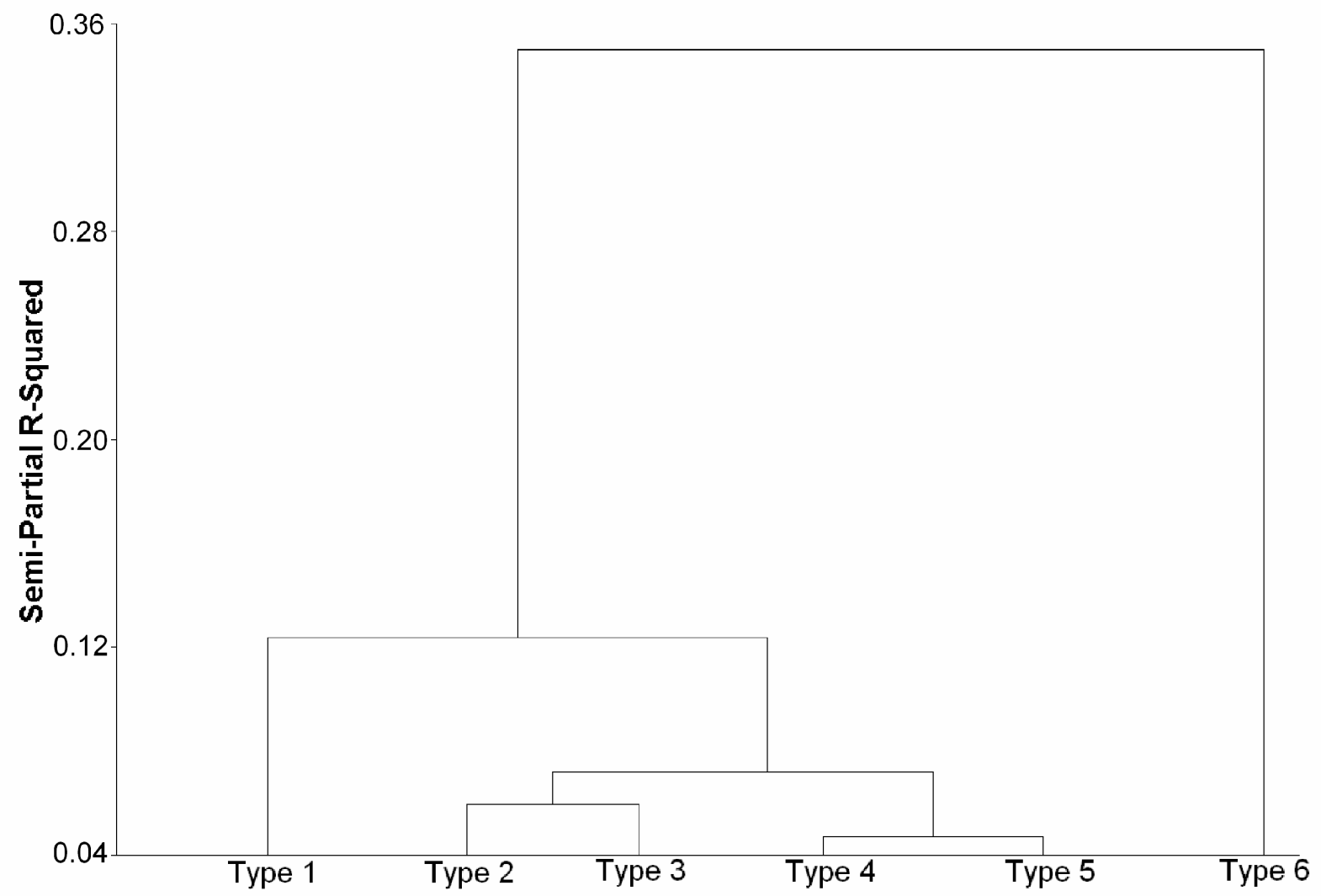




\section{Figure 2.}

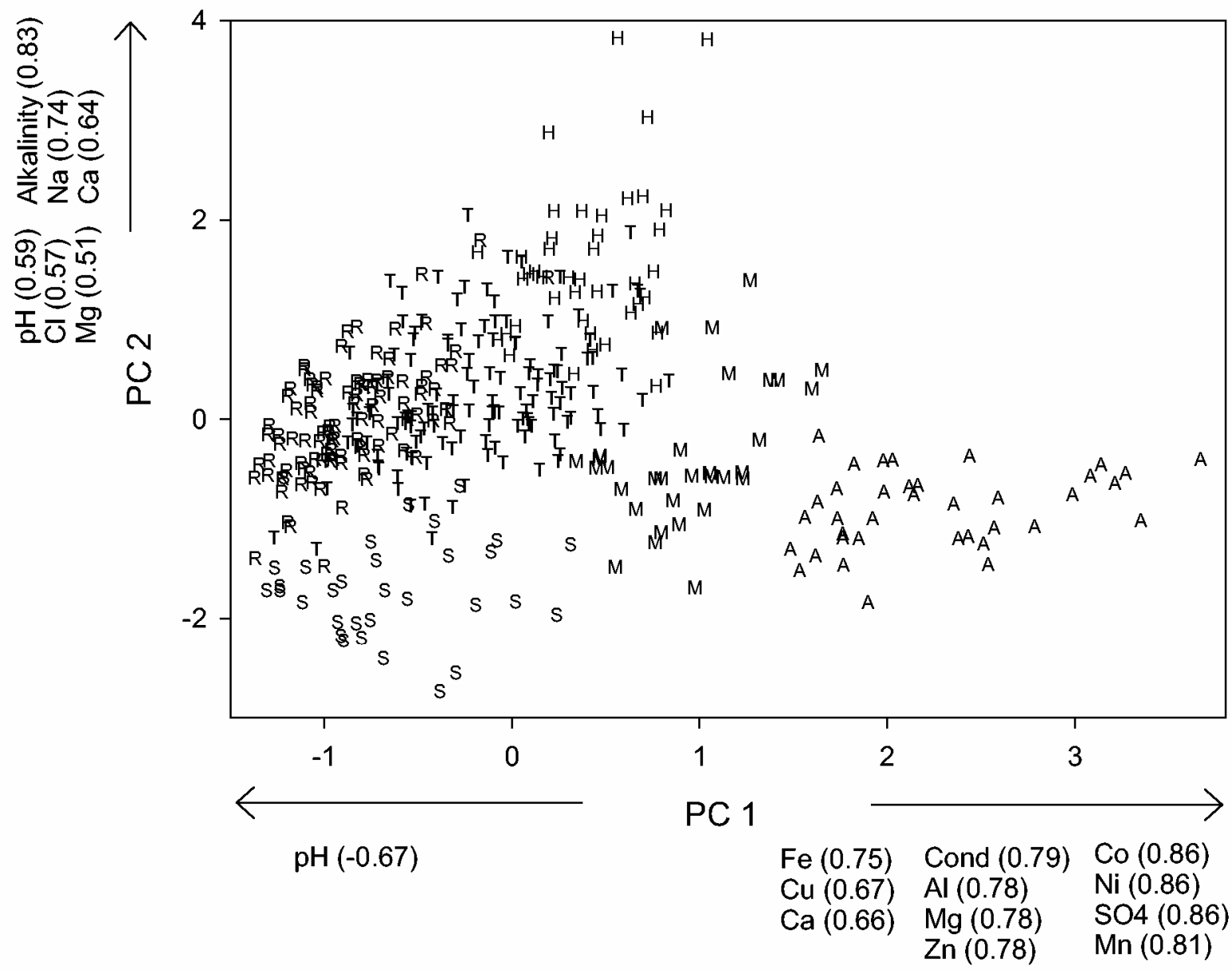


Figure 3.

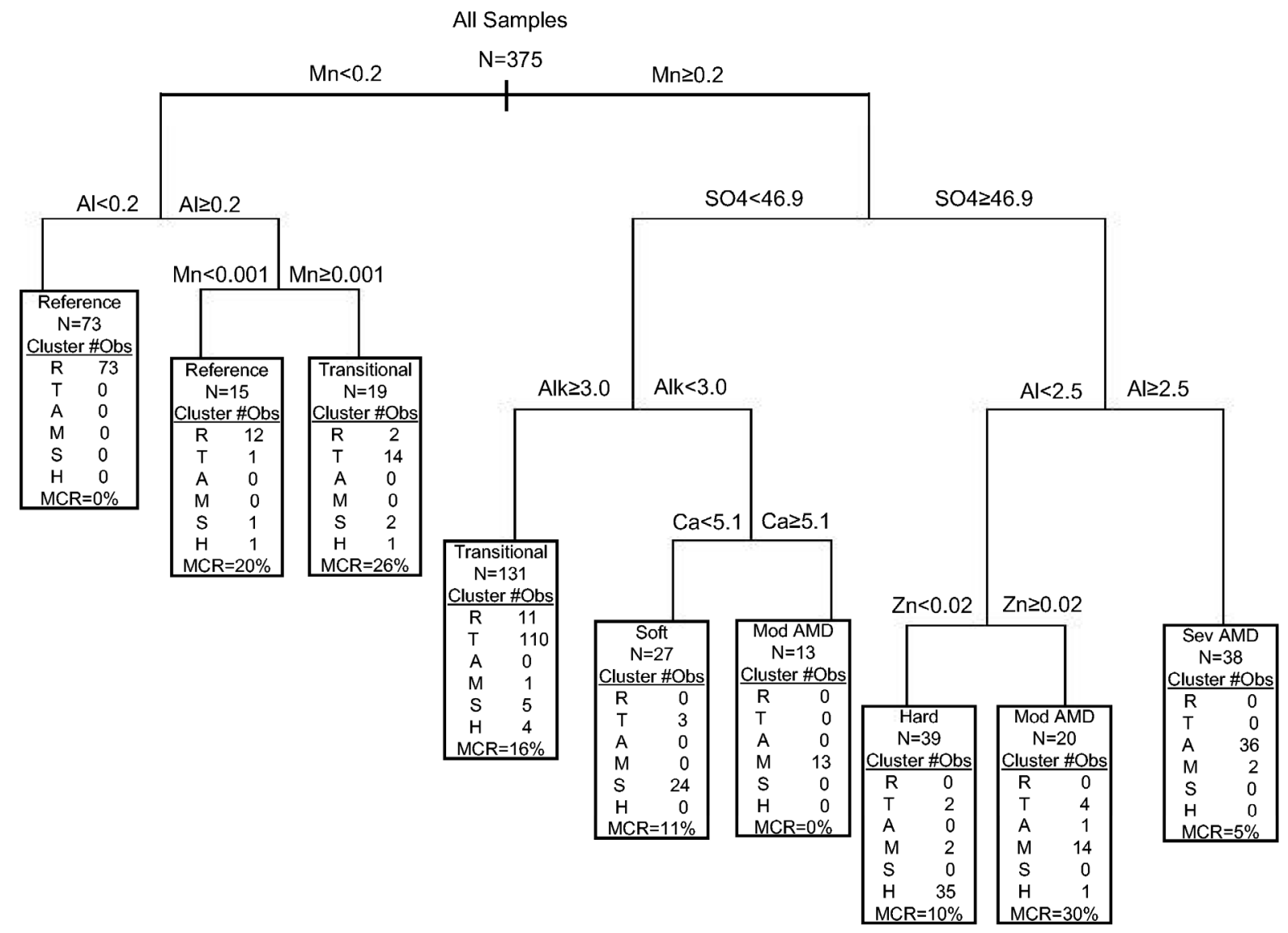




\section{Appendices}

\section{Appendix tables}

Appendix Table 1. Method detection limits (MDLs) of analytical methods used to determined concentrations of water chemistry parameters in water samples. ICP $=$ inductively coupled plasma-atomic emission spectrometry; IC = ion chromatography. The U.S. Environmental Protection Agency (EPA) method source is also given.

\begin{tabular}{|c|c|c|c|}
\hline Parameter & Analytical Method & MDLs (mg/L) & EPA Method [38] \\
\hline $\mathrm{Al}$ & ICP & 0.021 & 200.7 \\
\hline $\mathrm{Ba}$ & ICP & 0.0024 & 200.7 \\
\hline $\mathrm{Ca}$ & ICP & 0.1 & 200.7 \\
\hline $\mathrm{Cd}$ & $\mathrm{ICP}$ & 0.0028 & 200.7 \\
\hline $\mathrm{Cl}$ & IC & 0.11 & 325.2 \\
\hline Co & ICP & 0.003 & 200.7 \\
\hline $\mathrm{Cr}$ & ICP & 0.0024 & 200.7 \\
\hline $\mathrm{Cu}$ & ICP & 0.003 & 200.7 \\
\hline $\mathrm{Fe}$ & ICP & 0.0026 & 200.7 \\
\hline $\mathrm{Mn}$ & ICP & 0.0034 & 200.7 \\
\hline $\mathrm{Mg}$ & ICP & 0.1 & 200.7 \\
\hline $\mathrm{Na}$ & ICP & 0.1 & 200.7 \\
\hline $\mathrm{Ni}$ & ICP & 0.0038 & 200.7 \\
\hline $\mathrm{Zn}$ & ICP & 0.0032 & 200.7 \\
\hline Sulfates & Flow Injection Analysis & 0.117 & 375.1 \\
\hline Acidity & Automatic Titrator & -- & 310.1 \\
\hline
\end{tabular}


Appendix Table 2. The factor pattern (i.e., loadings) and eigenvalue magnitude for the first four principle components (PC) identified by principal components analysis.

\begin{tabular}{|c|c|c|c|c|}
\hline & PC 1 & PC 2 & PC 3 & PC 4 \\
\hline Eigenvalue & 7.8857 & 3.4849 & 1.3221 & 1.0718 \\
\hline $\mathrm{pH}$ & -0.6741 & 0.5910 & 0.0542 & -0.0945 \\
\hline Conductivity & 0.7933 & 0.4607 & -0.1712 & -0.0162 \\
\hline Alkalinity & -0.3611 & 0.8273 & 0.0293 & -0.1193 \\
\hline $\mathrm{Al}$ & 0.7794 & -0.3956 & -0.1038 & 0.0471 \\
\hline $\mathrm{Ba}$ & 0.1041 & 0.3214 & 0.4917 & -0.1877 \\
\hline $\mathrm{Ca}$ & 0.6596 & 0.6362 & -0.1286 & -0.1714 \\
\hline $\mathrm{Cl}$ & 0.3861 & 0.5709 & 0.1134 & 0.4861 \\
\hline Co & 0.8558 & -0.2039 & 0.2014 & -0.1519 \\
\hline $\mathrm{Cr}$ & 0.3978 & -0.0726 & 0.3746 & 0.6163 \\
\hline $\mathrm{Cu}$ & 0.6710 & -0.2622 & -0.1324 & 0.2159 \\
\hline $\mathrm{Cd}$ & 0.2008 & 0.1130 & 0.8091 & -0.0826 \\
\hline $\mathrm{Fe}$ & 0.7540 & -0.2495 & -0.1446 & 0.2178 \\
\hline $\mathrm{Mg}$ & 0.7761 & 0.5142 & -0.1336 & -0.1649 \\
\hline $\mathrm{Mn}$ & 0.8109 & -0.0410 & -0.0713 & -0.1038 \\
\hline $\mathrm{Na}$ & 0.4131 & 0.7419 & -0.0781 & 0.2775 \\
\hline $\mathrm{Ni}$ & 0.8639 & -0.1585 & 0.2525 & -0.2005 \\
\hline $\mathrm{Zn}$ & 0.7774 & -0.3585 & 0.1118 & -0.2565 \\
\hline $\mathrm{SO}_{4}$ & 0.8592 & 0.2965 & -0.1671 & -0.1435 \\
\hline
\end{tabular}




\section{Appendix figure legend}

Appendix Figure 1. Locations of water samples taken within the Tygart Valley and Cheat river basins, West Virginia. Geographic Information System data layers from Natural Resource Analysis Center, West Virginia University [18]. 
Appendix Figure 1.

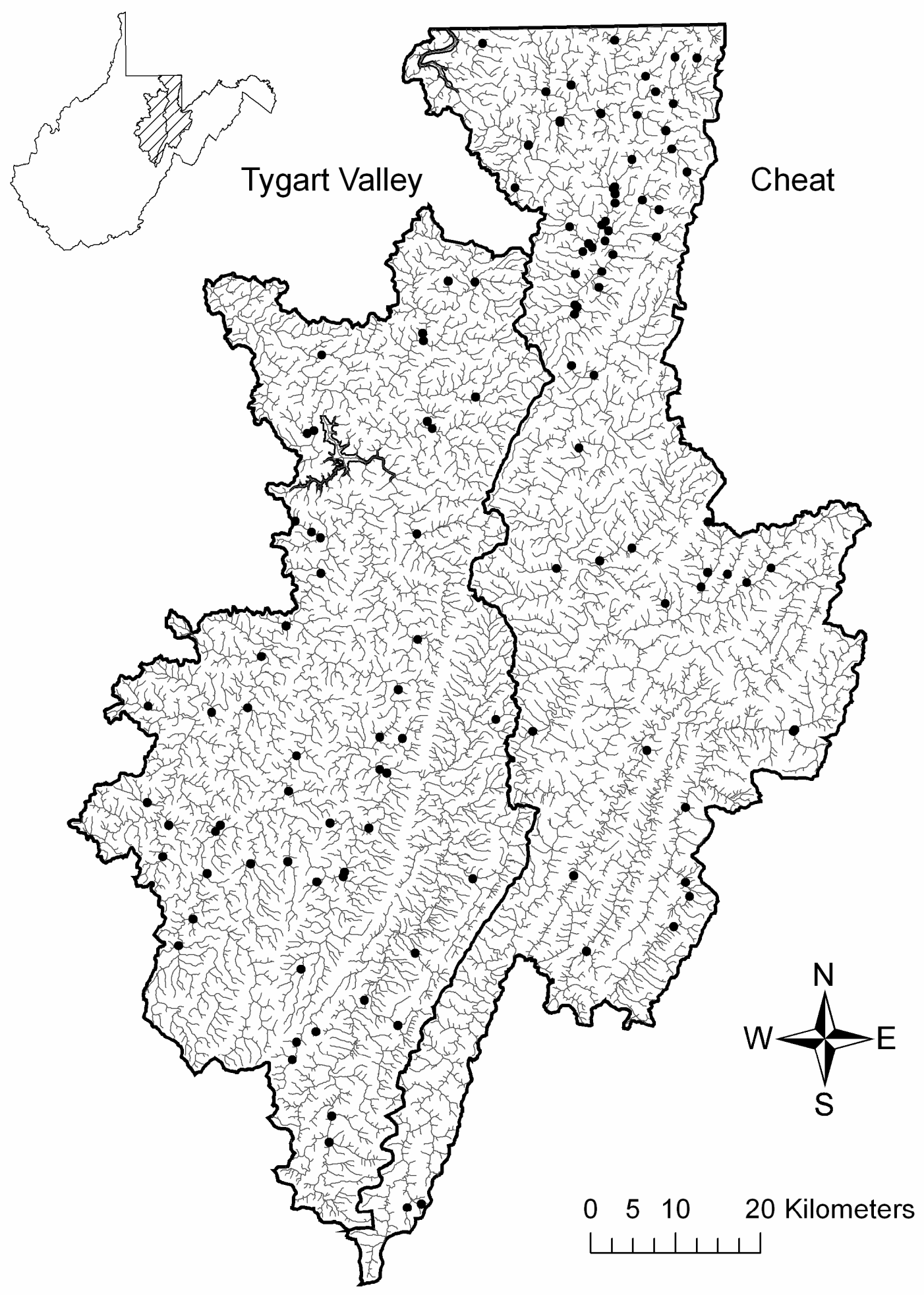




\section{Chapter 3: Correspondence between Stream Macroinvertebrates and a Discrete Disturbance Gradient: Consequences for Diagnosing Stressors}

Abstract-We sampled benthic macroinvertebrates in an acid-impacted watershed in north-central West Virginia, USA, to test whether or not community organization was structured by different types of water quality impairment. Cluster analysis and non-metric multidimensional scaling (NMDS) revealed Gleasonian gradients in the community data where composition was variable within and between water quality types. However, tests of compositional similarity identified significant links between community structure and water quality types, therefore suggesting components of Clementsian gradients. Communities from acid mine drainage (AMD) streams were highly variable, but were differentiated from communities of other stream types. Reference- type streams had the best group structure and were significantly different in composition compared to AMD-, transitional-, hard-, and soft-type streams. Benthic macroinvertebrate communities exhibited significant nestedness, but only AMD communities were clear subsets of reference-type communities. Non-parametric smooth surfaces significantly improved over linear models relating macroinvertebrate ordination to water chemistry data, which suggested strong, non-linear relationships between communities and water chemistry, especially conductivity, dissolved metals, and sulfate. Indicator species analysis found relatively few genera that were indicators for specific water quality types, but they were highly significant for reference streams (e.g., Epeorus, Dolophilodes), soft streams (e.g., Simulium, Leuctra), and hard streams (e.g., Ectopria). Consequently, complex distributional patterns exist for benthic macroinvertebrate communities in this acid-impacted region. However, there is evidence that distinct water quality types defined by extreme acidic conditions punctuate the expected continuous variation in communities and structure them into discrete units. The high degree of nestedness suggests that acidic conditions create subsets of richer communities where sensitive 
taxa are removed. It therefore may be possible to predict community response to mitigation efforts designed to improve water quality, and this could be used to establish biological endpoints for restoration. However, diagnosing stressors and multiple discrete types of water quality impairment with community level data will continue to be challenging in situations where tenuous links exist between biota and local conditions. Watershed-scale attributes may be needed to explain the variation in macroinvertebrate communities not captured by local water chemistry.

Key Words: acid mine drainage; acid rain; analysis of similarity; benthic macroinvertebrates; community structure; diagnosing stressors; indicator species; mean similarity analysis; nonmetric multidimensional scaling; streams; water chemistry; water quality 


\section{INTRODUCTION}

Species' abundances are commonly found to vary continuously across the landscape and more support has grown for the Gleasonian pattern of community organization in stream ecosystems (Heino 2005, Heino and Soininen 2005). This view maintains that communities are continuously variable entities being more homogenous across the landscape rather than heterogeneously organized into discrete subunits. Communities gradually change in composition presumably because individual species, rather than the community as a whole, change in response to environmental gradients. This pattern has made the identification of community types in aquatic ecosystems difficult (Heino et al. 2003a). In fact, Gleason $(1925,1926)$ noted for vegetation communities that, because of variability in environmental conditions and gradual changes in species abundances, there was no easy way to objectively recognize distinct plant associations.

Nestedness has also been a common pattern observed in community ecology (Fleishman and Murphy 1999, Leibold et al. 2004), and it may be associated with the Gleasonian pattern that species change gradually in their distribution. But, nestedness does not preclude the existence of community types emerging as a dominant pattern in community organization. Discrete communities (i.e., Clementsian gradients) could emerge as species assemblages become subsets of the whole community when abrupt environmental changes occur. For example, a pollution gradient could act as an environmental sieve that filters out most species and leaves behind an assemblage subset of species tolerant of the novel conditions.

These distribution patterns, however, could also result merely from the way communities were sampled in relation to environmental variability. Clearly, pattern depends on the scale of observation (Levin 1992), and typical sampling regimes often lack the scale needed to detect 
variability in abiotic conditions across sites and in communities that exist there (Heino et al. 2003a, Leibold et al. 2004). If greater environmental variability exists among metacommunities at the scale typical of ecological studies (e.g., catchment scale) then punctuated species' distributions might be expected where clearer patterns between biota and environmental gradients emerge (Weilhoefer and Pan 2006). Additionally, communities in disturbed habitats might be made up of subsets of the whole source community found in undisturbed habitats.

Although less support exists for the discrete view of community types, abrupt changes in environmental conditions may indeed punctuate the expected continuous variation in species' abundances. Abrupt environmental disturbances could conceivably produce nestedness and/or discrete community patterns where sites with different environmental conditions are significantly different in species composition. Kratzer et al. (2006), for example, found that environmental degradation from point-source pollution discharge produced distinct macroinvertebrate community types. A few recent studies have examined these non-random species distribution patterns in near pristine environments in hopes of elucidating community models and assembly rules (Heino et al. 2003a, Heino 2005, Heino and Soininen 2005). To our knowledge no study has tested for the correspondence of benthic macroinvertebrate communities with anthropocentric disturbance gradients that produce discrete habitats within a catchment. A strong link between stream communities and water quality types has important implications for current on going efforts to diagnose stressors and prioritize restoration efforts (Merovich and Petty 2007).

Aquatic ecosystems are being altered and destroyed at an alarming rate from both point and non-point sources of pollution and from physical manipulation (Allan 2004, Poff et al. 2006). In stream ecosystems, these changes often mean that there are clear boundaries between 
high quality habitats and degraded habitats downstream (Pringle 1997). Communities may respond to these discontinuities discretely in contrast to their expected range of natural variation when the natural range and variability of the physico-chemical environment abruptly shifts to extremes. A punctuated pattern in species distribution predicts existence of indicator species for discrete community types. If efficient indicator species exist then the possibility exists for diagnosing stressors that impair ecological health of stream communities.

In this study we sampled benthic macroinvertebrate communities in relation to water chemistry in the Cheat River basin, a mining influenced, acid-impacted region in north-central West Virginia, USA. Water chemistry here is influenced predominantly by acid mine drainage (AMD) and acid rain, and we have found that distinct water quality types exist because of these severe disturbances (Merovich et al. 2007). The discrete environmental gradient suggests that benthic macroinvertebrate communities should be organized by water quality types into discrete Clementsian, rather in continuous Gleasonian, gradients. Consequently, our specific objectives were to 1) test and quantify the level of correspondence between benthic macroinvertebrate communities and discrete water quality types; 2 ) test whether or not water quality degradation produces communities that are nested subsets of more diverse communities; 3 ) relate macroinvertebrate community patterns to water chemistry data; and 4) identify specific taxa that may serve as indicators of specific water quality conditions.

\section{METHODS}

\section{Study area}

The Cheat River watershed (Fig. 1) is located in north-central West Virginia, mostly within the central Appalachian and Ridge and Valley physiographic provinces. Nearly $75 \%$ of the basin is forested and approximately $13 \%$ is in agricultural use. Although mining activities 
account for less than $1 \%$ of land use, AMD from abandoned mine lands and acid rain are the most significant sources of impairment to stream water chemistry and biological integrity (Petty and Thorne 2005, Merovich and Petty 2007, Merovich et al. 2007). Surficial geology of the basin is predominantly sandstone (57\%) and shale (35\%) with little limestone (5\%). Coal deposits are only in Pennsylvanian strata, and come predominantly from the Conomaugh formation consisting of Elk Lick, Bakerstown, and Mahoning coals (67\% of all coal), and the Allegheny formation containing Kittanning, Freeport, and Clarion coals ( $28 \%$ of coal). These deposits occur mainly in the northern (lower) half of the basin and are typically associated with acid producing overburden materials with high sulfide content and little neutralizing capacity. Consequently, streams here often encounter acidic mine drainages containing high levels of metals (Fe, Al, Mn, Cr, Ni, Zn), mineral acidity, and sulfates (Petty and Barker 2004).

\section{Data collection}

We sampled benthic macroinvertebrate communities from 50 sites within the Cheat River watershed (Fig. 1) in May 2003 and 2004. At each site we also took 3 water samples, 1 each in April 2004, October 2004, and April 2005. These water samples were measured for pH, specific conductivity ( $\mu \mathrm{S} / \mathrm{cm})$, alkalinity $\left(\mathrm{mg} / \mathrm{L} \mathrm{CaCO}_{3}\right.$ equivalents), sulfates $(\mathrm{mg} / \mathrm{L})$, and dissolved aluminum, barium, cadmium, calcium, chloride, chromium, cobalt, copper, iron, magnesium, manganese, nickel, sodium, and zinc $(\mathrm{mg} / \mathrm{L})$. We used this water chemistry data to develop a stream classification scheme based on water quality (Merovich et al. 2007). Our analysis found 6 types that we described as severe AMD (A), moderate AMD (M), transitional (T), reference (R), hard (H), and soft (S). See Merovich et al. (2007) for detailed descriptions. For our purposes here, we grouped the severe and moderate AMD types into 1 type referred to simply as $\operatorname{AMD}(\mathrm{A})$. 
Benthic macroinvertebrates were sampled following rapid bioassessment protocols for wadeable rivers (Barbour et al. 1999). We took kick samples (net dimensions 335 x $508 \mathrm{~mm}$ with $500 \mu \mathrm{m}$ mesh) from 4 widely separated riffles areas and combined them into 1 sample for the site. Samples were preserved in $95 \%$ ethanol. In the lab, each composite sample was initially filtered through a $2-\mathrm{mm}$ sieve mounted on a $0.25-\mathrm{mm}$ sieve. All organisms retained by the 2-mm sieve were identified. All organisms retained by the $0.25-\mathrm{mm}$ sieve were suspended in water and were sub-sampled with a Folsom plankton splitter (Model Number 1831-F10, Wildco Supply Company, Buffalo, NY), and individuals from $1 / 8^{\text {th }}$ of the total water volume were identified. We used Peckarsky et al. (1990) and Merritt and Cummins (1996) to identify individuals to the lowest possible taxon name, usually Genus level, except for chironomid midges (Chironomidae). Rare taxa (i.e., those occurring in less than 2 sites) and freshwater annelids (Oligochaeta) were deleted from the dataset prior to subsequent analyses.

\section{Statistical analyses}

As an initial step toward testing for congruence with water quality types, we used 2 approaches to quantify the distribution patterns of benthic macroinvertebrate communities in the Cheat watershed. First, we used agglomerative hierarchical cluster analysis to summarize community similarities among sites and to group sites with respect to their macroinvertebrate composition. We used the flexible beta linkage strategy (beta equal to -0.5) (McCune and Grace 2002) on Bray-Curtis distance coefficients. Hierarchical cluster analysis begins with each site as a single group and successively combines sites into nested groups based on their similarity, with sites that are more similar being combined first. The algorithm ultimately provides the best hierarchical nesting of sites, because it seeks to minimize between group similarities. 
Secondly, we used non-metric multidimensional scaling (NMDS) as a method to quantify gradient structure in the macroinvertebrate data. This multivariate technique is a non-linear, unconstrained ordination method that maps sites in reduced dimensional space according only to rank distances determined from a community dissimilarity matrix (Clarke 1993). It also seeks to minimize stress, or the rank order differences between distances in reduced ordination space and distances from the original data matrix. NMDS is very well suited to ecological data because of non-normal data structure, preponderance of zeros, and high order interactions (Clarke and Green 1988, McCune and Grace 2002). We determined NMDS solutions in 2-6 dimensions on Bray-Curtis distance coefficients, but only a 3-dimensional solution was used because stress did not improve appreciably in more dimensions. Prior to NMDS, composition data were square root transformed and double standardized (Wisconsin method) by dividing taxa by their maxima and by setting sites to equal totals (Oksanen et al. 2007). In addition, to avoid the possibility of a spurious final stress value, because single NMDS runs are prone to getting trapped in local minima, we used multiple random starts to insure a high likelihood that the final stress value was the global minimum for the configuration (Clarke 1993).

We then used multiple subsequent techniques to test and quantify the correspondence between macroinvertebrates and water quality types. First, as a visual method, we overlaid the dominant water quality type from each site on the terminal branches of the cluster tree solution and on the NMDS ordination. Dominant water quality type was determined by choosing the type that occurred most often among the three sampling periods. We chose this way because water types tended to stay constant (Merovich et al. 2007), because macroinvertebrates integrate local conditions over time (Resh et al. 1996), and because using other ways to determine overall site 
water quality type for the sampling period (e.g., average water quality type) did not correspond with macroinvertebrate communities as well.

Secondly, the ability of the dominant water quality type factor to fit NMDS ordination of sites was assessed with the $R^{2}$ goodness of fit statistic (Oksanen et al. 2007). Statistical significance was tested with 1000 permutations. As a third test, we used analysis of similarity (ANOSIM) on Bray-Curtis distance coefficients. ANOSIM tests whether classes of a grouping vector are statistically different in species composition by using only the rank order of similarity values calculated from abundance data (Clarke and Green 1988, Clarke 1993). The ANOSIM statistic $\mathrm{R}$ is $(\mathrm{B}-\mathrm{W}) /(\mathrm{N}(\mathrm{N}-1) / 4$, where $\mathrm{B}$ and $\mathrm{W}$ are average between- and within-group rank dissimilarity, respectively, and it ranges from -1 to 1 . A value of 0 means that average rank dissimilarity values are no different between- versus within-groups. Values closer to 1.0 mean that average of ranked dissimilarity values are greater between groups and lower within groups, i.e., group structure is high and species composition is really different between groups. The statistical significance of $\mathrm{R}$ was assessed with 1000 permutation tests of the grouping vector water quality type. We followed this global test with all pair wise tests (10 total) to determine where statistical differences in community composition were located among water quality types. These tests are analogous to the multiple pair wise t-tests following a significant 1-way ANOVA. Because of the multiple comparisons, we evaluated statistical differences of the permutations at the Bonferroni-adjusted alpha level of 0.005 in order to control for Type I error rate.

Finally, we used mean similarity analysis (MEANSIM6.0 from Van Sickle 1998) to test for differences in taxa composition between dominant water quality groups. MEANSIM is allied with ANOSIM except that MEANSIM works directly on similarity values (Bray-Curtis coefficient) to find overall mean between-group (B) and overall mean within-group (W) 
similarities. The MEANSIM statistic $\mathrm{M}=\mathrm{B} / \mathrm{W}$, where $\mathrm{W}$ is weighted by within-group sample size, and ranges from 0 to 1 . Values of $\mathrm{M}$ closer to 0 signify better class structure, i.e., items within groups are more similar to themselves on average than to items in other groups. MEANSIM analysis is valuable in addition to ANOSIM because the results can be visualized in mean similarity dendrograms, which display the relative strength of group structure (Van Sickle 1997). These diagrams plot overall mean between-group similarity against mean within-group similarity for each class, in this case water quality type. A diagram with a vertical line at a low B and with long horizontal lines to $\mathrm{W}_{\mathrm{i}}$ (mean within-group similarity for group i) indicates stronger group structure. Statistical significance of $\mathrm{M}$ was assessed with 10,000 permutations of the grouping vector water quality type.

To address our second objective, we used Atmar and Patterson's (1995) nestedness calculator to test for nestedness in the community data. This analysis uses the presence-absence data matrix, and begins with the richest site located in the top row of the matrix and with the most ubiquitous species located in the left-most column. It then maximally packs the matrix in the upper-left direction to minimize unexpected presences and absences, which determine the degree of nestedness in the data. The analysis then calculates the number of unexpected presences and absences as the statistic $\mathrm{T}$, in essence the degree of order in the packed presenceabsence matrix. A perfectly nested dataset has a $\mathrm{T}$ value of 0 (maximally cold) and is perfectly ordered with species from poor communities being exact subsets of richer communities. A completely randomized dataset has a $\mathrm{T}$ value of 100 . The significance of $\mathrm{T}$ was computed with 500 randomizations.

For our third objective to relate macroinvertebrate data to water chemistry data, we fit environmental vectors (water chemistry data) to the NMDS solution to interpret the ordination. 
Vectors are models that show linear trends where the length of the vector for a specific variable is related to its correlative strength to the ordination, and its direction indicates the direction of its most rapid change in ordination space. The significance $\left(R^{2}\right)$ of each water chemistry vector to the ordination was determined with 1000 permutations. Because linear interpretation may not always be appropriate, we also fit chemistry variables with thin plate splines in two dimensions using generalized additive models. Model complexity was determined by generalized crossvalidation to select the degree of smoothing, and the coefficient of determination $\left(R^{2}\right)$ was used to assess significant of the surface from 1000 permutations. If the fitted vector really represents a linear response to the ordination then the fitted surface is a plane, but if not the non-linear surface will have a higher $R^{2}$ (Oksanen et al. 2007).

For our final objective, we used indictor species analysis (Dufrene and Legendre 1997) to quantify links between specific macroinvertebrate taxa and our water quality classification scheme. This analysis allowed us to identify taxa that may serve as indicators of specific water quality condition. Indicator species analysis calculates an indicator value (range 0 to 1 ) for each taxon as the product of its relative frequency and average relative abundance in each classification group. Higher indicator values mean that a taxon is more abundant in and exclusive to sites of a given class. Significance of each indicator value was assessed with 1000 permutations testing whether or not such a high value could be obtained by chance. If benthic macroinvertebrates are significantly structured by water quality types, and if communities are more discretely organized, then we would expect more genera to be closely linked to certain types, and such a result might make it possible to predict water quality type from biological samples. We used the $\mathrm{R}$ language and environment for statistical computing ( $\mathrm{R}$ Development Core Team 2006) for all of the above analyses except where noted. Package vegan (Oksanen et 
al. 2007) with function metaMDS was used for NMDS. Thin plate spline surfaces were fit in vegan with function gam from package mgcv (Wood 2003).

\section{RESULTS}

Excluding rare taxa, we identified 95 genera from 50 sites within the Cheat River basin. The site with the greatest richness contained 47 taxa. Two sites that were severely impaired with AMD had no macroinvertebrates and were deleted from analyses. Based on our dominant water quality classification scheme, the number of sites within each type were $\mathrm{AMD}=11$; transitional $=14 ;$ soft $=6 ;$ hard $=8 ;$ and reference $=11$. Cluster analysis showed weak clustering of sites based on macroinvertebrates, but water quality types of sites in some ways tended to group together on the dendrogram (Fig. 2). For example, macroinvertebrate samples from AMD, soft, and reference streams largely grouped together. However, samples from transitional and hard streams were widely scattered on the dendrogram.

The results of NMDS were similar to cluster analysis. Benthic macroinvertebrate communities broadly corresponded to, but were highly variable within and among, dominant water quality types (Fig. 3). However, the water quality factor overlaid on the NMDS ordination of sites was a significant grouping that distinguished communities (Goodness of Fit $R^{2}=0.52 ; p$ $<0.001$ ). Macroinvertebrate communities from AMD streams were highly variable in species ordination space, but were separated from other communities. Communities from transitional streams were both highly variable and were indistinguishable from hard streams, and overlapped reference streams somewhat. Communities from soft type streams were comparably more similar but weakly grouped together. Communities from reference type streams were the most strongly grouped. 
Analysis of similarity and mean similarity analysis provided insight into how benthic macroinvertebrate communities were structured by water quality types. Results of the global ANOSIM indicated that more compositional dissimilarity existed between the dominant water quality types than expected if group assignment was randomized $(\mathrm{R}=0.37 ; p<0.001)$. Result of MEANSIM were consistent indicating that dominant water quality was a significant classification for benthic macroinvertebrate communities $(\mathrm{M}=0.56 ; p<0.0001)$, i.e., weighted mean within-group similarity (Wbar) $>$ mean between group similarity (vertical line) in Fig. 4. However, the global ANOSIM and MEANSIM indexes were rather weak indicating much variation among groups. Multiple pair wise ANOSIMs (Table 1) and the mean similarity dendrogram (Fig. 4) revealed why. First, the pair wise ANOSIMs found that only reference sites were statistically different in composition compared to other community types. In these cases, $\mathrm{R}$ was high at 0.78 for the AMD-reference comparison and ranged to 0.42 for the transitionalreference comparison $(p<0.001$; Table 1$)$. $\mathrm{R}$ values for the other non-reference comparisons were low, indicating little if any difference in community structure across those water types $(\mathrm{R}<$ $0.35, p>0.01$; Table 1). Secondly, the MEANSIM dendrogram showed that communities from reference type streams had high within-group mean similarity compared to the other groups. Communities from transitional, soft, and AMD streams had lower mean within-group similarity, but communities here were still more similar to themselves than to communities from other water types. Communities from hard sites, in contrast, had the weakest class structure because mean within-group similarity was slightly less than mean overall between-group similarity (Fig. 4).

Benthic macroinvertebrate communities across the range of conditions in the Cheat River basin were significantly nested $(\mathrm{T}=17.1$ vs. $\mathrm{T}=66.4$ for 500 randomizations; $p(\mathrm{~T}<20)=6.0 \mathrm{e}$ - 
65). This pattern corresponded broadly to the classification of sites by dominant water quality type. Figure 5 displays the maximally pack matrix, where the curved line represents the boundary between taxa unexpected absences to the left and taxa unexpected presences to the right. Reference sites nearly always contained the richest communities, those located high on the y (site) axis, and AMD sites always contained communities that were subsets of more diverse sites (clumped low on the site axis). However, some AMD sites also contained several more taxa than were expected if nestedness was perfect (Fig. 5). Communities from transitional and hard sites were scattered across the site (y) axis of the packed matrix, whereas soft communities were located more in the middle. Therefore, there was not a clear pattern of nestedness with water quality types other than for reference and AMD types.

Of the 18 water chemistry parameters studied, 14 were significantly correlated with the NMDS ordination (Table 2). The fitted vectors of the significant parameters $(p<0.04)$, including $\mathrm{Cd}(p=0.07)$, are shown on top of the respective fitted surface in the NMDS ordination (Fig 6). All dissolved metals, conductivity, and sulfate increased quickest toward communities from AMD streams. Manganese $\left(R^{2}=0.73\right)$ and $\mathrm{pH}\left(R^{2}=0.79\right)$ had the best linear trends to the ordination. Manganese was greater than $0.35 \mathrm{mg} / \mathrm{L}$ at all AMD sites. PH ranged from less than 3.5 to 6.3 in the direction of AMD communities, and increased in the direction of communities from reference and transitional type streams. The non-linear surface fit for $\mathrm{pH}\left(R^{2}\right.$ $=0.82$ ), however, did not produce a much better model. Surface fits for conductivity, $\mathrm{Al}, \mathrm{Cr}, \mathrm{Cu}$, $\mathrm{Fe}, \mathrm{Mn}, \mathrm{Ni}, \mathrm{Zn}$, and sulfate improved over the respective linear models (surface $R^{2}>0.61$ ). Isosurfaces curved toward AMD sites, suggesting strong non-linear relationships between communities and especially conductivity, $\mathrm{Al}, \mathrm{Cu}, \mathrm{Fe}, \mathrm{Mn}, \mathrm{Ni}, \mathrm{Zn}$, and sulfate (surface $R^{2}>0.76$ ) (Fig. 6). Although significant, alkalinity, $\mathrm{Ca}, \mathrm{Cd}, \mathrm{Co}$, and $\mathrm{Mg}$ were not as directly correlated to 
the ordination $\left(R^{2}<0.33\right)$ and surface fitting did not produce much better models (surface $R^{2}<$ $0.40)$.

Finally, indicator species analysis found 29 indicator genera out of a total of 95 possibilities. Indicator genera occurred most frequently for reference and soft stream types, and indicator values were very high in these cases (Table 3). Mayfly genera, especially Epeorus, Accentrella, Cinygmula, Ephemerella were the best indicators for reference streams, but a few caddis flies (e.g., Dolophilodes, Cheumatopsyche, Hydropsyche), stoneflies (e.g., Isoperla, Acroneuria), riffle beetles (e.g., Optioservus), and a dipteran (Antocha) were important. Leuctra (stonefly) and Simulium (black fly) were the best indicators for soft streams where indicator values were high, followed by Eurylophella (mayfly), where the indicator value was moderately high. Although their indicator values were lower, Ectopria (water penny) and Microcylloepus (riffle beetle) were significantly linked to hard streams (Table 3).

\section{DISCUSSION}

Benthic macroinvertebrate communities within the Cheat River basin were highly variable in taxonomic composition across stream types, especially within the AMD-type and among transitional- and hard-types. Cluster analysis did not find highly clustered groups of streams based on macroinvertebrate composition, and the NMDS ordination showed a high degree of scatter. These results are characteristic of communities organized in a Gleasonian fashion, which is not surprising because many studies have concluded that communities are distributed more continuously than in discrete units (McIntosh 1995, Leibold and Mikkelson 2002, Heino 2005).

Despite the variability, communities had significant discrete association with the dominant water quality types in the basin, i.e., Clementsian gradients were evident in the data. 
This conclusion is supported on several fronts. First, communities from reference streams tended to group together on the cluster dendrogram. Grouping occurred, but was weaker, for AMD and soft stream types. Secondly, communities tended to group in ordination space and the Goodness of Fit statistic was significant for the classification. For example, communities from AMD streams were highly variable, but they were differentiated from other communities in other water types. Communities from transitional streams were the exception and highly overlapped communities from hard streams. This variation for transitional type streams in particular was to be expected because water chemistry is highly variable and very hard to characterize (Merovich et al. 2007). Finally, these results were consistent with both ANOSIM and MEANSIM, and ANOSIM provided a more formal way of statistical testing compositional differences among water types. Both ANOSIM and MEANSIM found significant differences in overall taxonomic composition and class structure in macroinvertebrate communities grouped by dominant water quality type. However, pair wise ANOSIMs detected statistical differences in composition only with comparisons to reference water type, therefore class structure with respect to the other water type comparisons was weak. MEANSIM also showed that communities from transitional, AMD, and soft streams had weak class structure and therefore were highly variable. Hard streams had the weakest class structure and in fact communities within this type were more dissimilar among themselves than to communities from other types. These observations are consistent with Pollard and Yuan (2006) who found that macroinvertebrate communities in West Virginia streams became less similar as metal pollution increased.

Nestedness was a dominant pattern in the macroinvertebrate data. This was expected because nestedness is common (Leibold et al. 2004), but it was weakly related to our dominant water quality classification of streams. Reference streams with the best water quality nearly 
always had communities located at the top left of the packed presence-absence matrix (Fig. 5). Communities from other water types moved to lower positions on this matrix, but this pattern was clearest only for communities from AMD stream types, which were located at the bottom of the matrix. This finding provides the first evidence that degradation of water quality from anthropocentric stressors filters benthic macroinvertebrate taxa from a regional species pool. However, communities from other stream types that were located in the middle of the matrix were not neatly arranged in any particular order. Therefore, there is no evidence that different water types represent a sequential set of pollution sieves that the regional species pool passes through as has been found for fish (Tonn et al. 1990) and macroinvertebrate (Lamouroux et al. 2004) communities under other environmental controls at multiple spatial scales.

Although nestedness was strongly supported statistically, there were many unexpected presences in packed matrix. In fact, nestedness is never expected to be perfect in a community dataset (Atmar and Patterson 1993). Many of these unexpected presences could be explained by regional processes that we did not account for in this study, and not just local water quality conditions. For example, sites with AMD are expected to be depauparate in species richness. However, if a severe AMD site is located within a neighborhood of streams with very good water quality in close proximity, then some more tolerant species from good areas could by chance occur at the poor site by drifting from upstream. This scenario might also explain the overlap of sites from different water quality types in NMDS ordination space and the lack of statistical difference among water quality types other than comparisons to reference types.

The complexity in macroinvertebrate community structure demonstrated above was also apparent in the way communities related to water chemistry variables. Macroinvertebrate communities never trended very strongly with individual water chemistry parameters, except for 
$\mathrm{pH}\left(R^{2}=0.79\right), \mathrm{Mn}\left(R^{2}=0.73\right)$, and perhaps $\mathrm{Ni}\left(R^{2}=0.63\right), \mathrm{Zn}\left(R^{2}=0.62\right)$, and $\mathrm{Al}\left(R^{2}=0.58\right)$.

These linear models, however, were much improved over with smooth non-parametric surfaces.

The spline models demonstrated complex, but still tractable, relationships between

macroinvertebrate communities and local water chemistry that was not conceivable with linear

models. For example, $\mathrm{Zn}$ increased quickest directly left in NMDS ordination space, bisecting

communities from AMD streams (Fig. 6). However, this linear model does not demonstrate how

AMD communities can be highly variable given similar $\mathrm{Zn}$ levels. The smooth surface model

for $\mathrm{Zn}\left(R^{2}=0.90\right)$, on the other hand, reflects that variation and is easily interpretable.

Therefore, surface models greatly improve our understanding of how local water chemistry

relates to macroinvertebrate community structure in this region.

Our analysis found only a relatively few indicator genera (31\%) for the water quality

classification. The presence of few indicator taxa is consistent with a Gleasonian community

model. However, we did find several taxa that were very strong indictors for reference and soft stream types, which suggest discrete community organization. Consequently, the analyses demonstrate that benthic macroinvertebrates can diagnosis stressors successfully at least at the broad categorical level (e.g., water quality type). The genus Epeorus (mayfly) was a strong indictor for reference streams, although it is often found to be dominant in soft, acid precipitation-influenced streams in the region (Kobuszewski and Perry 1993, McClurg et al. 2007). Our finding is consistent with many studies (e.g., Clements 2004, Pollard and Yuan 2006) that have found Epeorus to be sensitive to metal pollution. We also found Leuctra (stonefly) and Simulium (black fly) as strong indicators of soft, acid precipitation-sensitive streams. These 2 taxa including Eurylophella (mayfly) are often dominant, by far, in soft streams (Clayton and Menendez 1996, McClurg et al. 2007). However, our study is the first that 
explicitly tested for such patterns. Therefore, in a watershed-scale sampling regime, dominance of Leuctra and Simulium in this region is diagnostic for streams that are sensitive to acid rain. In addition, stream communities dominated with an assemblage of the other mayfly, stonefly, and caddis fly genera listed in Table 3 are most probably reference-type streams.

It is in some ways surprising that there were no indicator taxa for AMD streams. The strong nestedness pattern in the data and the complex way in which taxa may colonize these impaired streams in a fragmented landscape (McClurg et al. 2007), however, could preclude a faithful association and this is unfortunate because the lack of indicator species obscures the diagnosis of stressors. On the other hand, the lack of indicator taxa for transitional streams is not surprising, given the tremendous variation in chemistry and community composition. It will therefore continue to be difficult diagnosing the conditions of streams in this transitional zone, which is unfortunate also because treatment of AMD or acid rain streams with alkaline materials could shift stream chemistry in this direction. In contrast, if stream chemistry is shifted to hard chemistry types, then diagnosis may be possible, but tenuous because only 2 taxa were significant indicators of this stream type in our data set. It therefore may be possible to predict to some extent the response of benthic macroinvertebrate communities to reclamation efforts aimed to recover streams from AMD or acid rain influence.

In conclusion, we found that benthic macroinvertebrate communities were highly variable within the Cheat River basin, but communities were organized into significant groups by discrete water quality types we identified. Therefore, it appears that community structure has both characteristics of continuous variability and discrete organization associated with discrete water quality types. The extreme and discrete conditions imparted to water chemistry from AMD and acid rain conflict with the tendency of communities to gradually change and they act 
to punctuate the continuous variation expected in macroinvertebrate communities. Benthic communities from least impacted streams do not show this level of discreteness to local environmental conditions (e.g., Heino et al. 2003a, Heino and Soininen 2005, Weilhoefer and Pan 2006). This study was the first to test the expectation that continuous variation in community composition should be punctuated into discrete units explicitly where anthropocentric influence to water chemistry is severe. These results and the relationships we found between macroinvertebrates and water chemistry provide information that identifies where our understanding is lacking to effectively diagnose stressors and address restoration efforts.

Although the evidence for community structure by water quality types was mixed and these results may seem conflicting, they are better viewed as a consequence of the complex nature of community assembly and control in combination with the complex way acid sources interact with basin geology to create distinct water quality types that ecologically isolate stream reaches (McClurg et al. 2007, Merovich et al. 2007). Many factors, for instance, control macroinvertebrate communities in multiple ways and this also occurs at many spatial and temporal scales in a hierarchical fashion (Mykra et al. 2004). Recent work has attempted to separate the influence of local versus landscape-scale factors in macroinvertebrate community structure because of availability of advanced GIS-derived variables (e.g., Death and Joy 2004, King et al. 2005). In fact, recent research has focused on metacommunity organization and it is clear that not only local factors control organization, but large scale (i.e., landscape) factors also determine local site conditions to which invertebrates could respond (Poff 1997, Heino et al. 2003b, Kiflawi et al. 2003, Lamouroux et al. 2004, Mykra et al. 2004, Prusha and Clements 2004, Sandin and Johnson 2004). 
We found evidence that local water chemistry structures community composition, but we are also interested in how much of the remaining variation can be explained by processes occurring above the level of immediate site conditions in a metacommunity framework (e.g., Leibold et al. 2004) in this mining influenced, acid precipitation-sensitive region. For example, we believe in this system that upstream-downstream processes and the neighborhood effect (i.e., proximity of sites of different physico-chemical quality) may be important in explaining why stream macroinvertebrate composition can be so different when local water chemistry conditions are similar. Very poor streams within a network of un-impaired streams could have much higher species richness than expected, for instance, compared to another poor stream in a degraded watershed. Sites in close proximity but with extreme differences in water chemistry could be more similar than expected compared to distance sites with the same local water quality type. Likewise, restoration efforts may not recover ecological structure if streams remain insularized within a degraded network. For example, McClurg et al. (2007) found that limestone sand treatment used to mitigate the effects of acid rain rarely fully recovered acid-sensitive taxa, and they attributed this to extreme isolation from potential colonists because the watershed network remained impaired. Consequently, diagnosing water quality types or stressors using stream benthic macroinvertebrates from bioassessments will continue to be challenging until we put impaired stream reaches into a watershed and spatial framework, and this would also clarify decision-making processes in restoration programs where prioritizing restoration efforts among several degraded streams is often necessary. 


\section{ACKNOWLEDGEMENTS}

We thank Jennifer Fulton, Zach Liller, Jason Clingerman, and Anthony Grubb for their help in the field. Several undergraduate wildlife and fisheries students helped process benthic samples in the lab. Donna Hartman identified many of the samples. Zach Liller and Roy Martin

provided insightful discussions. John Wirts and Jeff Bailey of the West Virginia Department of Environmental Protection provided watershed assessment data to aid our site selection process, and reviewed earlier versions of the manuscript. This research was funded by a Science to Achieve Results (STAR) grant from U. S. Environmental Protection Agency to JTP. 


\section{LITERATURE CITED}

Allan, J. D. 2004. Landscapes and riverscapes: the influence of land use on stream ecosystems. Annual Review of Ecology, Evolution, and Systematics 35:257-284.

Atmar, W., and B. D. Patterson. 1993. The measure of order and disorder in the distribution of species in fragmented habitat. Oecologia 96:373-382.

Atmar, W., and B. D. Patterson. 1995. The nestedness temperature calculator: a visual basic program, including 294 presence-absence matrices. Version: March 2004. AICS Research, Inc., Chicago, IL. URL http://aics-research.com/nestedness/tempcalc.html.

Barbour, M. T., J. Gerritsen, B. D. Snyder, and J. B. Stribling. 1999. Rapid bioassessment protocols for use in streams and wadeable rivers: periphyton, benthic macroinvertebrates, and fish. Second Edition. EPA 841-B-99-022, U.S. Environmental Protection Agency; Office of Water, Washington, D.C.

Clarke, K. R. 1993. Non-parametric multivariate analyses of changes in community structure. Australian Journal of Ecology 18:117-143.

Clarke, K. R., and R. H. Green. 1988. Statistical design and analysis for a 'biological effects' study. Marine Ecology Progress Series 46:213-226.

Clayton, J. L., and R. Menendez. 1996. Macroinvertebrate responses to mitigative liming of Dogway Fork, West Virginia. Restoration Ecology 4:234-246.

Clements, W. H. 2004. Small-scale experiments support causal relationships between metal contamination and macroinvertebrate community responses. Ecological Applications 14:954-967. 
Death, R. G., and M. K. Joy. 2004. Invertebrate community structure in streams of the Manawatu-Wanganui region, New Zealand: the roles of catchment versus reach scale influences. Freshwater Biology 49:982-997.

Dufrene, M., and P. Legendre. 1997. Species assemblages and indicator species: the need for a flexible asymmetrical approach. Ecological Monographs 67:345-366.

Fleishman, E., and D. D. Murphy. 1999. Patterns and processes of nestedness in a Great Basin butterfly community. Oecologia 119:133-139.

Gleason, H. A. 1925. Species and area. Ecology 6:66-74.

Gleason, H. A. 1926. The individualistic concept of the plant association. Bulletin of the Torrey Botanical Club 53:7-26.

Heino, J. 2005. Metacommunity patterns of highly diverse stream midges: gradients, chequerboards, and nestedness, or is there only randomness? Ecological Entomology 30:590-599.

Heino, J., T. Muotka, H. Mykra, R. Paavola, H. Hamalainen, and E. Koskenniemi. 2003a. Defining macroinvertebrate assemblage types of headwater streams: implications for bioassessment and conservation. Ecological Applications 13:842-852.

Heino, J., T. Muotka, and R. Paavola. 2003b. Determinants of macroinvertebrate diversity in headwater streams: regional and local influences. Journal of Animal Ecology 72:425434.

Heino, J., and J. Soininen. 2005. Assembly rules and community models for unicellular organisms: patterns in diatoms of boreal streams. Freshwater Biology 50:567-577. 
Kiflawi, M., A. Eitam, and L. Blaustein. 2003. The relative impact of local and regional processes on macro-invertebrate species richness in temporary pools. Journal of Animal Ecology 72:447-452.

King, R. S., M. E. Baker, D. F. Whigham, D. E. Weller, T. E. Jordan, P. F. Kazyak, and M. K. Hurd. 2005. Spatial considerations for linking watershed land cover to ecological indicators in streams. Ecological Applications 15:137-153.

Kobuszewski, D. M., and S. A. Perry. 1993. Aquatic insect community structure in an acidic and a circumneutral stream in the Appalachian Mountains of West Virginia. Journal of Freshwater Ecology 8:37-45.

Kratzer, E. B., J. K. Jackson, D. B. Arscott, A. K. Aufdenkampe, C. L. Dow, L. A. Kaplan, J. D. Newbold, and B. W. Sweeney. 2006. Macroinvertebrate distribution in relation to land use and water chemistry in New York City drinking-water-supply watersheds. Journal of the North American Benthological Society 25:954-976.

Lamouroux, N., S. Doledec, and S. Gayraud. 2004. Biological traits of stream macroinvertebrate communities: effects of microhabitat, reach, and basin filters. Journal of the North American Benthological Society 23:449-466.

Leibold, M. A., M. Holyoak, N. Mouquet, P. Amarasekare, J. M. Chase, M. F. Hoopes, R. D. Holt, J. B. Shurin, R. Law, D. Tilman, M. Loreau, and A. Gonzalez. 2004. The metacommunity concept: a framework for multi-scale community ecology. Ecology Letters 7:601-613.

Leibold, M. A., and G. M. Mikkelson. 2002. Coherence, species turnover, and boundary clumping: elements of meta-community structure. Oikos 97:237-250.

Levin, S. A. 1992. The problem of pattern and scale in ecology. Ecology 73:1943-1967. 
McClurg, S. E., J. T. Petty, P. M. Mazik, and J. L. Clayton. 2007. Stream ecosystem response to limestone treatment in acid impacted watersheds of the Allegheny Plateau. Ecological Applications 17:1087-1104.

McCune, B., and J. B. Grace. 2002. Analysis of ecological communities. MjM Software Design, Gleneden Beach, OR.

McIntosh, R. P. 1995. H. A. Gleason's 'individualistic concept' and theory of animal communities: a continuing controversy. Biological Reviews 70:317-357.

Merovich, G. T., Jr., and J. T. Petty. 2007. Interactive effects of multiple stressors and restoration priorities in a mined Appalachian watershed. Hydrobiologia 575:13-31.

Merovich, G. T., Jr., J. M. Stiles, J. T. Petty, J. Fulton, and P. F. Ziemkiewicz. 2007. Water chemistry based classification of streams and implications for restoring mined Appalachian watersheds. Environmental Toxicology and Chemistry 26:1361-1369.

Merritt, R. W., and K. W. Cummins. 1996. An introduction to the aquatic insects of North America, Third edition. Kendall/Hunt Publishing Co., Dubuque, IA.

Mykra, H., J. Heino, and T. Muotka. 2004. Variability of lotic macroinvertebrate assemblages and stream habitat characteristics across hierarchical landscape classifications. Environmental Management 34:341-352.

Oksanen, J., R. Kindt, P. Legendre, and R. B. O'Hara. 2007. Vegan: community ecology package version 1.8-5. http://cran.r-project.org/.

Peckarsky, B. L., P. R. Fraissinet, M. A. Penton, and J. Conklin, D. J. 1990. Freshwater macroinvertebrates of Northeastern North America. Cornell University Press, Ithaca.

Petty, J. T., and J. Barker. 2004. Water quality variability in tributaries of the Cheat River, a mined Appalachian watershed. Pages 1484-1504 in 2004 National Meeting of the 
American Society of Mining and Reclamation and the 25th West Virginia Surface Mine Drainage Task Force. American Society of Mining and Reclamation, Morgantown, WV. Petty, J. T., and D. Thorne. 2005. An ecologically based approach to identifying restoration priorities in an acid-impacted watershed. Restoration Ecology 13:348-357.

Poff, N. L. 1997. Landscape filters and species traits: towards mechanistic understanding and prediction in stream ecology. Journal of the North American Benthological Society 16:391-409.

Poff, N. L., B. P. Bledsoe, and C. O. Cuhaciyan. 2006. Hydrologic variation with land use across the contiguous United States: geomorphic and ecological consequences for stream ecosystems. Geomorphology 79:264-285.

Pollard, A. I., and L. Yuan. 2006. Community response patterns: evaluating benthic invertebrate composition in metal-polluted streams. Ecological Applications 16:645-655.

Pringle, C. M. 1997. Exploring how disturbance is transmitted upstream: going against the flow. Journal of the North American Benthological Society 16:425-438.

Prusha, B. A., and W. H. Clements. 2004. Landscape attributes, dissolved organic C, and metal bioaccumulation in aquatic macroinvertebrates (Arkansas River Basin, Colorado). Journal of the North American Benthological Society 23:327-339.

R Development Core Team. 2006. R: A language and environment for statistical computing. $\mathrm{R}$ Foundation for Statistical Computing, Vienna, Austria. ISBN 3-900051-07-0, URL http://www.R-project.org.

Resh, V. H., M. J. Meyers, and M. J. Hannaford. 1996. Macroinvertebrates as biotic indicators of environmental quality. Pages 647-667 in F. R. Hauer and G. A. Lamberti, editors. Methods in Stream Ecology. Academic Press, San Diego, CA, USA. 
Sandin, L., and R. K. Johnson. 2004. Local, landscape and regional factors structuring benthic macroinvertebrate assemblages in Swedish streams. Landscape Ecology 19:501-514.

Tonn, W. M., J. J. Magnuson, M. Rask, and J. Toivonen. 1990. Intercontinental comparison of small-lake fish assemblages: the balance between local and regional processes. The American Naturalist 136:345-375.

Van Sickle, J. 1997. Using mean similarity dendrograms to evaluate classifications. Journal of Agricultural, Biological, and Environmental Statistics 2:370-388.

Van Sickle, J. 1998. A set of programs for mean similarity analysis. Corvallis, OR. URL http://www.epa.gov/wed/pages/models/dendro/mean_similarity_analysis.htm.

Weilhoefer, C. L., and Y. Pan. 2006. Diatom assemblages and their associations with environmental variables in Oregon Coast Range streams, USA. Hydrobiologia 561:207219.

Wood, S. N. 2003. Thin plate regression splines. Journal of the Royal Statistical Society. Series B (Methodological). 65:95-114. 
Table 1. Results from analysis of similarity (ANOSIM), including all pair wise comparisons between dominant water quality type where $\mathrm{A}=$ acid mine drainage $(\mathrm{AMD}), \mathrm{H}=$ hard, $\mathrm{R}=$ reference, $\mathrm{S}=$ soft, $\mathrm{T}=$ transitional. The asterisk indicates statistical difference evaluated at the 0.005 level of significance (Bonferroni adjusted).

\begin{tabular}{lcl}
\hline Test & R-Statistic & $p$-value \\
\hline Global & 0.37 & $<0.001^{*}$ \\
A-H & 0.21 & 0.02 \\
A-R & 0.78 & $<0.001^{*}$ \\
A-S & 0.35 & 0.01 \\
A-T & 0.26 & 0.01 \\
H-R & 0.51 & $<0.001^{*}$ \\
H-S & 0.11 & 0.14 \\
H-T & 0.12 & 0.10 \\
R-S & 0.57 & $<0.001^{*}$ \\
R-T & 0.42 & $<0.001^{*}$ \\
S-T & 0.22 & 0.05 \\
\hline
\end{tabular}


Table 2. Water chemistry parameters studied and related to NMDS ordination of macroinvertebrate genera in two dimensions by vector fitting (linear model) and surface fitting (non-linear general additive model) using thin plate splines. Corresponding $R^{2}$ and $p$-values are given.

\begin{tabular}{|c|c|c|}
\hline Water chemistry variable & Vector $R^{2}$ ( $p$-value) & Surface $R^{2}$ ( $p$-value) \\
\hline $\mathrm{pH}$ & $0.79(<0.001)$ & $0.82(3.7 \mathrm{e}-13)$ \\
\hline Conductivity & $0.52(<0.001)$ & $0.80(2.4 \mathrm{e}-12)$ \\
\hline Alkalinity & $0.19(0.03)$ & $0.15(0.01)$ \\
\hline $\mathrm{Al}$ & $0.58(<0.001)$ & $0.86(4.2 \mathrm{e}-15)$ \\
\hline $\mathrm{Ba}$ & $0.06(0.41)$ & $0.02(0.26)$ \\
\hline $\mathrm{Ca}$ & $0.19(0.04)$ & $0.22(0.02)$ \\
\hline $\mathrm{Cd}$ & $0.15(0.07)$ & $0.15(0.06)$ \\
\hline $\mathrm{Cl}$ & $0.07(0.38)$ & $0.21(0.03)$ \\
\hline Co & $0.33(0.001)$ & $0.34(0.002)$ \\
\hline $\mathrm{Cr}$ & $0.36(<0.001)$ & $0.61(3.8 \mathrm{e}-07)$ \\
\hline $\mathrm{Cu}$ & $0.53(<0.001)$ & $0.85(2.7 \mathrm{e}-14)$ \\
\hline $\mathrm{Fe}$ & $0.44(<0.001)$ & $0.76(7.0 \mathrm{e}-11)$ \\
\hline $\mathrm{Mg}$ & $0.33(0.001)$ & $0.40(0.0004)$ \\
\hline $\mathrm{Mn}$ & $0.73(<0.001)$ & $0.82(1.9 \mathrm{e}-13)$ \\
\hline $\mathrm{Na}$ & $0.05(0.58)$ & $0.10(0.16)$ \\
\hline $\mathrm{Ni}$ & $0.63(<0.001)$ & $0.88(<5.6 \mathrm{e}-16)$ \\
\hline $\mathrm{Zn}$ & $0.62(<0.001)$ & $0.89(<2.0 \mathrm{e}-16)$ \\
\hline Sulfate & $0.53(<0.001)$ & $0.82(3.4 \mathrm{e}-13)$ \\
\hline
\end{tabular}


Table 3. Significant indicator genera ( 29 of 95 total) sorted by descending indicator value for water quality types (abbreviations as in Table 1) determined from dominant water chemistry profile. $P$-values are estimated from 1000 randomizations of the data $($ sum of all probabilities $=$ 27.7). Relative frequency and abundance is for genera for their indictor group.

\begin{tabular}{|c|c|c|c|c|c|}
\hline Taxa & $\begin{array}{l}\text { Indicator } \\
\text { group }\end{array}$ & $\begin{array}{l}\text { Indictor } \\
\text { value }\end{array}$ & $p$-value & $\begin{array}{l}\text { Relative } \\
\text { frequency }\end{array}$ & $\begin{array}{l}\text { Relative } \\
\text { abundance }\end{array}$ \\
\hline Epeorus & $\mathrm{R}$ & 0.71 & 0.001 & 1.00 & 0.71 \\
\hline Leuctra & $\mathrm{S}$ & 0.67 & 0.001 & 1.00 & 0.67 \\
\hline Dolophilodes & $\mathrm{R}$ & 0.65 & 0.001 & 0.73 & 0.89 \\
\hline Simulium & S & 0.60 & 0.009 & 0.83 & 0.72 \\
\hline Antocha & $\mathrm{R}$ & 0.59 & 0.003 & 0.73 & 0.81 \\
\hline Accentrella & $\mathrm{R}$ & 0.58 & 0.001 & 0.82 & 0.71 \\
\hline Cinygmula & $\mathrm{R}$ & 0.58 & 0.002 & 0.91 & 0.64 \\
\hline Optioservus & $\mathrm{R}$ & 0.58 & 0.003 & 0.82 & 0.71 \\
\hline Ephemerella & $\mathrm{R}$ & 0.57 & 0.004 & 1.00 & 0.57 \\
\hline Isoperla & $\mathrm{R}$ & 0.54 & 0.01 & 0.82 & 0.66 \\
\hline Cheumatopsyche & $\mathrm{R}$ & 0.49 & 0.007 & 0.73 & 0.68 \\
\hline Drunella & $\mathrm{R}$ & 0.49 & 0.002 & 0.82 & 0.60 \\
\hline Hydropsyche & $\mathrm{R}$ & 0.48 & 0.02 & 0.82 & 0.59 \\
\hline Blepharicera & $\mathrm{R}$ & 0.47 & 0.002 & 0.55 & 0.87 \\
\hline Acroneuria & $\mathrm{R}$ & 0.46 & 0.01 & 0.73 & 0.63 \\
\hline Malirekus & $\mathrm{R}$ & 0.44 & 0.004 & 0.64 & 0.69 \\
\hline
\end{tabular}




\begin{tabular}{lccccc} 
Rhyacophilla & $\mathrm{R}$ & 0.44 & 0.03 & 1.00 & 0.44 \\
Eurylophella & $\mathrm{S}$ & 0.43 & 0.01 & 0.50 & 0.85 \\
Oulimnius & $\mathrm{R}$ & 0.38 & 0.04 & 0.73 & 0.52 \\
Serratella & $\mathrm{R}$ & 0.37 & 0.01 & 0.45 & 0.82 \\
Neophylax & $\mathrm{R}$ & 0.36 & 0.03 & 0.55 & 0.66 \\
Ectopria & $\mathrm{H}$ & 0.35 & 0.04 & 0.38 & 0.94 \\
Stenonema & $\mathrm{R}$ & 0.35 & 0.05 & 0.55 & 0.64 \\
Hydroisotoma & $\mathrm{S}$ & 0.33 & 0.01 & 0.33 & 1.00 \\
$\begin{array}{l}\text { Podura } \\
\text { Peltoperla }\end{array}$ & $\mathrm{S}$ & 0.33 & 0.02 & 0.33 & 1.00 \\
Suwallia & $\mathrm{S}$ & 0.32 & 0.04 & 0.50 & 0.65 \\
$\begin{array}{l}\text { Zealeuctra } \\
\text { Microcylloepus }\end{array}$ & $\mathrm{R}$ & 0.32 & 0.03 & 0.36 & 0.88 \\
\hline & $\mathrm{S}$ & 0.31 & 0.04 & 0.33 & 0.93 \\
\hline
\end{tabular}




\section{FIGURE LEGENDS}

Figure 1. Sample locations within the Cheat River basin, WV (inset), USA.

Figure 2. Cluster dendrogram from agglomerative nesting cluster analysis on Bray-Curtis distance coefficient using flexible beta $($ beta $=-0.5)$ linkage method. Macroinvertebrate communities are labeled by dominant water quality type of the sites from which they were sampled $(\mathrm{A}=$ acid mine drainage; $\mathrm{T}=$ transitional; $\mathrm{S}=$ soft $\mathrm{H}=$ hard $; \mathrm{R}=$ reference $)$.

Figure 3. Non-metric multidimensional scaling ordination of benthic macroinvertebrate samples (Bray-Curtis distance coefficient) in two dimensions. Stress $=16.0$ in three dimensional solution. Two convergent solutions were found after 15 runs. The plot is rotated so axis one contains the largest variance in site scores, and is scaled in half-change units so change in one unit halves community similarity. Sites are labeled as in Figure 2.

Figure 4. Mean similarity dendrogram for benthic macroinvertebrate communities grouped by dominant water quality type. The vertical line is plotted at the overall between-group mean similarity and the horizontal branches extend out to the within-group mean similarity for that group. The name of each dominant water quality type is given at the end of each horizontal branch. The number in parenthesis is number of sites classifying into the group. AMD has 9 sites, because 2 sites with no individuals were deleted from the analysis. The overall withingroup mean similarity (Wbar) is also plotted, and it can be interpreted as the center of mass of the plot.

Figure 5. Maximally packed matrix from Nestedness Calculator. The x-axis is taxa and the yaxis is sites labeled by dominant water quality type. Dark blocks represent taxa presences, whereas clear blocks represent taxa absences. Dark blocks to the right of the line are unexpected 
presences, and clear blocks left of the curved line are unexpected absences assuming a nested pattern.

Figure 6. The NMDS solution from Figure 3 fitted to vectors (Linear) and smooth surfaces (Surf) for water chemistry parameter studied (excluding $\mathrm{Ba}, \mathrm{Cl}$, and $\mathrm{Na}$ ). The $\mathrm{R}$-sq $\left(R^{2}\right)$ value for each model is at the top. 
Figure 1.

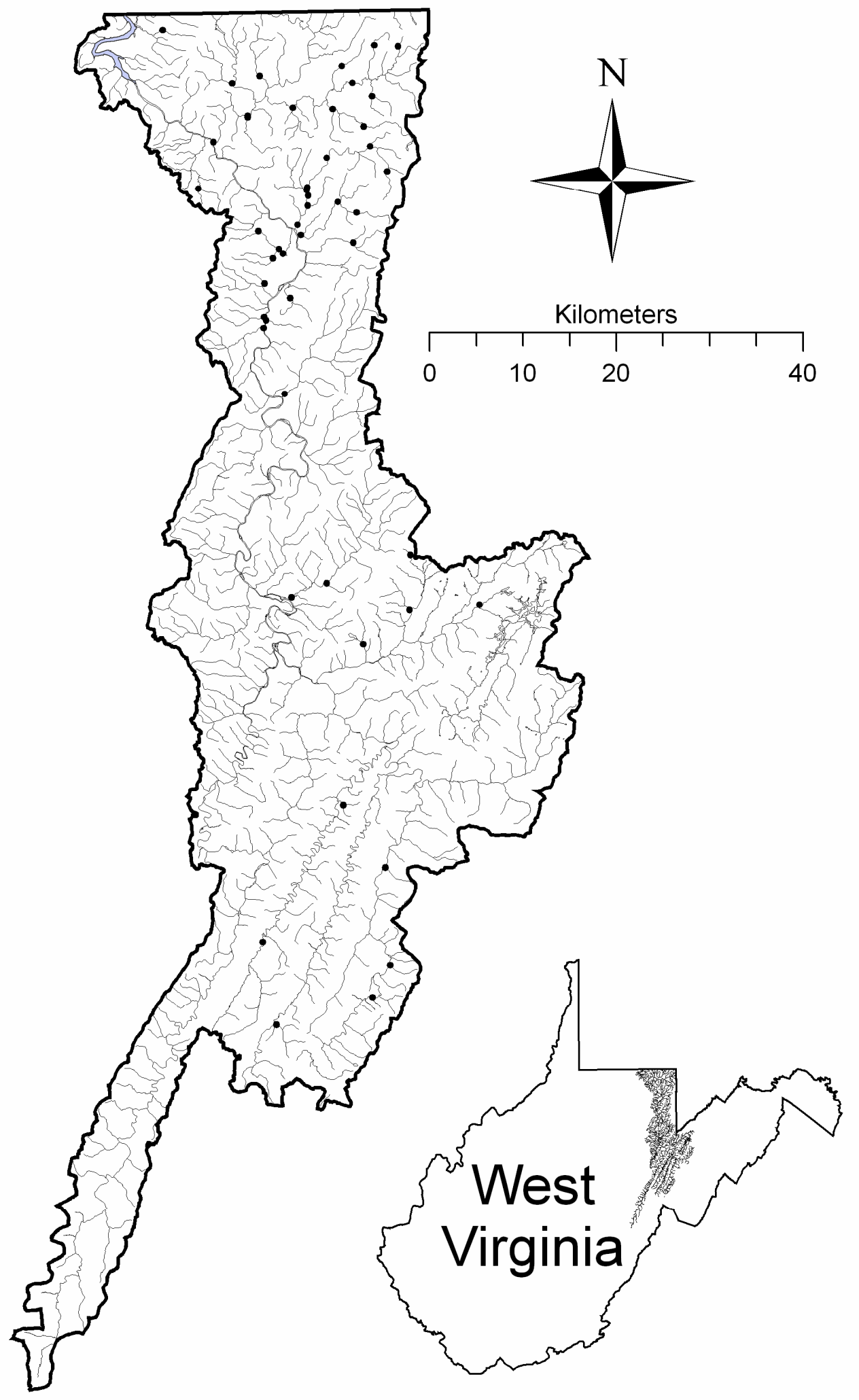


Figure 2.

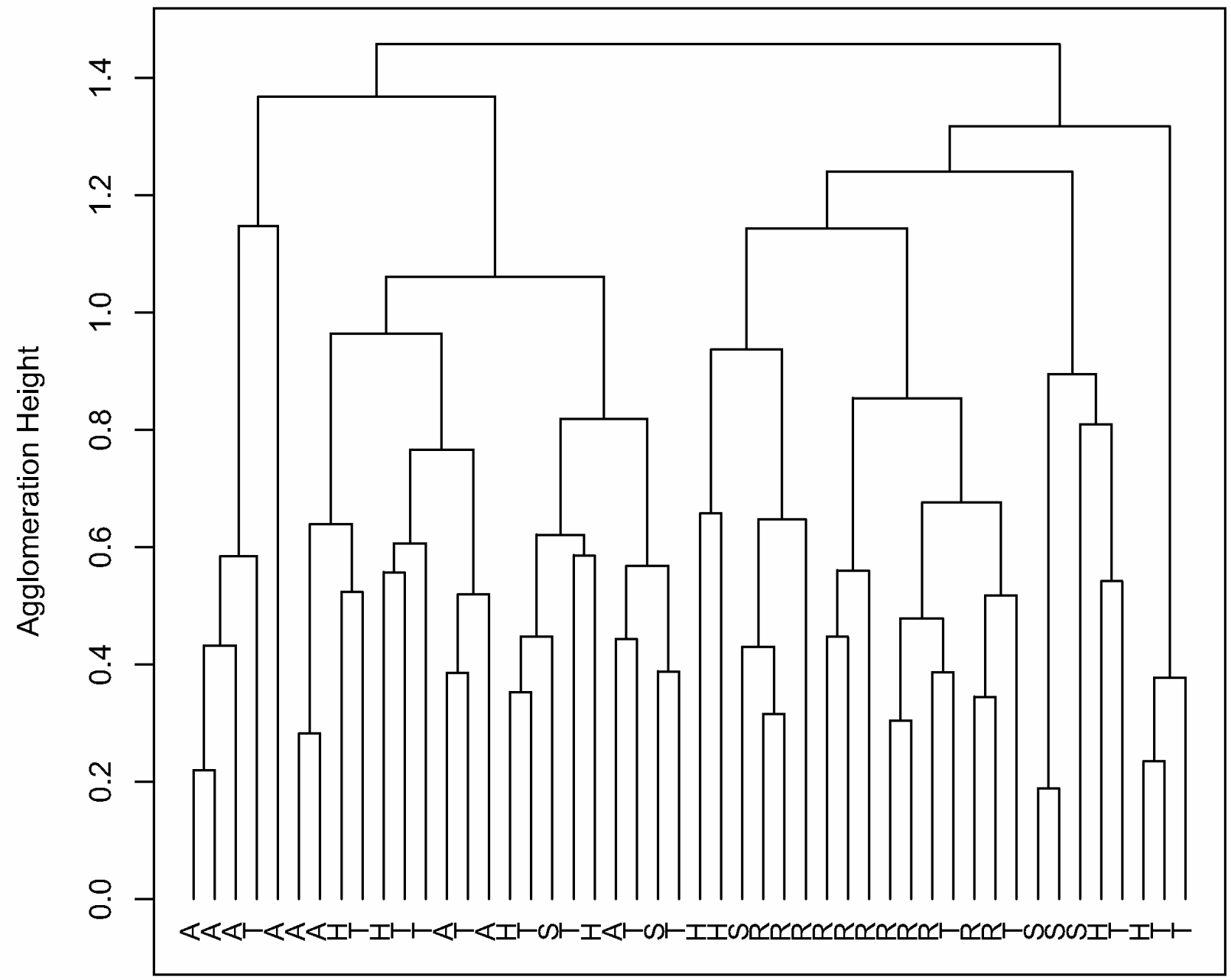


Figure 3.

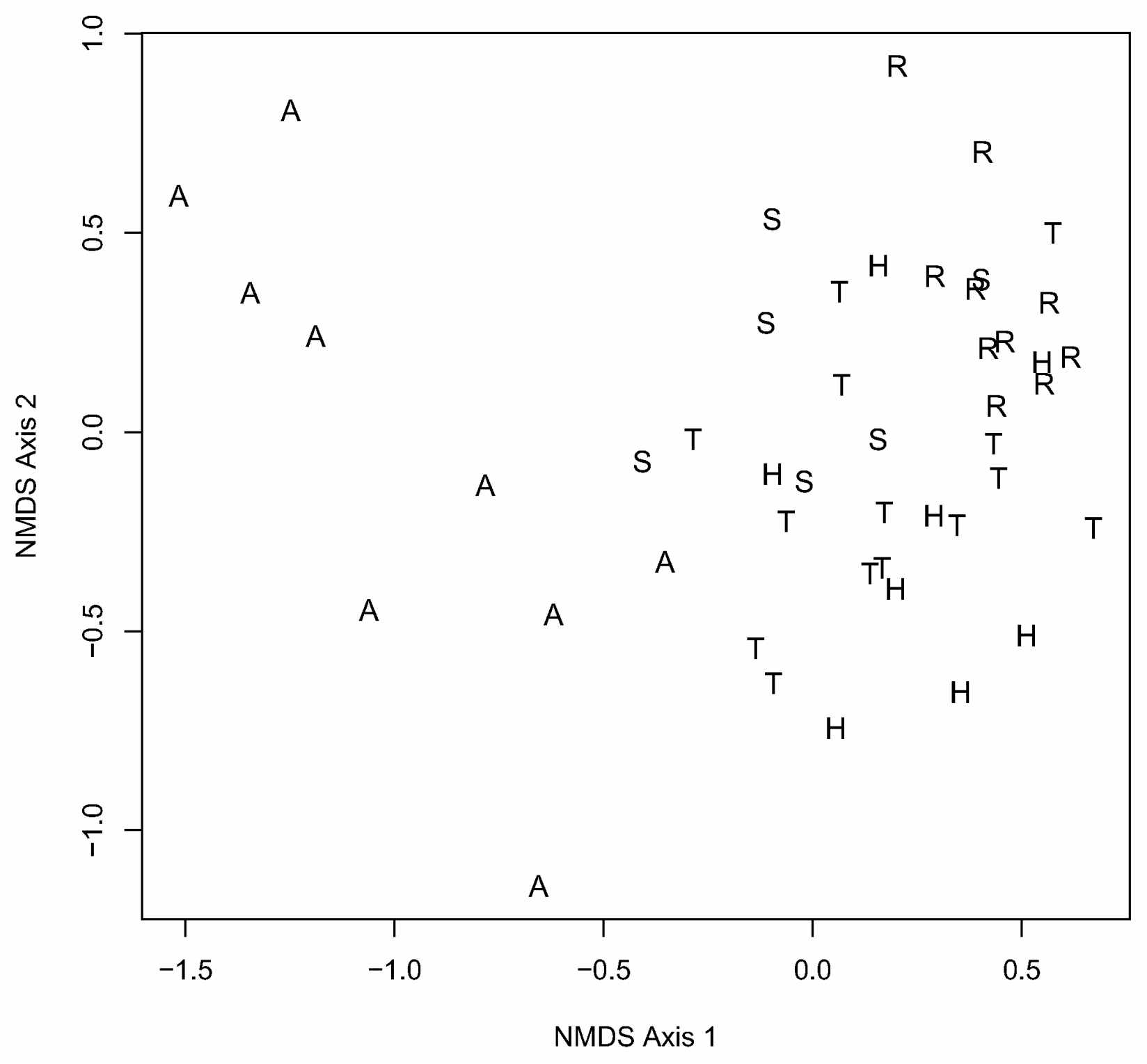


Figure 4.

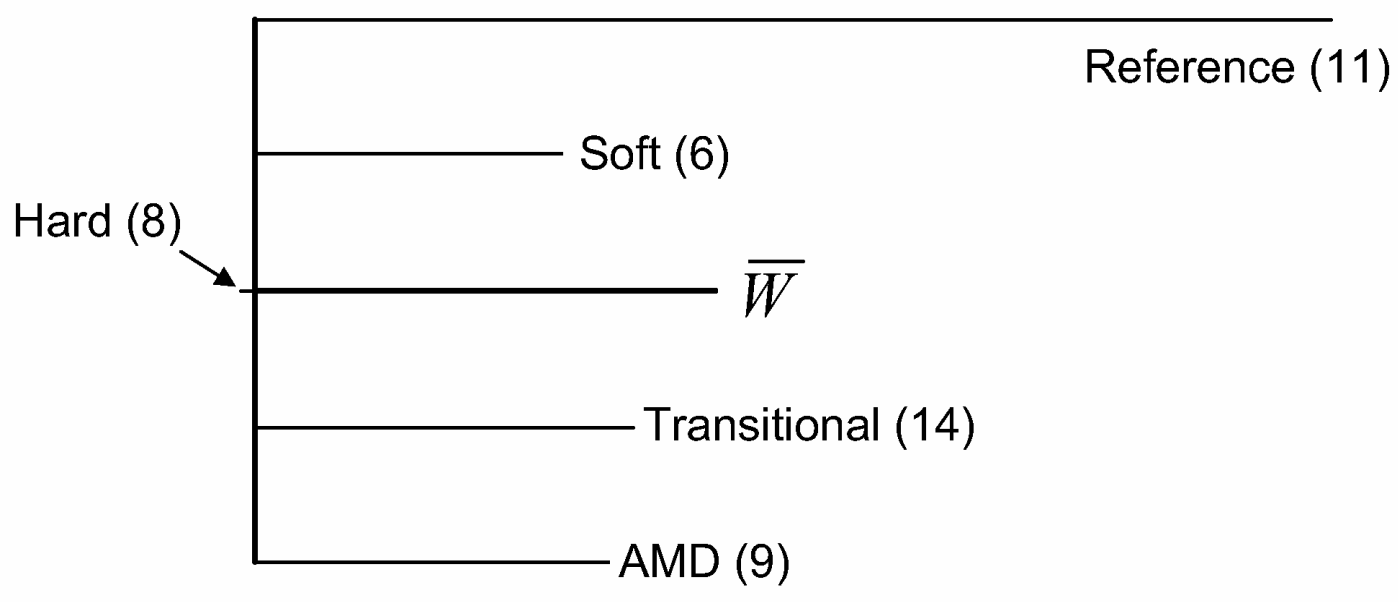

\begin{tabular}{ccccccc}
\hline 0.1 & 0.15 & 0.2 & 0.25 & 0.3 & 0.35 & 0.4 \\
\multicolumn{4}{c}{ Bray-Curtis Similarity } & &
\end{tabular}


Figure 5.

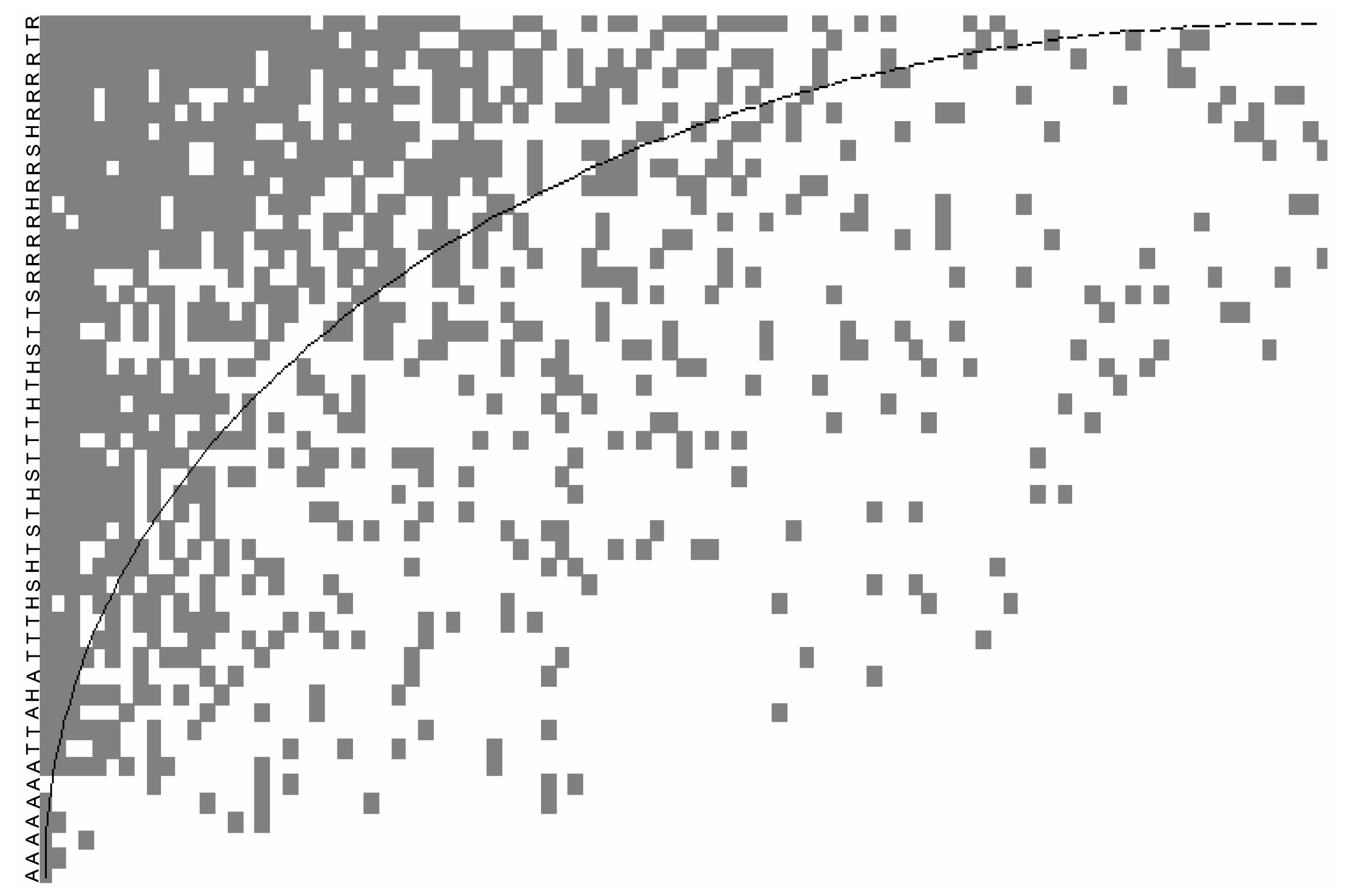


Figure 6.
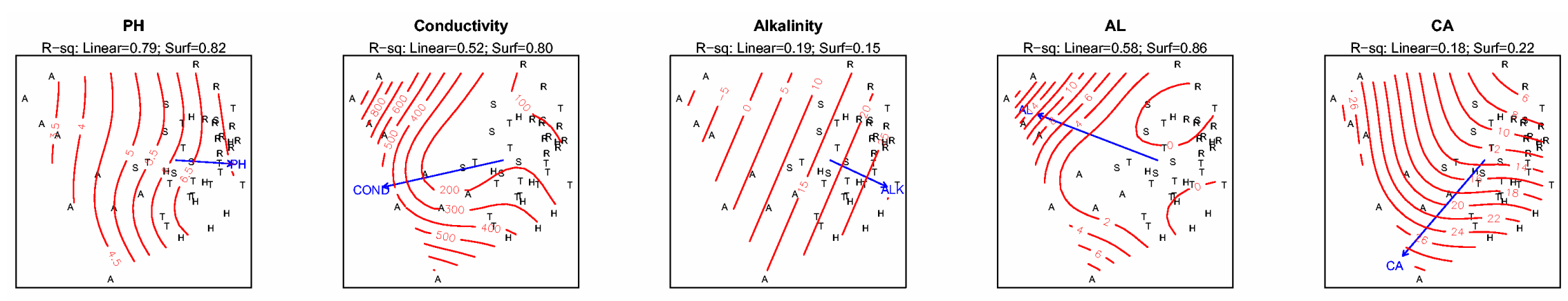

CD

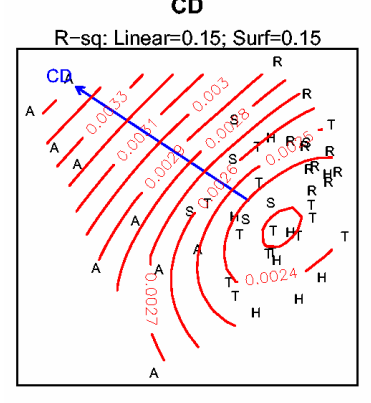

co

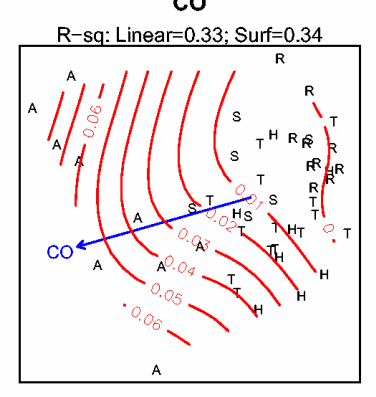

CR

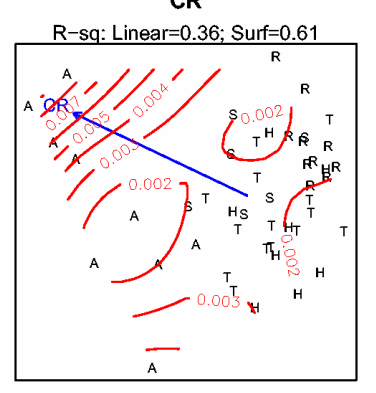

CU

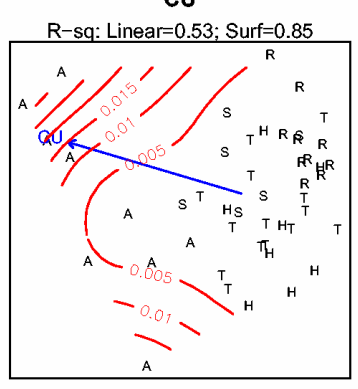

FE

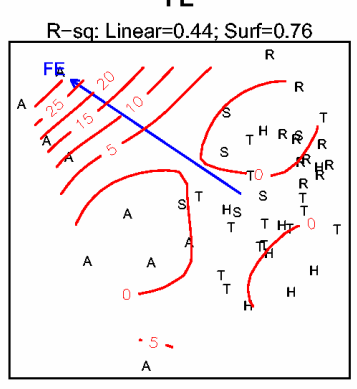

MG

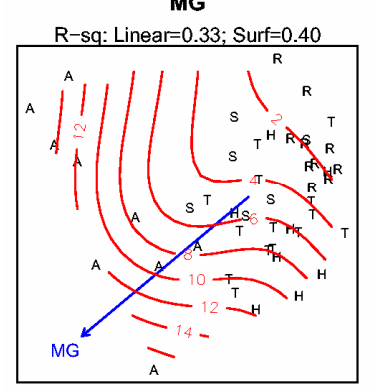

MN
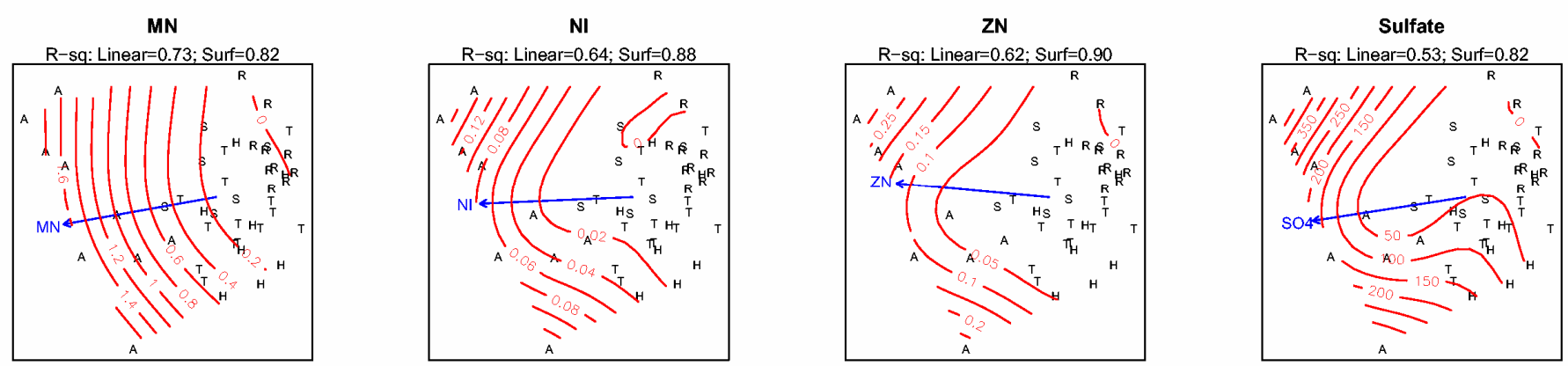


\section{Chapter 4: Interactive Effects of Multiple Stressors and Restoration Priorities in a Mined Appalachian Watershed}

Abstract. We surveyed benthic macroinvertebrate communities, water chemistry, and thermal regime in the Cheat River, WV, USA in an attempt to quantify the interactive effects of multiple stressors on ecological condition and identify priorities for restoration in this mined Appalachian watershed. We used a novel approach, which combined use of the West Virginia Stream Condition Index (WVSCI) to quantify ecological losses and community similarity analysis to assign specific levels of ecological loss to AMD, thermal effluent, and their interaction. Finally, we developed an ecological currency to quantify the relative benefits of a restoration program that focused either on AMD remediation or heat reduction and to identify spatially explicit restoration priorities. Variation in ecological condition was strongly correlated to variation in water quality when AMD and heat stress occurred in isolation. Acute inputs of AMD or heat caused predictable reductions in condition followed by rapid recovery downstream. However, benthic communities failed to recover from combined inputs of heat and AMD even when these stressors occurred at relatively low levels. Over the course of an entire year, AMD alone was over 2 times more responsible than heat alone for ecological loss. Consequently, AMD is the dominant factor limiting ecological condition and should be the primary target for restoration. Nevertheless, an AMD x heat interaction also was responsible for extensive ecological loss in lower reaches of the river. Consequently, full restoration of the lower Cheat River mainstem will require an approach that integrates AMD remediation with effective management of thermal effluent. Our results provide some of the first field evidence of the interactive effects of multiple stressors on biological communities in a mined watershed. This approach may be valuable for quantifying impacts from multiple interacting stressors and for prioritizing restoration efforts in other mined watersheds. 
Key Words: Acid mine drainage; IBI; Multiple interacting stressors; river restoration; similarity analysis; thermal pollution 


\section{$\underline{\text { Introduction }}$}

Benthic macroinvertebrate communities have been used as indicators of anthropogenic stress in stream ecosystems for over a century (Williams and Feltmate 1992), and aquatic biologists still regard the benthos as one of the best indicators of local stream health (Resh et al. 1996, Rosenberg and Resh 1996). In the United States (US), focus has been on the use of multimetric indices, whereas in Europe and Australia it has been on multivariate approaches where observed to expected taxa ratios are considered informative measures of biological condition (Barbour et al. 1999, Hawkins et al. 2000, Sloane and Norris 2003).

Field studies examining benthic community response to multiple interacting stressors, however, are rare. This is surprising considering that multiple stressors are probably more common in the environment than individual pollutants (Folt et al. 1999, Culp et al. 2000a). The US Clean Water Act, in part, mandates that water resources support healthy aquatic communities, and bioassessment indices are essential to the process of identifying streams not meeting this mandate. But, multimetric indices of biotic integrity (IBI) and presumably other multivariate-derived indices, which simply assess the ecological integrity of aquatic ecosystems, cannot necessarily diagnose sources of ecological impairment or partition the quantity of impairment between multiple interacting stressors.

Community similarity analysis, on the other hand, is a technique that potentially can be used to diagnose sources of impairment from multiple stressors. For example, disturbed sites should become more dissimilar to undisturbed sites as stress increases (Rosenberg and Resh 1996). Therefore, the average deviation of community similarity from reference could also provide a measure of impairment. In addition, impaired sites with similar IBI scores may have very different community compositions resulting from different stressors. Consequently, 
comparing community similarity among sites with known stressors can provide stressor specific measures of impact on community composition and be used to diagnose sources of stress in cases where stressors are unknown. Finally, community similarity analysis could aid in partitioning total biological impairment among multiple, interacting stressors.

On the Cheat River mainstem in north-central West Virginia, acid mine drainage (AMD) and thermal pollution from a coal-fired power plant act separately and in concert at various river segments to degrade biological integrity. Therefore, the Cheat River represents an ideal opportunity to study the combined effects of these interacting stressors on benthic macroinvertebrate community composition. Furthermore, it provides an opportunity to apply community similarity analysis with a focus on distinguishing and assigning specific levels of ecological impairment to AMD versus heat where they interact. Consequently, our goal for this field study was to quantify the interactive effects of multiple stressors on ecological condition, and to use this information to prioritize restoration efforts. Specifically, our objectives were to: 1) quantify spatial and seasonal variation in ecological condition in response to AMD and thermal effluent inputs along the Cheat River mainstem; 2) use similarity analysis to identify the relative effect of specific stressors on community composition and to assign levels of ecological impairment to each stressor separately and to their interaction where they co-occur; and 3) develop an ecological currency to quantify the potential ecological benefits of a Cheat River restoration program focused on AMD remediation and heat reduction.

\section{Methods}

Study Area 
The Cheat River flows north through north-central WV for $252 \mathrm{~km}$ and drains an area of approximately $3,683 \mathrm{~km}^{2}$ (Williams et al. 1999). The mainstem can be divided into four distinct regions on the basis of known impairments to the river (Fig. 1). In the upper basin (upstream of Pringle Run), the Cheat River is relatively unimpaired and receives no known pollutant sources (Fig. 1). In Region 2 (Pringle Run downstream to the Albright Power Station), a series of small to moderate sized AMD-impacted streams enter on river left (perspective facing downstream). Lick Run is the most significant AMD source to the mainstem in Region 2 and represents nearly $25 \%$ of the total AMD load to the lower Cheat River (Williams et al. 1999). Region 3 is a short (3-km) region immediately downstream of the Albright Power Station (APS), but upstream of two additional AMD inputs (Greens Run on river left and Muddy Creek on river right) (Fig. 1). Thermal effluent is the dominant stressor in this region, as the effects of AMD inputs from Lick Run upstream are no longer detectable by the time the river reaches the power station. Finally, Region 4 is a 19-km segment extending from the Muddy Creek confluence downstream to Big Sandy Creek (Fig. 1). Impacts from both thermal effluent and AMD are detectable in this segment.

We selected 14 sites along the river in relation to the type and level of pollutant entering the river (Fig. 1, Table 1). First, we chose two reference sites in Region 1 (Fig. 1, Table 1). Sites 3-5 were located in Region 2 on the right side of the river, opposite AMD inputs. Water quality and ecological condition at these sites were uncertain at the beginning of this study, and consequently, they were not considered reference sites. Sites 6-7 were located on the left side of the river within Region 2. These sites were positioned at different distances from Lick Run, beginning with site 6 immediately below the Lick Run confluence. Site 8 , positioned near the Elsey Run confluence, was 8 km below Lick Run (Fig. 1, Table 1). Sites 9 and 10 were located 
within Region 3 at varying distances from the power plant (Fig. 1, Table 1). Sites 11-14 were located in Region 4 at varying distances from Greens Run and Muddy Creek, two streams severely impacted by AMD (Fig. 1, Table 1).

\section{Field Sampling}

Water Chemistry and Temperature - We sampled water quality at 12 of the 14 sites in September 2002 and April 2003. Sites 12 and 13 were sampled for water quality and benthic macroinvertebrates in spring 2003 only. At each site, we collected a 500-mL filtered water sample using Nalgene polysulfone filter apparatus with mixed cellulose ester membrane disc filters ( $0.45 \mu \mathrm{m}$ pore size) for determination of dissolved aluminum, cadmium, chromium, iron, manganese, nickel, and total hardness (mg/L) (Petty and Barker 2004). Filtered samples were immediately acidified with $5 \mathrm{~mL} \mathrm{1:1} \mathrm{nitric} \mathrm{acid} \mathrm{to} \mathrm{prevent} \mathrm{precipitation} \mathrm{of} \mathrm{metals.} \mathrm{We} \mathrm{also}$ collected a 1-L unfiltered water sample for determination of sulfates $(\mathrm{mg} / \mathrm{L})$, and alkalinity and acidity $\left(\mathrm{mg} / \mathrm{L} \mathrm{CaCO}_{3}\right)$. These samples were stored at $4{ }^{\circ} \mathrm{C}$ until laboratory analysis. All water samples were analyzed at Black Rocks Test Lab in Morgantown, WV, using procedures from the $18^{\text {th }}$ edition of Standard Methods for the Examination of Water and Wastewater (Clesceri et al. 1992, Petty and Barker 2004). At each site we also took instantaneous measures of $\mathrm{pH}$, specific conductivity $(\mu \mathrm{S} / \mathrm{cm})$, dissolved oxygen $(\mathrm{mg} / \mathrm{L})$, and total dissolved solids $(\mathrm{g} / \mathrm{L})$ with a YSI 650 unit with a 600XL sonde (Yellow Springs Instruments, Yellow Springs, OH). In addition, we monitored river water temperature $\left({ }^{\circ} \mathrm{C}\right)$ from May - October 2002 and 2003 with continuous temperature loggers $\left(\mathrm{HOBO}^{\circledR}\right.$ Water Temp Pro and Optic ${ }^{\circledR}$ StowAway, Onset Computer Corporation, Bourne, MA) deployed at a site 2-km upstream of site 2 and at sites 3, 5, 9, 13, and 
14. Finally, average daily discharge data (cms) for the river was retrieved from a USGS gauging station (USGS 03069870) near site 2.

Benthic Macroinvertebrates - We collected benthic macroinvertebrates from each site in fall 2002 and spring 2003. We followed standardized procedures outlined by West Virginia Department of Environmental Protection's Watershed Assessment Program and the US Environmental Protection Agency’s Rapid Bioassessment Protocols for wadeable streams (WVDEP 1996, Barbour et al. 1999, WVDEP 2003). Sites 12 and 13 were sampled in spring 2003 only. A total of four targeted riffle samples (kick net dimensions 335 x 508 mm with 500 $\mu \mathrm{m}$ mesh) was taken at each site. Kick samples were combined for each site and were preserved with 95\% ethanol and Rose Bengal solution.

In the lab, macroinvertebrate samples were washed over a 2-mm sieve mounted on a 0.25-mm sieve. All individuals retained by the 2-mm sieve were removed from debris, identified, and stored in $95 \%$ ethanol. Individuals retained by the $0.25-\mathrm{mm}$ sieve were elutriated from the sediment and sub-sampled $\left(1 / 8^{\text {th }}\right.$ of total) with a Folsom plankton splitter (Model Number 1831-F10, Wildco Supply Company, Buffalo, NY) for identification. Sediment was visually inspected for remaining macroinvertebrates prior to sub-sampling. Macroinvertebrates were identified to family level using Merritt \& Cummins (1996), and were enumerated.

\section{$\underline{\text { Statistical Analyses }}$}

Water Chemistry and Temperature - We analyzed water quality data for each site to identify stressor types and levels during our sampling period. The seven-day moving average of the daily average temperature (7DMADA), mean daily temperature range, and maximum daily temperature were calculated from hourly temperature data. Mean and standard error were 
calculated for all other water chemistry parameters and river discharge. Mean $\mathrm{pH}$ was calculated from the mean of the hydrogen ion concentration.

Ecological Condition and Invertebrate Community Similarity - We used the West Virginia Stream Condition Index (WVSCI) to quantify ecological condition at each sampling site each season (Gerritsen et al. 2000). WVSCI is a family-level benthic macroinvertebrate IBI, and ranges from 0-100 where scores $<55,55-69.9,70-85$, and $>85$ represent poor, marginal, good, and excellent stream health, respectively (Gerritsen et al. 2000).

Following guidelines of Hawkins \& Norris (2000), we also used the Bray-Curtis index on benthic macroinvertebrate family abundance data to calculate a measure of community dissimilarity among sites for each season. This index is robust to scale differences and is not influenced by conjoint absences (Clarke 1993, Su et al. 2004). We used family level abundance data to be consistent with WVSCI based analyses. Several studies have indicated that genuslevel data are no more useful than family-level data for quantifying anthropogenic impacts in streams (Bowman and Bailey 1997, Hewlett 2000, Waite et al. 2004).

To interpret the dissimilarity matrices, we used each site in each season as a focal site in all possible site pair-wise similarity comparisons. In addition, we used non-metric multidimensional scaling (NMDS) to further visualize differences among all sites within and between seasons. NMDS is a non-parametric ordination technique that maps samples (sites) in k-dimensional space while minimizing stress in the plot (Clarke 1993, Lee 2004, Zamon and Welch 2005). Sites that map close to each other in NMDS space are more similar to each other than sites that map further apart. The dimensionality (k) of the NMDS model that best represented the data without continually increasing dimensions was determined by examining scree plots (stress vs. k). Dimensionality was chosen where stress in the model was $<10 \%$. 
Then, a scatter plot of the first two NMDS dimensions was constructed. The meaning of these axes was determined with Spearman Rank correlations between NMDS scores and macroinvertebrate abundances and community metrics (e.g., family-level richness). Correlations were considered statistically significant when $p<0.05$. Similarity analyses and NMDS were conducted with the R language and environment for statistical computing Version 1.8.1 (R Development Core Team 2003).

Assigning Levels of Ecological Impairment to Each Stressor and Identifying Restoration Priorities - As an initial step, we divided the Cheat River mainstem into a series of 0.5-km longitudinal increments. River surface area in hectares (ha) for each increment was determined using the Watershed Characterization and Modeling System version 2.8, an ArcView GIS interface developed by the Natural Resource Analysis Center at West Virginia University (NRAC 2001). We then assigned each of our observed WVSCI scores to the most appropriate river segment and linearly interpolated between them to estimate WVSCI scores for segments bounded by observed scores. We believe this approach was reasonable because ecological condition in the Cheat River basin is tightly associated with water chemistry attributes and increases as water chemistry improves with distance from sources of impairment (see Results). The average of WVSCI scores from reference sites in the upper basin was used to represent ecological condition in Region 1. WVSCI scores for each increment were then standardized to 1.0 by dividing by the average WVSCI in Region 1 . Each standardized score was then multiplied by river surface area of their respective river segment to obtain a measure of current ecological units (EUs) present in ha. EUs represent ecological value in units of river surface area and can be viewed as the weighted functional surface area of the river (Petty and Thorne 2005). 
We then calculated absolute and percent EUs lost from AMD and heat by determining the expected EUs for each river segment. Expected EUs were calculated as the surface area of each river segment multiplied by 1.0 , which represents the weight given to reference conditions in Region 1. For river segments subjected to one stressor, we simply assigned all lost EUs to that stressor. For example all EUs lost in Region 2 were assigned to AMD. Where both AMD and heat impairment co-occurred (i.e., all segments in Region 4), we used similarity analysis to partition total EUs lost into those lost from AMD alone, from heat alone, and from their interaction. We did this by comparing the minimum and maximum percent by which the confounded site was as similar to a site with a single known stressor. The percent similarities of the total EUs lost were then assigned to minimum and maximum possible EU losses from the stressor in question. Any remaining lost EUs that were not accounted for by either AMD or heat were considered confounded loss and were assigned to the interaction of AMD and heat. Therefore, we estimated the minimum and maximum EUs lost that could be attributed to AMD, heat, and AMD x heat interaction for each $0.5 \mathrm{~km}$ river increment. We then summed present EUs and stressor specific EU losses across all increments within each region (i.e., regions 1-4). The calculations were derived separately for fall 2002 and spring 2003 and then averaged across seasons to obtain annualized estimates of ecological loss in Regions 1-4 of the Cheat River.

Finally, we estimated the minimum and maximum levels of EUs that could be recovered from each river segment through AMD remediation and heat reduction. Estimates of segment specific, recoverable EUs were made for each season separately and over an entire year. In segments with only one stressor present, EUs recoverable from a specific remediation action (e.g., AMD reduction) were simply those lost due to the particular stressor being removed. In segments where stressors co-occurred, recoverable EUs were calculated by adding losses 
incurred directly by the stressor to be mitigated to a fraction of the loss from AMD x heat interaction. The fractional loss from stressor interaction was calculated using information from spring 2003, when heat impacts were not present, and consequently all observed ecological losses were from AMD only (see Results). For example, loss from heat in fall was determined from the decrease in EUs lost in spring. This heat effect was subtracted from the loss from AMD $\mathrm{x}$ heat interaction to determine how much AMD was responsible for interaction effects. That value was then added to loss from AMD alone to estimate total recoverable EUs from AMD treatment. The results of these calculations were subsequently used to identify which regions of the river should be targeted for remediation and which stressor should be targeted first to maximize recovery in the lower Cheat River mainstem.

\section{$\underline{\text { Results }}$}

Water Quality

We observed significant spatial and seasonal variability in water chemistry in response to AMD inputs from tributaries to the Cheat River. Water chemistry was very good at reference sites in Region 1 and at sites 3-5 in Region 2 (sites opposite AMD inputs) (Table 2). Mean pH was circum-neutral at these sites and alkalinity tended to be highest. Conductivity and sulfates were usually lowest. Acidity, $\mathrm{Al}, \mathrm{Fe}$, and $\mathrm{Mn}$ also tended to be lowest. These findings indicate that upper reaches of the Cheat River possess very good water quality and that this continues downstream into Region 2 on the side of the river away from major AMD inputs.

Water quality was dramatically reduced immediately downstream of Lick Run (site 6 of Region 2) and Muddy Creek (site 11 of Region 4), the two largest AMD inputs to the Cheat River (Table 2). For example, mean $\mathrm{pH}$ dropped from circum-neutral upstream of Lick Run to a 
pH of 3 immediately downstream, and a similar pattern was observed above and below Muddy

Creek. Likewise, we observed dramatic increases in conductivity, sulfates, acidity, and dissolved metals associated with major AMD inputs to the mainstem (Table 2). Interestingly, dissolved chemistry at sites downstream of Lick Run and Muddy Creek improved rapidly with increasing distance from the inputs. For example, $\mathrm{pH}$ increased steadily with distance below Lick Run (Table 2).

We also observed clear evidence of power plant effects on water temperatures in summer, but not spring. An extreme spike in average and maximum late spring to early fall water temperature was observed at site 9 immediately below the power plant (Fig. 2). Like AMD chemistry, water temperature effects tended to moderate with distance. Nevertheless, slightly elevated summer water temperatures were observed throughout Regions 3 and 4 all the way downstream to Big Sandy Creek (Fig. 2a). Although summer 2002 was an extremely dry period with flows nearly approaching $\mathrm{Q}_{7,10}(1.3 \mathrm{cms})$ in September, river water temperatures were not warmer compared to summer 2003 when flows were more moderate (Fig. 2b). Despite severe effects of the power plant on summer water temperatures, these effects were not observed during late fall and early spring when maximum river temperatures approximated those upstream (Fig. 2b). Reduced effects during this time period probably were the result of reduced power generation, increased river flows (Fig. 2b), and lower overall river temperatures.

\section{Ecological Condition Based on WVSCI}

Ecological condition in the Cheat River varied predictably in response to both AMD and heat inputs (Fig. 3). In fall and spring, WVSCI was exceptionally high in Region 1 and at sites 3-5 on river right opposite AMD inputs in Region 2. Good to excellent ecological conditions 
were expected in these areas given the excellent water quality observed. In contrast, WVSCI at sites 6-8 on river left showed an immediate reduction in response to AMD inputs. Immediately below Lick Run (site 6), WVSCI dropped from excellent condition to a score of 65 in fall and a score of 25 in spring. Like dissolved water chemistry, there was a tendency for ecological condition in sites 7-8 to recover to near reference conditions. For example, WVSCI indicated good to excellent conditions at site 8 in both fall and spring, suggesting that the river had fully recovered from AMD inputs before reaching the power plant.

The effect of thermal effluent on ecological condition in Region 3 and the strength of AMD x heat interaction in Region 4 were readily apparent in fall 2002 (Fig. 3). At site 9, below the power plant, WVSCI declined to 28 in fall 2002. Three km downstream, at site 10, ecological condition improved to 55, suggesting moderate recovery from heat effluent over a relatively short distance. Presumably, this improvement in ecological condition with distance from the APS would continue downstream, except for AMD inputs from Muddy Creek at site 11. In fall 2002, WVSCI at site 11 dropped to extremely poor conditions and remained poor all the way downstream to site 14 , a distance of $16 \mathrm{~km}$. The failure of ecological condition to recover in Region 4 in fall is interesting given that water chemistry and temperatures improve dramatically with distance from Muddy Creek and the power plant.

Consistent with observations on water temperature, we failed to detect an effect of the power plant on WVSCI in spring 2003. Despite poor conditions in fall, spring conditions were good to excellent in Region 3 (sites 9 and 10) below the power plant. Nevertheless, AMD inputs from Muddy Creek produced poor conditions at site 11 in spring. However, WVSCI rapidly improved to good at sites 12-14, suggesting a relatively quick recovery from AMD inputs alone. In contrast, little or no recovery was observed downstream of site 11 in fall when both heat and 
AMD related stressors were present. These findings suggest that much of the impacts to benthic communities in Region 4 in fall are the result of interactive effects between AMD and heat, rather than a direct effect from a single dominant stressor.

\section{Macroinvertebrate Community Similarity}

Results from similarity analysis where reference site 1 was used as a focus for comparison were generally consistent with WVSCI scores (Fig. 4). The dominant result was a reduction in community similarity to reference conditions immediately downstream of major stressor inputs: at site 6 below Lick Run, at site 9 below the APS in fall, and at site 11 below Muddy Creek (Fig. 4a, b). No effect of APS on community similarity at site 9 was observed in spring, further supporting WVSCI based analyses (Fig. 4a, b). Finally, we also observed a general recovery of community composition in the Cheat River toward reference conditions with increasing distance from AMD inputs at Lick Run (i.e. from sites 6 to 8 in Region 2). A moderate recovery in community similarity at site 14 was also observed in spring but not in fall.

Additional comparisons of community similarity using sites 8 and 14 as foci provide clear evidence of the strength of the AMD $x$ heat interaction in fall but not spring (Fig. $4 c-f$ ). First, site 8 in fall was moderately similar only to sites $1-5$. Site 8 was extremely dissimilar to site 14 at the base of the study area in fall (Fig. 4c). Second, in fall, site 14 was highly dissimilar from all sites upstream (Fig. 4e). Third, this pattern abruptly changed in spring; site 8 was moderately similar to sites $1-5,9,10$ and highly similar to site 14 (Fig. 4d). Fourth, site 14 in spring was moderately similar to sites $4,5,9$, and 10 and highly similar to site 8 (Fig. 4f).

NMDS ordination also provided evidence of community change in response to AMD and heat (Fig. 5). Axis 1 distinguished between diverse, ecologically complex sites and, degraded 
sites dominated by tolerant taxa. Axis 2 separated sites by relative abundance of Ephemeroptera vs. Trichoptera taxa. In fall and spring, sites $1-5$ tended to group together. AMD inputs at sites 6 and 11 displaced community similarity from this group. With increasing distance from AMD inputs, community similarity moved back towards reference, except in fall when the trajectory from site 11 to 14 failed to move this direction. The response of community change to heat inputs in fall was similar to that of AMD, but with more pronounced displacement at site 9. Consistent with WVSCI and similarity analyses, NMDS ordination detected no thermal effect on invertebrate similarities in spring. Combined, these findings suggest that much degradation of ecological condition in Region 4 in fall is the result of an AMD x heat interaction, whereas in spring impairment is from AMD alone.

Assigning Levels of Ecological Impairment to Each Stressor and Identifying Restoration $\underline{\text { Priorities }}$

We delineated 73 0.5-km segments along the Cheat River mainstem from site 1 to 14 . This represented a total surface area of 544 ha along a $62.7-\mathrm{km}$ river course (Table 3 ). The total area was divided into 4 regions based on stressor types (see Methods): 1) Reference, 2) AMD only, 3) Heat only, and 4) AMD x Heat (Fig. 1).

In fall 2002, a total of 438 ha of EUs were present in the river, and 106 ha or $19 \%$ of the total expected EUs were lost as a result of AMD and heat related stress (Table 3). Loss accumulated at a greater rate from Region 3 through 4 than in Region 2 (Fig. 6). The greatest region-specific loss occurred in Region 4 (62\%). AMD x heat interaction accounted for most of this loss (47\%). Of the total ecological loss in the river in fall, 17\% occurred in Region 3 downstream of APS. In addition, of the 106 ha of EUs lost in fall, approximately $18 \%$ could be 
attributed directly to AMD, $29 \%$ was attributed to heat, and the remaining $53 \%$ was attributed to the interactive effects of AMD and heat (Table 3).

In spring 2003, we observed a lower rate of EU loss (Table 3; Fig. 6). A total of 493 ha of EUs were present in spring, which represented a total ecological loss of only $10 \%$ river-wide. Much of the improvements could be attributed to a lack of direct heat effect downstream of APS. In spring, we observed only minimal loss in Region 3 (Table 3 ). In contrast, AMD was a significantly more important stressor in spring than fall. In the AMD only segment, loss accumulated at a greater rate in spring than in fall (Fig. 6), and total EU losses increased from 14 to 21 (Table 3). In addition, total EU loss attributable to AMD river-wide increased from 19 EUs (18\%) in fall to 49 EUs (94\%) in spring (Table 3).

Annualized over the entire year, a total of 79 EUs were lost from the Cheat River, representing a $15 \%$ loss of EUs expected in the absence of heat or AMD related stress. Of this total loss, $23 \%$ occurred in Region 2 as a direct result of AMD inputs (Table 4). In the area below the APS (i.e., Regions 3 and 4), 25\% of the total EU loss could be attributed directly to heat, $27 \%$ could be attributed directly to AMD, and the remaining $47 \%$ was attributed to an AMD x heat interaction. Over the entire river-year, heat accounted for $20 \%$ of the loss, AMD accounted for $43 \%$, and the remaining $37 \%$ was attributed to their interaction (Table 3 ).

Finally, over the annualized period, Region 4 had significantly greater loss of EUs than Regions $2-3$, and we estimated that Region 4 of the Cheat River would recover more lost EUs from stressor mitigation than any other region of the river (Table 4). In Region 4, reduction of heat would return more EUs than AMD treatment. Eliminating heat in Regions $3-4$ would recover approximately $41 \%$ of the total EUs lost river-wide. Conversely, AMD treatment riverwide would return slightly more EUs lost (49\%) than heat reduction over the annual period. 


\section{$\underline{\text { Discussion }}$}

We conclude that much of the ecological loss in Region 4 in fall was from interactive effect of both AMD and heat rather than from either stressor acting as the dominant limiting factor. In fall, site 8 (a recovering AMD site) was very dissimilar to site 14 (a site recovering from both AMD and heat inputs). In fact, site 14 was very dissimilar to all other sites. In addition, NMDS analysis indicated that community change from site 11 (the AMD site immediately below Muddy Creek) to site 14 in fall was on a trajectory away from biological characteristics associated with recovery from AMD only or heat only. This pattern was quite different in spring when thermal inputs were absent. In spring, ecological condition at site 14 behaved similarly to site 8 by recovering to near reference conditions. Consequently, these patterns indicate that the combination of diffuse levels of AMD and slightly elevated temperatures in Region 4 of fall may create poor local conditions for invertebrate survival for a distance of nearly $16 \mathrm{~km}$ despite general improvements in water chemistry and temperature with distance from heat and AMD inputs.

In contrast, when each stressor occurred in isolation, impacts to benthic communities were locally severe immediately below AMD and heat inputs, but conditions rapidly improved over relatively short distances $(3-6 \mathrm{~km})$. For example, water quality and ecological condition were extremely poor immediately downstream of Lick Run. Similarly, conditions immediately below the APS were extremely poor in fall 2002. However, chemical and biological conditions downstream recovered rapidly in areas impacted by AMD only or heat only.

Overall, our results are consistent with numerous studies documenting negative impacts of mining-related discharges (e.g., Cain et al. 2000, Soucek et al. 2001a, DeNicola and Stapleton 2002) and thermal pollution (e.g., Poff and Matthews 1986, Lauritsen and Starkel 1989, 
Wellborn and Robinson 1996) on water quality and aquatic organisms. The dominant effect of these stressors is to reduce invertebrate numbers, diversity, and richness to a few tolerant taxa (Cherry et al. 2001, DeNicola and Stapleton 2002, Schmidt et al. 2002). For example, Malmqvist \& Hoffsten (1999), Clements et al. (2000), Cherry et al. (2001), and Schmidt et al. (2002) all found reduced macroinvertebrate abundance and EPT richness at sites with AMD. Cole et al. (2001) and Clements (2004) also found greater drift in macroinvertebrates exposed to AMD and heavy metals, respectively. Similarly, Poff \& Matthews (1986), Lauritsen \& Starkel (1989), and Wellborn \& Robinson (1996) found that thermal effluent from power plants reduced invertebrate numbers and diversity.

Our results also are consistent with studies reporting rapid improvements in water quality and ecological condition over time or distance from stressor inputs (e.g., Poff and Matthews 1986, Hoiland et al. 1994, Wellborn and Robinson 1996, Adams and Greeley 2000). For example, Sloane \& Norris (2003) found that observed to expected ratios of macroinvertebrate occurrence increased with distance downstream of pollution from metal mines. Sola et al. (2004) found numbers of macroinvertebrate families increased $6 \mathrm{~km}$ downstream of a large spill of mine waste, but richness was still lower than upstream of the spill. Similarly in a heatstressed system, Lauritsen \& Starkel (1989) found that macroinvertebrate taxa richness, density, and biomass recovered within about a month after shutdown of a nuclear power plant eliminated thermal effluent.

To our knowledge, however, our study is one of the first to document the interactive effects of AMD and heat on benthic macroinvertebrate communities. In fact, field studies examining interactive effects of multiple stressors are rare in general. Most studies examining multiple stressors employ experimental designs containing manipulated levels of stressors with 
individual organisms or transplanted stream assemblages. For example, Clements (2004) demonstrated in a very powerful experimental study that synergistic effects of $\mathrm{Zn}, \mathrm{Cd}$, and $\mathrm{Cu}$ decreased invertebrate abundance and increased invertebrate drift compared to $\mathrm{Zn}$ alone. Culp et al. (2000b) showed that the phosphorus content of chemically complex pulp mill effluent increased invertebrate biomass and abundance by stimulating food web productivity. Lenihan et al. (2003) found that marine benthic invertebrates responded differently to organic enrichment and toxins in sediments compared to when each stressor was alone.

Vinebrook's et al. (2004) stress-induced community sensitivity model could explain the interactive impacts of multiple stressors on aquatic organisms in the Cheat River. According to this model, when species' tolerances to two different stressors are negatively correlated, the two stressors eliminate more species compared to when species' tolerances are independent or positively correlated. This occurs because species persisting in the presence of the first stressor have higher sensitivity to the second (Vinebrooke et al. 2004). We are unaware of any field study that has examined the potential for wide-spread impact to aquatic ecosystems from diffuse levels of multiple stressors that support Vinbrooke et al. (2004). The extensive impairment we observed from AMD and heat suggests that diffuse levels of these stressors may be more important than severe local impacts from AMD or heat alone, indicating a negative correlation between heat and AMD tolerance by aquatic organisms. Another possibility is that abnormally high water temperatures may increase the likelihood that harmful chemical conditions like dissolved metals will block important cellular receptor sites of poikilothermic organisms. This possibility could be especially detrimental to organisms already experiencing increased metabolic rates due to elevated temperatures. Regardless of these scenarios, the fact that anthropogenic stressors such as heat and toxins (Folt et al. 1999), heat and salinity (Porter et al. 
1999), acid and nutrients (Soucek et al. 2001b), and organic and inorganic toxins (Lenihan et al. 2003) often co-occur, we suggest that additional field studies in rivers with multiple stressors are needed.

Because of the short time scale of our study, it is uncertain whether our results accurately represent long-term trends in water temperature, chemistry, and ecological conditions in the Cheat River. Year-to-year variability in physical, chemical, and biological characteristics is a common feature of riverine ecosystems (Poff and Ward 1989, Grossman et al. 1998). Consequently, it is possible that patterns we observed from late summer 2002 through spring 2003 are not indicative of conditions of the Cheat River in most years. Nevertheless, we know from other multi-year studies that water temperature, chemistry, and ecological conditions we observed in this study were well within the normal range of conditions for this watershed (WVDEP 1996, Martin 2004, Petty and Barker 2004). Previous studies indicate that benthic macroinvertebrate communities are relatively stable, despite year-to-year variability in physicochemical conditions (Bopp 2002, McClurg 2004). One reason for this may be that benthic communities are established by minimum conditions (e.g., maximum temperatures, maximum metal concentrations), which tend to be relatively constant from year-to-year, rather than the overall thermal or chemical regime, which tends to be highly variable (Petty and Barker 2004). Regardless, long-term monitoring of temperature, water chemistry, and ecological conditions will be necessary to understand the long-term dynamics and interactions of heat, AMD, and biological communities in this system.

A second shortcoming of our study was that we cannot guarantee the absence of an AMD effect in Region 3, located immediately downstream of APS. Ideally, we would have had an opportunity to sample a reach impacted by heat only that was upstream of any AMD inputs. 
However, APS is the only power plant on the river, and it happens to occur below the first inputs of AMD. This problem with study design is common in field impact assessments, where it is difficult to control for all possible stressors and their interactions over time (Stewart-Oaten et al. 1986, Stewart-Oaten et al. 1992, Osenberg et al. 1994). Often, experimental studies are the only way to control for unknown or potentially confounding impacts (Clements 2004). Nevertheless, an important objective of our study was to demonstrate independent and interactive effects of two stressors under field, rather than experimental, conditions. In addition, several findings suggest that AMD-related stress was not present in Region 3 of the Cheat River in fall 2002. First, all water chemistry variables in Region 3 were indistinguishable from those in Region 1 above AMD inputs. In fact, alkalinity in Region 3 was slightly higher than in the upstream reference region. Second, invertebrate community composition at Site 8 immediately upstream of the APS recovered to near-reference conditions in both spring and fall, further suggesting that the river had fully recovered from AMD inputs by the time it reached APS. Finally, Region 3 possessed very good ecological conditions in Spring 2003, a period of time when heat was not present, but presumably AMD would have been. If AMD were affecting Region 3, we would have expected a significant reduction in ecological condition in Region 3 in both fall and spring. Nevertheless, controlled experimental studies (sensu Clements 2004) would greatly improve our understanding of the direct and interactive effects of heat and AMD on ecological conditions in the Cheat River.

Also, we cannot guarantee that habitat conditions along the Cheat River continuum did not significantly influence community structure. In general, rivers are dynamic systems and, by nature, habitat patchiness creates a heterogeneity to which organisms should be expected to respond (Heino 2005a). Tributary sources of sediment, for example, punctuate gradual changes 
in sediment character along river continua, which in turn could cause abrupt shifts in invertebrate community structure (Rice et al. 2001). However, studies examining the influence of habitat on macroinvertebrates are equivocal (see Vinson and Hawkins 1998). For example, Heino et al. (2003a) and Heino (2005a) found that water chemistry variables most often explained the most variation in community structure and function, respectively, in unimpaired headwater streams in Finland. In contrast, local physical variables explained slightly more variation in macroinvertebrates than local chemistry in Swedish streams (Sandin and Johnson 2004). In our study area, benthic macroinvertebrates are highly related to variation in water quality, which most likely overwhelms minor changes in physical conditions, along the river. Consequently, water chemistry (AMD inputs), temperature (thermal effluent), and their interaction probably are the dominant features controlling benthic macroinvertebrates at the segment scale of this miningimpacted river.

Macroinvertebrate community indices including multimetric IBIs are informative measures of local stream condition (Barbour et al. 1999), and many of the above cited studies have shown their predictable response to stressors. Similarity analysis also is a convenient descriptor of community similarity among samples and it is commonly used in ecological studies. Within the last several years, the implementation of NMDS ordination also has been used to examine community response to disturbance from diverse sources such as grazing (Reed 2003), wildfires (Lee 2004), AMD (Hamsher et al. 2004), and timber harvesting (Kreutzweiser et al. 2005). For example, Thomson et al. (2005) found that macroinvertebrate composition upstream versus downstream of a small dam was similar after dam removal. McRae et al. (1998) showed that macroinvertebrate communities were different between low versus high salinity streams in Florida. 
To our knowledge, however, no study has combined the use of IBIs and similarity analysis. With this combined approach we found that WVSCI score and percent similarity of sites in Region $2-4$ to reference sites displayed the same general pattern of response to AMD and heat stressors. NMDS provided a visual representation of the similarity between sites in both seasons that was consistent with WVSCI response to these stressors. Consequently, similarity analysis may be useful as a measure of local stress in mining impacted watersheds. However, similarity analysis may fail to correctly assess the degree of biological health of sites subjected to isolation by cumulative upstream impacts, because the quality of recovery (i.e., the similarity of taxa at recovering sites relative to that at reference sites) may not increase in the same manor as the quantity of recovery indicated by multimetric IBIs. On the other hand, similarity analysis may detect poor regional conditions better than an IBI for the same reason.

We also developed an ecological currency and used our combined approach to diagnose stressors and assign biological impairment to specific stressors in areas where they interacted. In addition, we were able to compare benefits of eliminating AMD versus heat. Our combined analytical approach resulted in several important conclusions with implications for restoring the Cheat River watershed. First, AMD continues to be the dominant factor limiting ecological conditions in the river. AMD alone was approximately two times more responsible for EU loss than heat alone. Furthermore, AMD is a significant stressor throughout the entire year, whereas heat-related stress is seasonal. Consequently, any watershed scale restoration program must target acid load reductions. Second, the greatest rate of EU loss occurred in Region 4 in fall. This region is where heat and AMD interact to produce extensive ecological impairment. Consequently, AMD remediation actions should be designed to reduce or completely eliminate acid loads to this area. Third, because of strong interactive effects of AMD and heat, a 
restoration program that focuses only on AMD will be far less successful than one that integrates AMD remediation with effective management of thermal effluent. Although AMD reclamation in lieu of heat reduction would likely produce broad benefits to the river, it is unlikely that full ecological potential of Region 4 can be reached without addressing heat impacts as well.

\section{Acknowledgements}

We thank Jennifer Barker Fulton, Brock Reggi, Roy Martin, and Zach Liller for their field help. We also thank Steven L. Kohler, Craig Mains, Donna Hartman, and Seth Lemley for help identifying macroinvertebrates and numerous undergraduate students for their help processing samples. Comments from Bob Goldstein, Rick Herd and an anonymous reviewer greatly improved previous versions of this manuscript. Funding for this research was provided by the Electrical Power Research Institute, Allegheny Energy Supply Co. and USEPA STAR Grant RD-83136401-0. 


\section{$\underline{\text { References }}$}

Adams, S. M. \& M. S. Greeley, 2000. Ecotoxicological indicators of water quality: using multiresponse indicators to assess the health of aquatic ecosystems. Water, Air, and Soil Pollution 123: 103-115.

Barbour, M. T., J. Gerritsen, B. D. Snyder \& J. B. Stribling, 1999. Rapid bioassessment protocols for use in streams and wadeable rivers: periphyton, benthic macroinvertebrates, and fish. Second Edition. EPA 841-B-99-022, U.S. Environmental Protection Agency; Office of Water, Washington, D.C.

Bopp, J. A., 2002. Combined effects of water chemistry, canopy cover, and stream size on benthic macroinvertebrates along a Central Appalachian stream continuum. Master's Thesis, West Virginia University.

Bowman, M. F. \& R. C. Bailey, 1997. Does taxonomic resolution affect the multivariate description of the structure of freshwater benthic macroinvertebrate communities? Canadian Journal of Fisheries and Aquatic Sciences 54: 1802-1807.

Cain, D. J., J. L. Carter, S. V. Fend, S. N. Luoma, C. N. Alpers \& H. E. Taylor, 2000. Metal exposure in a benthic macroinvertebrate, Hydropsyche californica, related to mine drainage in the Sacramento River. Canadian Journal of Fisheries and Aquatic Sciences 57: 380-390.

Cherry, D. S., R. J. Currie, D. J. Soucek, H. A. Latimer \& G. C. Trent, 2001. An integrative assessment of a watershed impacted by abandon mined land discharges. Environmental Pollution 111: 377-388.

Clarke, K. R., 1993. Non-parametric multivariate analyses of changes in community structure. Australian Journal of Ecology 18: 117-143.

Clements, W. H., 2004. Small-scale experiments support causal relationships between metal contamination and macroinvertebrate community responses. Ecological Applications 14: 954967.

Clements, W. H., D. M. Carlisle, J. M. Lazorchak \& P. C. Johnson, 2000. Heavy metals structure benthic communities in Colorado mountain streams. Ecological Applications 10: 626-638.

Clesceri, L. S., A. E. Greenberg \& A. D. Eaton, 1992. Standard methods for the examination of water and wastewater. American Public Health Association, Washington D.C.

Cole, M. B., D. E. Arnold \& B. J. Watten, 2001. Physiological and behavioral responses of stonefly nymphs to enhanced limestone treatment of acid mine drainage. Water Research 35: 625-632.

Culp, J. M., K. J. Cash \& F. J. Wrona, 2000a. Cumulative effects assessment for the Northern River Basins Study. Journal of Aquatic Ecosystem Stress and Recovery 8: 87-94. 
Culp, J. M., C. L. Podemski \& K. J. Cash, 2000b. Interactive effects of nutrients and contaminants from pulp mill effluents on riverine benthos. Journal of Aquatic Ecosystem Stress and Recovery 8: 67-75.

DeNicola, D. M. \& M. G. Stapleton, 2002. Impact of acid mine drainage on benthic communities in streams: the relative roles of substratum vs. aqueous effects. Environmental Pollution 119: 303-315.

Folt, C. L., C. Y. Chen, M. V. Moore \& J. Burnaford, 1999. Synergism and antagonism among multiple stressors. Limnology and Oceanography 44: 864-877.

Gerritsen, J., J. Burton \& M. T. Barbour, 2000. A stream condition index for West Virginia wadeable streams, Tetra Tech, Inc., Owings Mills, MD.

Grossman, G. D., R. E. Ratajczak, Jr., M. Crawford \& M. C. Freeman, 1998. Assemblage organization in stream fishes: Effects of environmental variation and interspecific interactions. Ecological Monographs 68: 395-420.

Hamsher, S. E., R. G. Verb \& M. L. Vis, 2004. Analysis of acid mine drainage impacted streams using a periphyton index. Journal of Freshwater Ecology 19: 313-324.

Hawkins, C. P. \& R. H. Norris, 2000. Performance of different landscape classifications for aquatic bioassessments: introduction to the series. Journal of the North American Benthological Society 19: 367-369.

Hawkins, C. R., R. H. Norris, J. N. Hogue \& J. W. Feminella, 2000. Development and evaluation of predictive models for measuring the biological integrity of streams. Ecological Applications 10: $1456-1477$.

Heino, J., 2005. Functional biodiversity of macroinvertebrate assemblages along major ecological gradients of boreal headwater streams. Freshwater Biology 50: 1578-1587.

Heino, J., T. Muotka, H. Mykra, R. Paavola, H. Hamalainen \& E. Koskenniemi, 2003. Defining macroinvertebrate assemblage types of headwater streams: implications for bioassessment and conservation. Ecological Applications 13: 842-852.

Hewlett, R., 2000. Implications of taxonomic resolution and sample habitat for stream classification at a broad geographic scale. Journal of the North American Benthological Society 19: 352-361.

Hoiland, W. K., F. W. Rabe \& R. C. Biggam, 1994. Recovery of macroinvertebrate communities from metal pollution in the South Fork and mainstem of the Coeur d'Alene River, Idaho. Water Environment Research 66: 84-88. 
Kreutzweiser, D. P., S. S. Capell \& K. P. Good, 2005. Macroinvertebrate community responses to selection logging in riparian and upland areas of headwater catchments in a northern hardwood forest. Journal of the North American Benthological Society 24: 208-222.

Lauritsen, D. \& W. Starkel, 1989. A study of post-thermal recovery of the macroinvertebrate community of Four Mile Creek June 1985-September 1987. NAI-SR-105, Normandeau Associates Inc., Aiken, SC.

Lee, P., 2004. The impact of burn intensity from wildfires on seed and vegetative banks, and emergent understory in aspen-dominated boreal forests. Canadian Journal of Botany 82: 14681480 .

Lenihan, H. S., C. H. Peterson, S. L. Kim, K. E. Conlan, R. Fairey, C. McDonald, J. H. Grabowski \& J. S. Oliver, 2003. Variation in marine benthic community composition allows discrimination of multiple stressors. Marine Ecology Progress Series 261: 63-73.

Malmqvist, B. \& P. Hoffsten, 1999. Influence of drainage from old mine deposits on benthic macroinvertebrate communities in central Swedish streams. Water Research 33: 2415-2423.

Martin, R. W., 2004. Watershed-scale thermal regimes and the distribution of brook trout (Salvelinus fontinalis) and smallmouth bass (Micropterus dolomieui) in the Cheat River watershed, WV. Master's Thesis, West Virginia University.

McClurg, S. E., 2004. Stream ecosystem response to mitigative limestone treatment. Master's Thesis, West Virginia University.

McRae, G., D. K. Camp, W. G. Lyons \& T. L. Dix, 1998. Relating benthic infaunal community structure to environmental variables in estuaries using nonmetric multidimensional scaling and similarity analysis. Environmental Monitoring and Assessment 51: 233-246.

Merritt, R. W. \& K. W. Cummins, 1996. An introduction to the aquatic insects of North America. Kendall/Hunt Publishing Co., Dubuque, IA.

NRAC, 2001. Watershed characterization and modeling system version 2.8. Natural Resource Analysis Center, Division of Resource Management. West Virginia University, Morgantown, WV.

Osenberg, C. W., R. J. Schmitt, S. J. Holbrook, K. E. Abu-Saba \& A. R. Flegal, 1994. Detection of environmental impacts: natural variability, effect size and power analysis. Ecological Applications 4: 16-30.

Petty, J. T. \& J. Barker, 2004. Water quality variability in tributaries of the Cheat River, a mined Appalachian watershed, 2004 National Meeting of the American Society of Mining and Reclamation and the 25th West Virginia Surface Mine Drainage Task Force. American Society of Mining and Reclamation, Morgantown, WV 1484-1504. 
Petty, J. T. \& D. Thorne, 2005. An ecologically based approach to identifying restoration priorities in an acid-impacted watershed. Restoration Ecology 13: 348-357.

Poff, N. L. \& R. A. Matthews, 1986. Benthic macroinvertebrate community structural and functional group response to thermal enhancement in the Savannah River and a coastal plain tributary. Archiv fur Hydrobiologie 106: 119-137.

Poff, N. L. \& J. V. Ward, 1989. Implications of streamflow variability and predictability for lotic community structure: a regional analysis of streamflow patterns. Canadian Journal of Fisheries and Aquatic Sciences 46: 1805-1818.

Porter, J. W., S. K. Lewis \& K. G. Porter, 1999. The effect of multiple stressors on the Florida Keys coral reef ecosystem: A landscape hypothesis and a physiological test. Limnology and Oceanography 44: 941-949.

R Development Core Team, 2003. R: A language and environment for statistical computing. R Foundation for Statistical Computing, Vienna, Austria.

Reed, T., 2003. Macroinvertebrate assemblage change in a small eastern Oregon stream following disturbance by grazing cattle. Journal of Freshwater Ecology 18: 315-318.

Resh, V. H., M. J. Meyers \& M. J. Hannaford, 1996. Macroinvertebrates as biotic indicators of environmental quality. In Hauer, F. R. \& G. A. Lamberti (eds), Methods in Stream Ecology. Academic Press, San Diego, CA, USA: 647-667.

Rice, S. P., M. T. Greenwood \& C. B. Joyce, 2001. Tributaries, sediment sources, and the longitudinal organisation of macroinvertebrate fauna along river systems. Canadian Journal of Fisheries and Aquatic Sciences 58: 824-840.

Rosenberg, D. M. \& V. H. Resh, 1996. Use of aquatic insects in biomonitoring. In Merritt, R. W. \& K. W. Cummins (eds), An introduction to the aquatic insects of North America. Kendall/Hunt Publishing Company, Dubuque, IA: 87-97.

Sandin, L. \& R. K. Johnson, 2004. Local, landscape and regional factors structuring benthic macroinvertebrate assemblages in Swedish streams. Landscape Ecology 19: 501-514.

Schmidt, T. S., D. J. Soucek \& D. S. Cherry, 2002. Integrative assessment of benthic macroinvertebrate community impairment from metal-contaminated waters in tributaries of the Upper Powell River, Virginia, USA. Environmental Toxicology and Chemistry 21: 2233-2241.

Sloane, P. I. W. \& R. H. Norris, 2003. Relationship of AUSRIVAS-based macroinvertebrate predictive model outputs to a metal pollution gradient. Journal of the North American Benthological Society 22: 457-471.

Sola, C., M. Burgos, A. Plazuelo, J. Toja, M. Plans \& N. Prat, 2004. Heavy metal bioaccumulation and macroinvertebrate community changes in a Mediterranean stream affected 
by acid mine drainage and an accidental spill (Guadiamar River, SW Spain). Science of the Total Environment 333: 109-126.

Soucek, D. J., D. S. Cherry \& C. E. Zipper, 2001a. Aluminum-dominated acute toxicity to the cladoceran Ceriodaphnia dubia in neutral waters downstream of an acid mine drainage discharge. Canadian Journal of Fisheries and Aquatic Sciences 58: 2396-2404.

Soucek, D. J., T. S. Schmidt \& D. S. Cherry, 2001b. In situ studies with Asian clams (Corbicula fluminea) detect acid mine drainage and nutrient inputs in low-order streams. Canadian Journal of Fisheries and Aquatic Sciences 58: 602-608.

Stewart-Oaten, A., J. R. Bence \& C. W. Osenberg, 1992. Assessing effects of unreplicated perturbations: no simple solutions. Ecology 73: 1396-1404.

Stewart-Oaten, A., A. A. Murdoch \& K. R. Parker, 1986. Environmental impact assessment: "pseudoreplication" in time? Ecology 67: 929-940.

Su, J. C., D. M. Debinski, M. E. Jakubauskas \& K. Kindscher, 2004. Beyond species richness: community similarity as a measure of cross-taxon congruence for coarse-filter conservation. Conservation Biology 18: 167-173.

Thomson, J. R., D. D. Hart, D. F. Charles, T. L. Nightengale \& D. M. Winter, 2005. Effects of removal of a small dam on downstream macroinvertebrate and algal assemblages in a Pennsylvania stream. Journal of the North American Benthological Society 24: 192-207.

Vinebrooke, R. D., K. L. Cottingham, J. Norberg, M. Scheffer, S. I. Dodson, S. C. Maberly \& U. Sommer, 2004. Impacts of multiple stressors on biodiversity and ecosystem functioning: the role of species co-tolerance. Oikos 104: 451-457.

Vinson, M. R. \& C. P. Hawkins, 1998. Biodiversity of stream insects: variation at local, basin, and regional scales. Annu. Rev. Entomol. 43: 271-93.

Waite, I. R., A. T. Herlihy, D. P. Larsen, N. S. Urquhart \& D. J. Klemm, 2004. The effects of macroinvertebrate taxonomic resolution in large landscape bioassessments: an example from the Mid-Atlantic Highlands, U.S.A. Freshwater Biology 49: 474-489.

Wellborn, G. A. \& J. V. Robinson, 1996. Effects of a thermal effluent on macroinvertebrates in a central Texas reservoir. The American Midland Naturalist 136: 110-120.

Williams, D. D. \& W. B. Feltmate, 1992. Aquatic insects. Cab International, Oxon.

Williams, D. R., M. E. Clark \& J. B. Brown, 1999. Stream water quality in coal mined areas of the lower Cheat River basin, West Virginia and Pennsylvania, during low-flow conditions, July 1997. Water-Resources Investigations Report 98-4258, U. S. Geological Survey. 
WVDEP, 1996. An ecological assessment of the Cheat River watershed. Report Number0502004-1996, West Virginia Division of Environmental Protection, Charleston, WV.

WVDEP, 2003. Benthic invertebrate sampling, processing, and analysis standard operating procedures. West Virginia Division of Environmental Protection.

Zamon, J. E. \& D. W. Welch, 2005. Rapid shift in zooplankton community composition on the northeast Pacific shelf during the 1998-1999 El Nino-La Nina event. Canadian Journal of Fisheries and Aquatic Sciences 62: 133-144. 


\section{$\underline{\text { Tables and Figures }}$}

$\underline{\text { Tables }}$

Table 1. Sample sites and locations within major regions defined by stressor type in the Cheat River, WV. Region 2 was the AMD region. Sites in Region 2 containing no dominant stressor were on the side of the river opposite the tributary source of AMD. Upstream distance to the source of the dominant stressor is also listed. $\mathrm{DS}=$ Downstream; RR = River Right; RL = River Left; $\mathrm{A}=\mathrm{AMD} ; \mathrm{H}=$ heat; APS = Albright Power Station.

\begin{tabular}{|c|c|c|c|c|c|c|}
\hline $\begin{array}{l}\text { Site } \\
\text { No. }\end{array}$ & Site Description & $\begin{array}{l}\text { River } \\
\text { Kilometer }\end{array}$ & Region & $\begin{array}{c}\text { Dominant } \\
\text { Stressor }\end{array}$ & $\begin{array}{c}\text { Distance to } \\
\text { AMD Source } \\
(\mathrm{km})\end{array}$ & $\begin{array}{c}\text { Distance to } \\
\text { Heat Source } \\
(\mathrm{km})\end{array}$ \\
\hline 1 & Seven Islands & 93.7 & 1 & None & - & - \\
\hline 2 & Manheim & 69.6 & 1 & None & - & - \\
\hline 3 & DS Pringle Run & 59.9 & 2 & None & - & - \\
\hline 4 & DS Lick Run & $59.8(\mathrm{RR})$ & 2 & None & - & - \\
\hline 5 & Rt. 7 Bridge & $53.9(\mathrm{RR})$ & 2 & None & - & - \\
\hline 6 & DS Lick Run & $59.8(\mathrm{RL})$ & 2 & $\mathrm{~A}$ & 0 & - \\
\hline 7 & Rt. 7 Bridge & $53.9(\mathrm{RL})$ & 2 & A & 6 & - \\
\hline 8 & DS Elsey Run & 51.4 & 2 & $\mathrm{~A}$ & 8 & - \\
\hline 9 & DS APS & 49.8 & 3 & $\mathrm{H}$ & - & 0.5 \\
\hline 10 & Decision Rapids & 46.8 (RL) & 3 & $\mathrm{H}$ & - & 3 \\
\hline 11 & Decision Rapids & 46.8 (RR) & 4 & $\mathrm{~A}+\mathrm{H}$ & 0 & 3 \\
\hline 12 & Big Nasty Rapids & 43.0 & 4 & $\mathrm{~A}+\mathrm{H}$ & 3 & 6 \\
\hline 13 & Coliseum Rapids & 39.8 & 4 & $\mathrm{~A}+\mathrm{H}$ & 7 & 10 \\
\hline 14 & Jenkinsburg & 31.0 & 4 & $\mathrm{~A}+\mathrm{H}$ & 16 & 19 \\
\hline
\end{tabular}


Table 2. Mean and standard error of water chemistry parameters measured over the study period at sampling sites. Site No. as in Table 1. NA = Not Available.

Mean Water Chemistry Parameters (Standard Error)

\begin{tabular}{|c|c|c|c|c|c|c|c|c|}
\hline $\begin{array}{l}\text { Site } \\
\text { No. }\end{array}$ & $\mathrm{pH}$ & $\begin{array}{l}\text { Conductivity } \\
(\mu \mathrm{S} / \mathrm{cm})\end{array}$ & $\begin{array}{c}\text { Alkalinity } \\
\left(\mathrm{mg} / \mathrm{L} \mathrm{CaCO}_{3}\right)\end{array}$ & $\begin{array}{c}\text { Acidity } \\
\left(\mathrm{mg} / \mathrm{L} \mathrm{CaCO}_{3}\right)\end{array}$ & $\begin{array}{l}\text { Sulfate } \\
(\mathrm{mg} / \mathrm{L})\end{array}$ & $\begin{array}{c}\mathrm{Al} \\
(\mathrm{mg} / \mathrm{L})\end{array}$ & $\begin{array}{c}\mathrm{Fe} \\
(\mathrm{mg} / \mathrm{L})\end{array}$ & $\begin{array}{c}\mathrm{Mn} \\
(\mathrm{mg} / \mathrm{L})\end{array}$ \\
\hline 1 & $7.0(7.8)$ & $96(15)$ & $20.4(4.0)$ & $10.0(2.5)$ & $15.7(2.1)$ & $0.19(0.07)$ & $0.26(0.20)$ & $0.04(0.02)$ \\
\hline 2 & $7.1(7.6)$ & $92(13)$ & $21.8(4.7)$ & $5.0(2.3)$ & $18.6(2.7)$ & $0.20(0.06)$ & $0.07(0.02)$ & $0.04(0.02)$ \\
\hline 3 & $7.0(7.2)$ & 97 (14) & $20.3(5.0)$ & $7.0(3.9)$ & $15.5(1.7)$ & $0.17(0.05)$ & $0.16(0.08)$ & $0.03(0.01)$ \\
\hline 4 & NA & NA & NA & NA & NA & NA & NA & NA \\
\hline 5 & $6.9(7.3)$ & $129(21)$ & $17.6(2.6)$ & $26.3(8.7)$ & $40.0(10.0)$ & $0.22(0.07)$ & $0.26(0.18)$ & $0.09(0.04)$ \\
\hline 6 & $3.0(3.3)$ & $1002(597)$ & $0.0(0.0)$ & $116.5(20.8)$ & $197.0(26.1)$ & $5.51(1.01)$ & $10.71(1.80)$ & $0.37(0.10)$ \\
\hline 7 & $6.6(6.8)$ & $118(19)$ & $11.6(1.9)$ & $22.9(8.7)$ & $35.8(10.3)$ & $0.20(0.04)$ & $0.10(0.03)$ & $0.08(0.03)$ \\
\hline 8 & $7.2(7.9)$ & $111(17)$ & $13.6(1.2)$ & $19.0(7.1)$ & $22.4(11.7)$ & $0.15(0.05)$ & $0.27(0.14)$ & $0.03(0.02)$ \\
\hline 9 & $7.4(7.9)$ & $125(15)$ & $17.1(2.6)$ & $16.5(6.6)$ & $36.1(7.9)$ & $0.27(0.03)$ & $0.18(0.07)$ & $0.03(0.01)$ \\
\hline 10 & $6.9(7.4)$ & $131(29)$ & $15.4(0.31)$ & $14.5(7.4)$ & $37.6(15.0)$ & $0.20(0.07)$ & $0.18(0.05)$ & $0.02(0.01)$ \\
\hline 11 & $3.4(3.8)$ & $912(178)$ & $0.0(0.0)$ & $139.7(55.1)$ & $383.3(114.3)$ & $8.82(3.52)$ & $5.35(2.87)$ & $2.20(0.80)$ \\
\hline 12 & NA & NA & NA & NA & NA & NA & NA & NA \\
\hline 13 & NA & NA & NA & NA & NA & NA & NA & NA \\
\hline 14 & $7.0(7.5)$ & $141(21)$ & $10.3(1.2)$ & $17.8(6.9)$ & $41.9(10.8)$ & $0.13(0.03)$ & $0.18(0.04)$ & $0.10(0.03)$ \\
\hline
\end{tabular}


Table 3. Estimates of EUs and EU loss from each of AMD alone, heat alone, and AMD x heat interaction for Fall 2002 and Spring 2003 across regions of the Cheat River. Estimates for the river overall in both seasons and for the annualized period are also presented. In the fall AMD $\mathrm{x}$ heat region where we estimated minimum and maximum loss from each stressor (see Methods), we report the average of those estimates here.

\begin{tabular}{|c|c|c|c|c|c|c|c|}
\hline Date/Region & $\begin{array}{c}\text { Surface } \\
\text { Area } \\
\text { ha }\end{array}$ & $\begin{array}{c}\text { Current } \\
\text { EUs } \\
\text { ha }\end{array}$ & $\begin{array}{l}\text { Expected } \\
\text { EUs } \\
\text { ha } \\
\end{array}$ & $\begin{array}{c}\text { Total Loss } \\
\text { ha ( } \% \text { of Total } \\
\text { Loss in River) } \\
\end{array}$ & $\begin{array}{c}\text { AMD Loss } \\
\text { ha ( } \% \text { of Total } \\
\text { Loss in Region) } \\
\end{array}$ & $\begin{array}{c}\text { Heat Loss } \\
\text { ha ( } \% \text { of Total } \\
\text { Loss in Region) }\end{array}$ & $\begin{array}{l}\text { AMD x Heat Loss } \\
\text { ha ( } \% \text { of Total Loss } \\
\text { in Region) }\end{array}$ \\
\hline \multicolumn{8}{|l|}{ Fall 2002} \\
\hline 1-Reference & 295 & 295 & 295 & $0(0)$ & $0(0)$ & $0(0)$ & $0(0)$ \\
\hline 2-AMD & 98 & 84 & 98 & $14(13)$ & $14(100)$ & $0(0)$ & $0(0)$ \\
\hline 3-Thermal & 32 & 14 & 32 & $18(17)$ & $0(0)$ & $18(100)$ & $0(0)$ \\
\hline 4-AMD x Heat & 120 & 46 & 120 & $74(70)$ & $5(7)$ & $13(18)$ & $56(75)$ \\
\hline Fall Total & 544 & 438 & 544 & $106(100)$ & $19(18)$ & $31(29)$ & $56(53)$ \\
\hline \multicolumn{8}{|l|}{ Spring 2003} \\
\hline 1-Reference & 295 & 295 & 295 & $0(0)$ & $0(0)$ & $0(0)$ & $0(0)$ \\
\hline 2-AMD & 98 & 77 & 98 & $21(40)$ & $21(100)$ & $0(0)$ & $0(0)$ \\
\hline 3-Thermal & 32 & 29 & 32 & $3(6)$ & $0(0)$ & $0(0)$ & $0(0)$ \\
\hline 4-AMD x Heat & 120 & 92 & 120 & $28(54)$ & $28(100)$ & $0(0)$ & $0(0)$ \\
\hline Spring Total & 544 & 493 & 544 & $52(100)$ & 49 (94) & $0(0)$ & $0(0)$ \\
\hline Annual Total & 544 & 465 & 544 & 79 (100) & $34(43)$ & $16(20)$ & $29(37)$ \\
\hline
\end{tabular}


Table 4. Annualized estimates of EUs recoverable (Gain) in Regions $1-4$ and river-wide (Annual Total) from AMD treatment vs. heat removal. Annualized estimates of total EU loss are also listed. In Region 4 of fall 2002 where we estimated minimum and maximum gain from stressor mitigation (see Methods), we report the average of those estimates.

\begin{tabular}{lccc}
\hline Region & $\begin{array}{c}\text { Total Loss } \\
\text { ha }(\% \text { of Total Loss })\end{array}$ & $\begin{array}{c}\text { Gain from AMD } \\
\text { Treatment } \\
\text { ha }(\% \text { of Total Loss })\end{array}$ & $\begin{array}{c}\text { Gain from Heat } \\
\text { Removal } \\
\text { ho of Total Loss })\end{array}$ \\
\hline 1-Reference & $0(0)$ & $0(0)$ & $0(0)$ \\
2-AMD & $18(23)$ & $18(23)$ & $0(0)$ \\
3-Thermal & $10(13)$ & $0(0)$ & $9(11)$ \\
4-AMD x Heat & $51(64)$ & $21(26)$ & $24(30)$ \\
\cline { 2 - 4 } Annual Total & $79(100)$ & $39(49)$ & $33(41)$ \\
\hline
\end{tabular}




\section{$\underline{\text { Figure Legend }}$}

Figure 1. Study area of the Cheat River, WV. Asterisks and numbers indicate sampling sites (Table 1). The bar on the left of the figure delineates assigned regions along the river. APS $=$ Albright Power Station. GIS database source: NRAC (2001).

Figure 2. Temperature and discharge data for the Cheat River. a) Seven-day moving average of the daily average temperature $\left({ }^{\circ} \mathrm{C}\right)$ at selected sites from May-Oct 2002 and 2003. Error bars represent mean daily temperature range. The data points in Region 1 were from a temperature logger deployed at a site $2 \mathrm{~km}$ upstream of site 2 . Of eight loggers deployed during each season, only two were recovered in 2002 and six were recovered in 2003. b) Average daily and overall mean discharge (Q cms) of the Cheat River (5/1/200210/13/2003) $2 \mathrm{~km}$ upstream of site 2 (USGS 03069870) in relation to the maximum daily temperature $\left({ }^{\circ} \mathrm{C}\right)$ profile at site 9 just downstream of the Albright Power Station (DS APS) in 2002 and 2003 and at two sites upstream of the Albright Power Station (US APS) with continuous temperature data. In 2002, the US APS temperature site was approximately $2 \mathrm{~km}$ upstream of site 2. In 2003, the US APS site was at sites 5 and 7. The record period for temperature extended from mid May to mid September (2002) - mid October (2003), but ended approximately one month earlier at sites upstream of APS.

Figure 3. West Virginia Stream Condition Index (WVSCI) scores at study sites in fall 2002 and spring 2003. Stream rating categories are indicated by horizontal lines. WVSCI scores at sites 12 and 13 were unavailable in fall 2002.

Figure 4. Pair-wise similarity (Bray-Curtis index) comparisons in fall 2002 and spring 2003. In each panel, the focal site for comparisons is the site where similarity is 1.0. Invertebrate data at sites 12 and 13 were unavailable in fall 2002.

Figure 5. Non-metric multidimensional scaling (NMDS) ordination of sites on invertebrate data from fall 2002 and spring 2003. The minimum number of dimensions (axes) that best represented the data was 6 (stress $=3.9 \%$ ). NMDS scores from Axis 1 (x-axis) and Axis 2 (y-axis) are plotted. Taxa abundances and invertebrate community metrics with high Spearman Rank correlations $(p<0.05)$ with the axes are listed; arrows indicate their direction of increase. Percent tolerant metric is the percentage of individuals in the sample with tolerance values $\geq 7$ (Gerritsen et al., 2000). Invertebrate data at sites 12 and 13 were unavailable in fall 2002.

Figure 6. Cumulative EU loss (ha) (0.5 km segment scale) along the Cheat River in the downstream direction from Site 1 to the bottom of the study area. 
Figure 1.

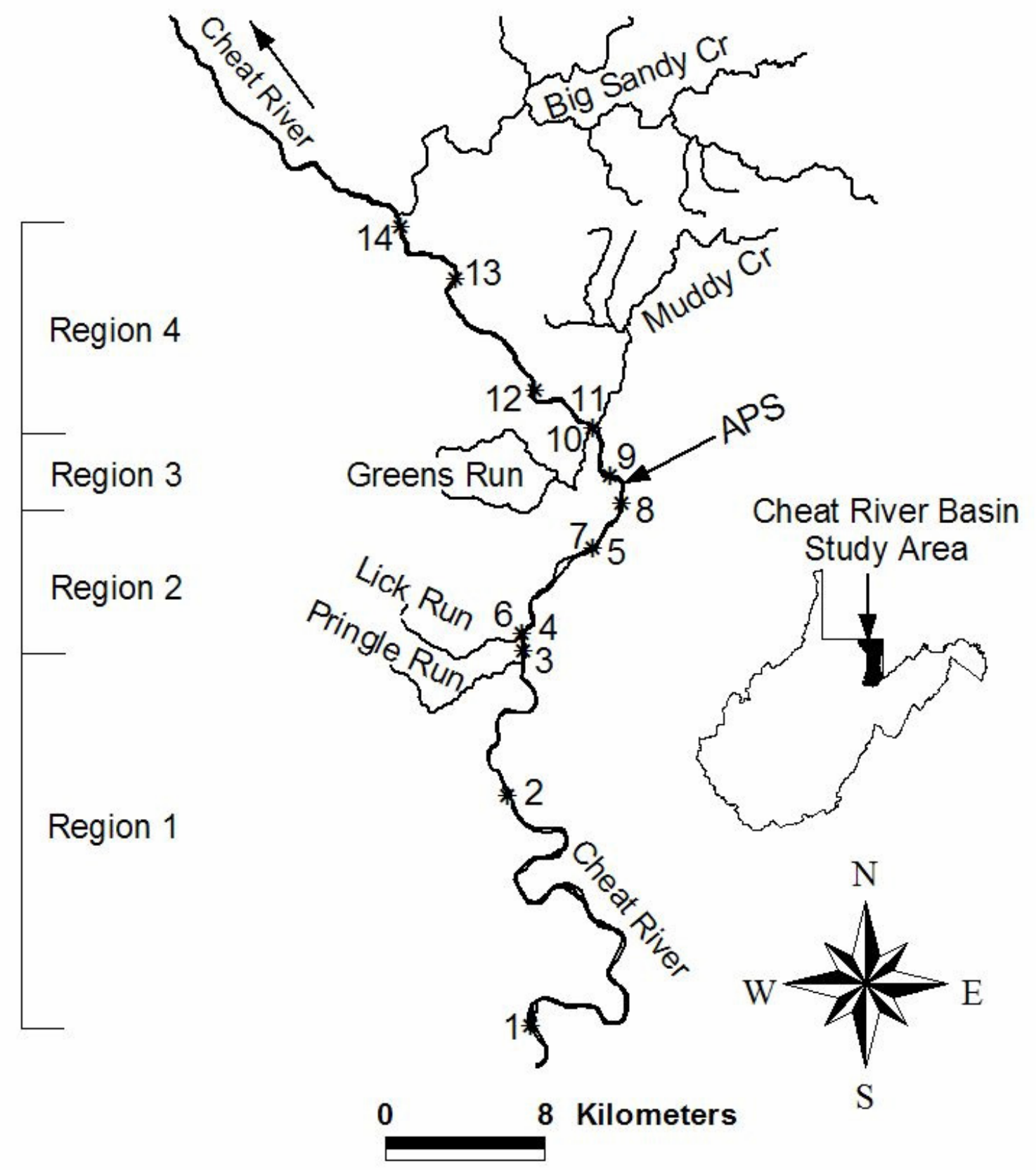


Figure 2.

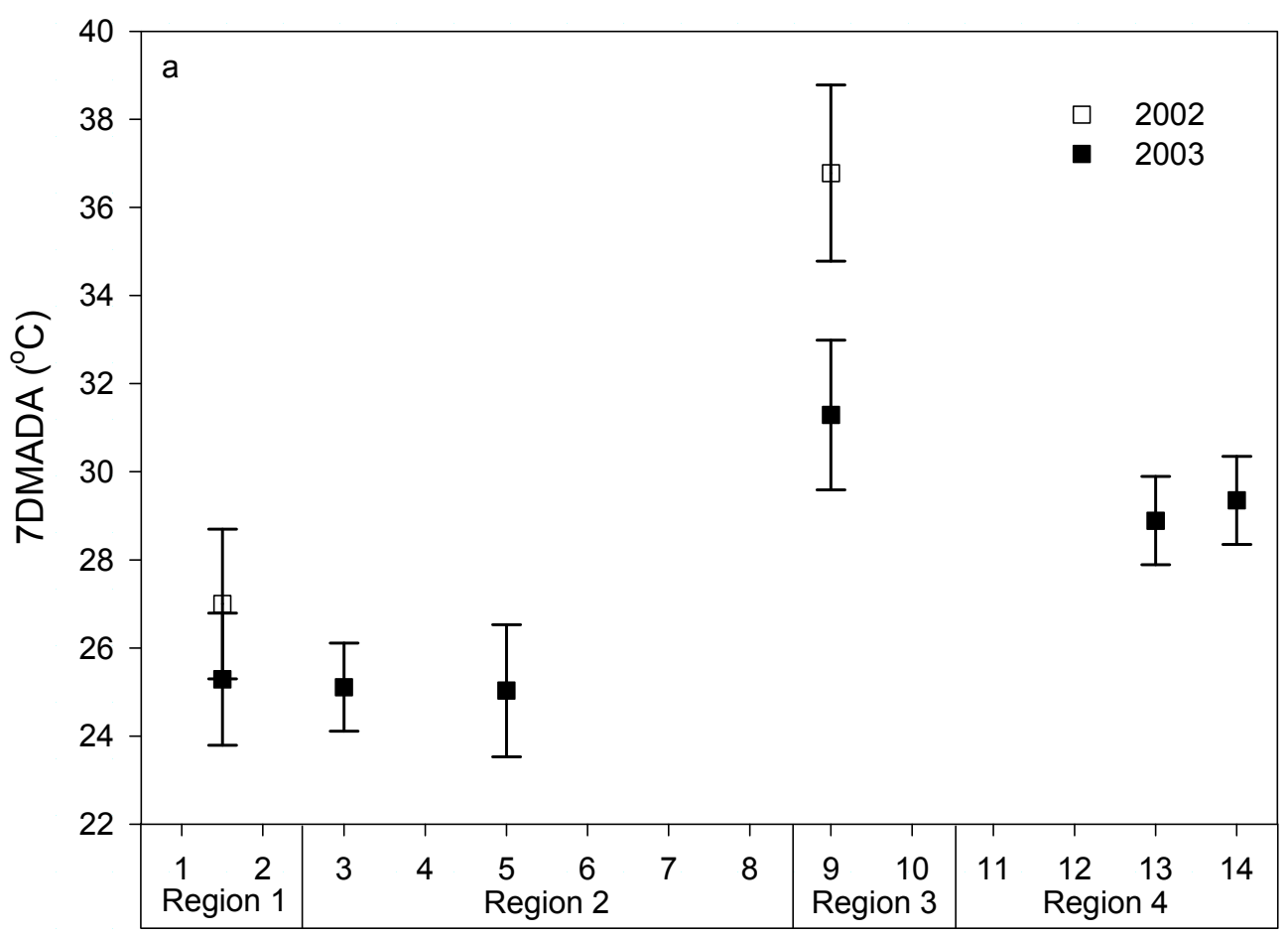

Site/Region

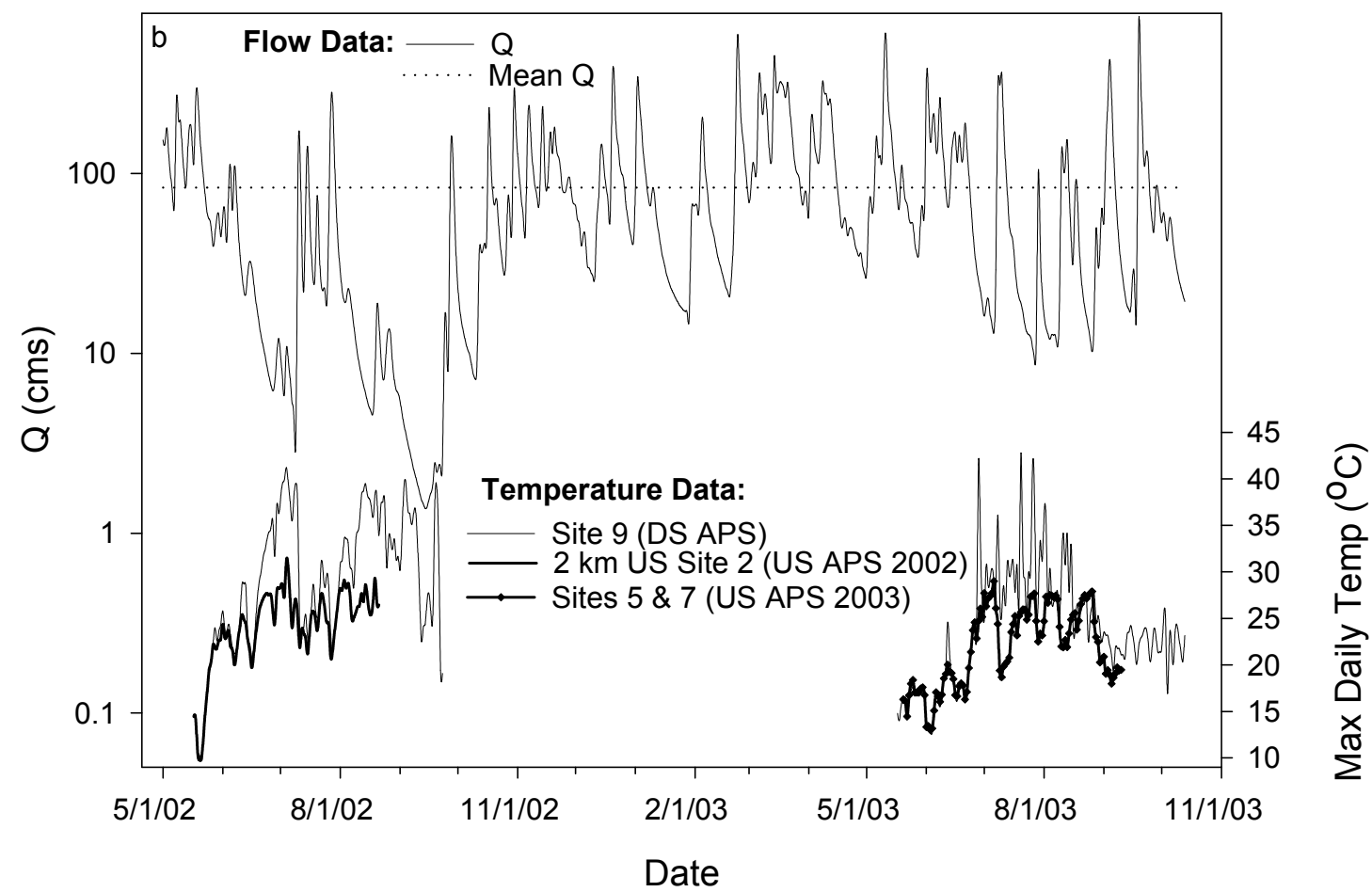


Figure 3.

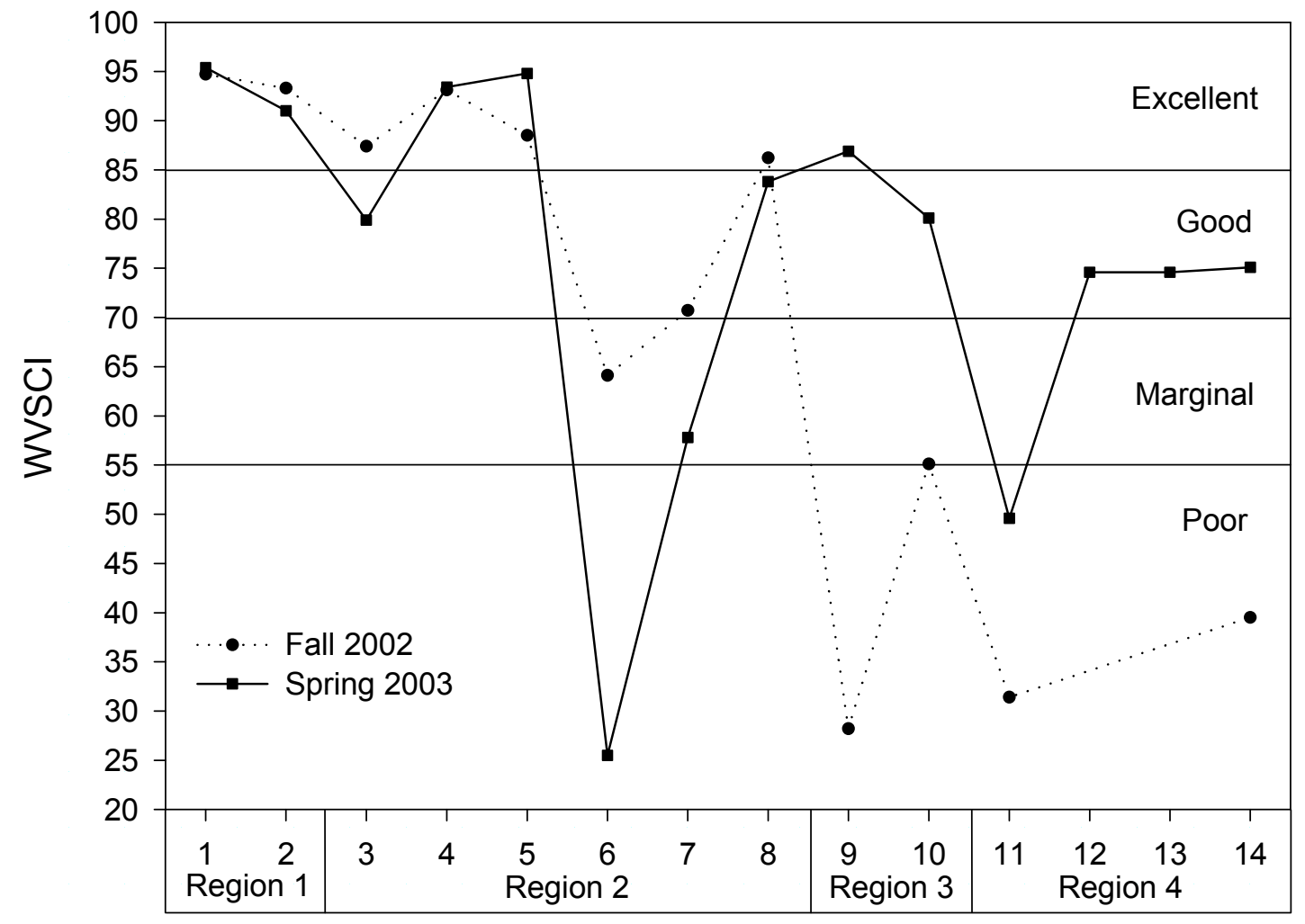

Site/Region 
Figure 4.

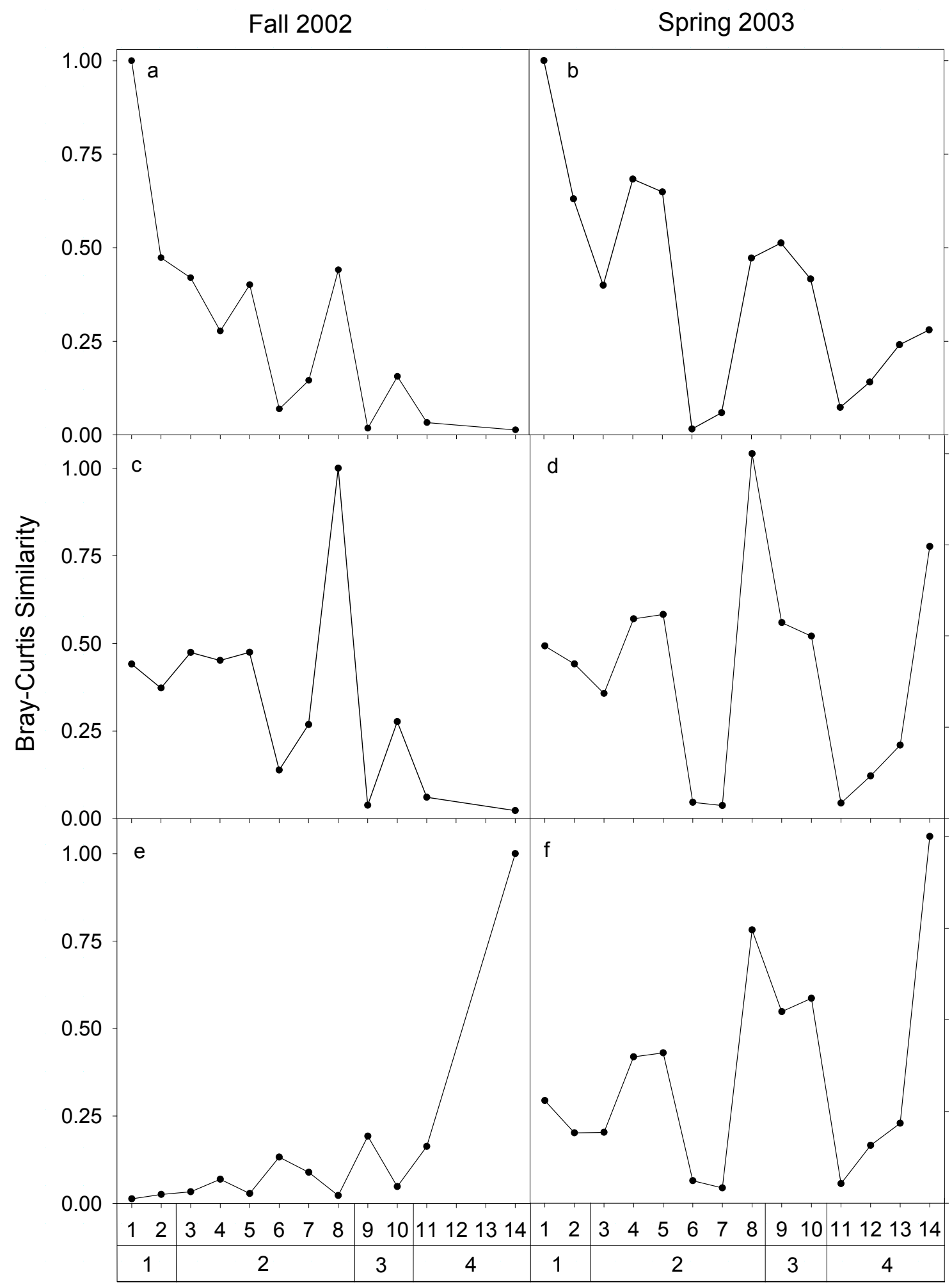

Site/Region 
Figure 5.

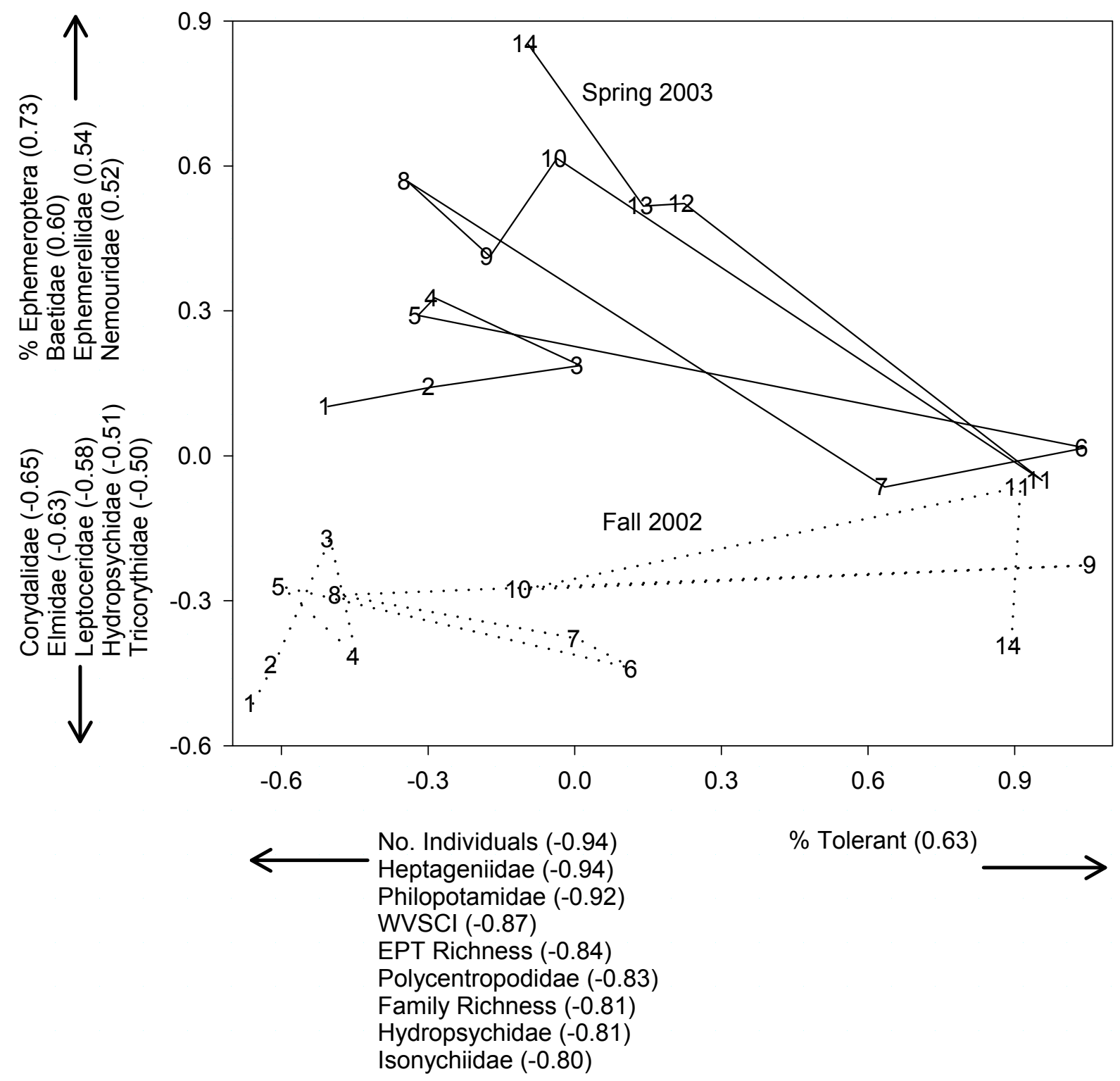


Figure 6.

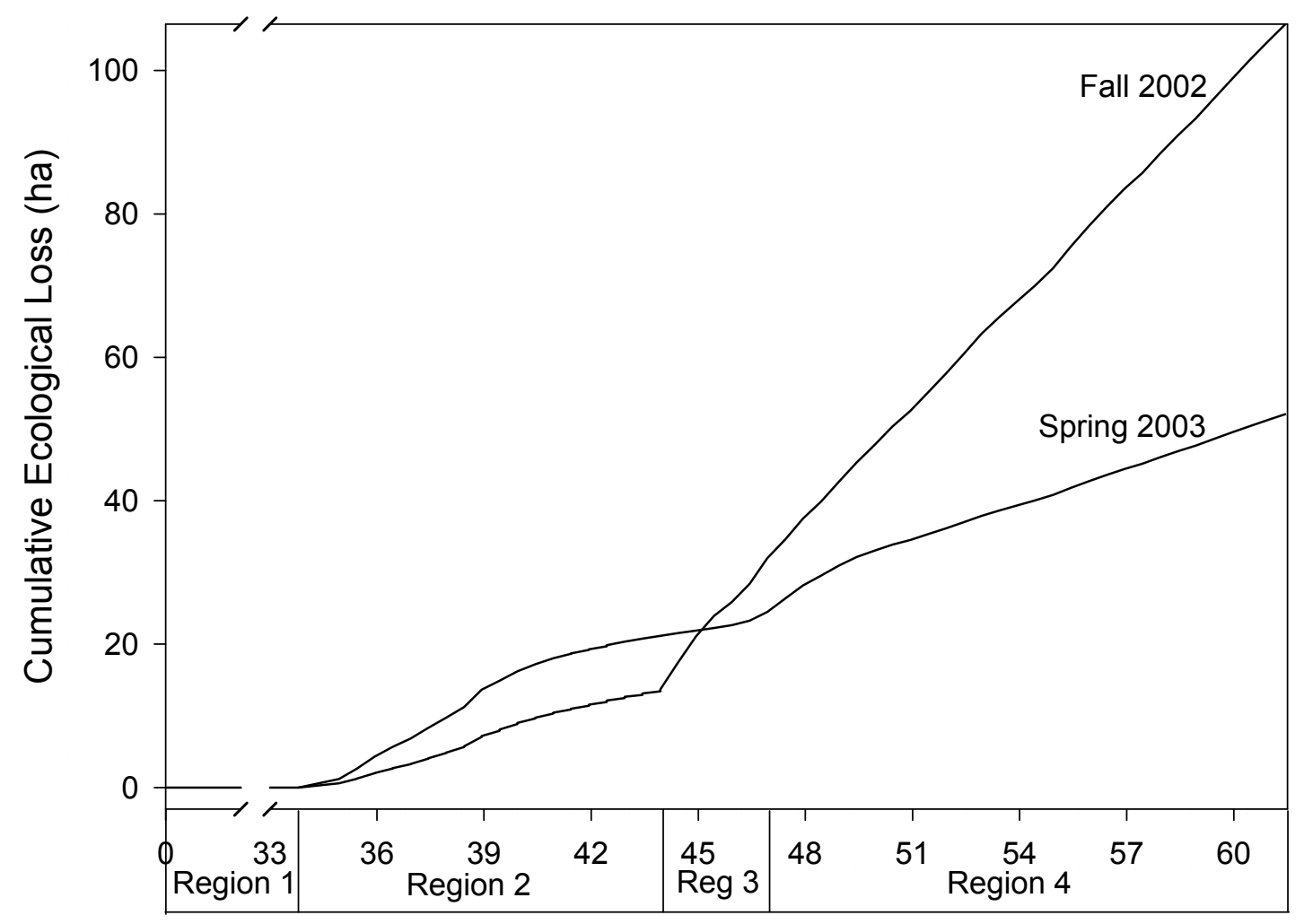

Downstream Distance (km)/Region 


\section{Appendix 1: Submission of Chapter 2 to Environmental Toxicology and Chemistry- Submission Cover Letters, Reviewers' Comments, and Response to Comments}

\section{Cover Letter Accompanying Submission}

Dear Editor Environmental Toxicology and Chemistry:

We would like to have the enclosed manuscript entitled "Water Chemistry Based Classification of Streams and Implications for Restoring Mined Appalachian Watersheds" considered for publication in Environmental Toxicology and Chemistry. These data are not contained in any other manuscript.

In this manuscript, we present an innovative approach that combines multivariate statistical techniques to produce and validate a stream classification system based on water chemistry in a two coal-mined watersheds in north-central West Virginia. To our knowledge, these results are the first of their kind. The ability to classify water quality as we have found in this region has practical implications in generalizing remediation of strategies and prioritizing remediation efforts, and potentially can be transferable to other coal-mined, acidimpacted watersheds.

Jason Freund, Michael Strager and Richard Herd are acknowledged for their ideas and contributions to the development of this study. This paper was prepared with the support of a grant from the U.S. Environmental Protection Agency to J. Todd Petty, Paul F. Ziemkiewicz, and James M. Stiles under Contract Agreement No. RD-83136401-0. However, any opinions, findings, conclusions, or recommendations expressed in our manuscript are those of the authors and do not reflect the views of the U.S. Environmental Protection Agency.

Thank you for your consideration. I can be reached easily via email (gmerovic@mix.wvu.edu) or phone (304-293-2941 ext. 2318).

George T. Merovich, Jr.

Corresponding Author 


\section{Cover Letter Accompanying Revised Submission}

Dear Mr. Howard,

Enclosed is our revised manuscript entitled "Water Chemistry Based Classification of Streams and Implications for Restoring Mined Appalachian Watersheds." We appreciate your helpful comments on the original manuscript. We have addressed all reviewer comments in the revised manuscript and/or in the response letter to reviewer comments. We hope this revision meets your approval. To reiterate, these data are not contained in any other manuscript. In this manuscript, we present an innovative approach that combines multivariate statistical techniques to produce and statistically confirm a stream classification system based on water chemistry in a two coal-mined watersheds in north-central West Virginia. To our knowledge, these results are the first of their kind. The ability to classify water quality as we have found in this region has practical implications for generalizing remediation of strategies and prioritizing remediation efforts, and potentially can be transferable to other coal-mined, acid-impacted watersheds. Jason Freund, Michael Strager, Richard Herd, and Ken Stewart are acknowledged for their ideas and contributions to the development of this study. This paper was prepared with the support of a grant from the U.S. Environmental Protection Agency to J. Todd Petty, Paul F. Ziemkiewicz, and James M. Stiles under Contract Agreement No. RD-83136401-0. However, any opinions, findings, conclusions, or recommendations expressed in our manuscript are those of the authors and do not reflect the views of the U.S. Environmental Protection Agency. Thank you for your consideration. I can be reached easily via email (gmerovic@mix.wvu.edu) or phone (304293-2941 ext. 2318).

Sincerely,

George T. Merovich, Jr.

Corresponding Author 


\section{Reviewer Comments and Responses to Comments (in blue)}

Dear Mr. Howard,

We appreciate the helpful comments on our manuscript "WATER CHEMISTRY BASED CLASSIFICATION OF STREAMS AND IMPLICATIONS FOR RESTORING MINED APPALACHIAN WATERSHEDS". We have addressed all comments in the revised manuscript and/or in this letter. We used BLUE font color to distinguish our response from the reviewer comments or questions here and to highlight the changes in the revised manuscript as per your instructions to authors. We hope this revision meets your approval.

Sincerely,

George T. Merovich, Jr., Corresponding Author

Reviewer \#1 (Comments for the Author(s)):

Review of ET\&C ms\# 06-424, by G.T. Merovich et al., "Water chemistry based classification of streams and implications for restoring mined Appalachian watersheds."

This manuscript describes a novel approach towards developing a water chemistrybased classification scheme for streams in mined watersheds. The classification scheme is based on a chemical analysis of a relatively large number water samples taken during two seasons (spring and fall), representing high and low stream flow conditions. A robust multivariate descriptive approach was used to classify streams with considerable success.

The authors should be commended for preparing a very well-written and highly comprehensible manuscript from such a complex dataset. I have no major concerns for this work. Although quite minor (and more semantic than scientific), I am a little uncomfortable with the phrase 'statistical significance' (e.g., lines 150, 153, 157 and elsewhere) in the context of a descriptive multivariate approach, such as PCA and CA. Discussion around 'statistical significance' is typically reserved for inferential analyses involving tests on null 
hypotheses, which, of course, is not the case for PCA and CA. In this manuscript, the authors set out a priori criteria for including principal components in the final analysis, variables in the cluster analysis, among others. Those meeting the a priori criteria are referred to as 'statistically significant,' where it's probably more appropriate to say, 'met the a priori criteria,' (or something equivalent). There is nothing wrong with the approach-just the phraseology around 'significance.'

Although PCA is generally considered a descriptive technique, the terminology "statistical significance" is used in its presentation (e.g., Hair et al. 1995, McCune and Grace 2002). Given that the objective of PCA is summarization and data reduction, we used it to search for patterns within the variation of our water chemistry data that were significant in the sense of being meaningful for a stream classification system. Furthermore, because of the data reduction purpose and because PCA is finding new variables that are combinations of the original variables, one must ultimately determine a cutoff point (fuzzy as it might be at times) as to where to draw this line at extracting meaningful dimensions from the whole population of dimensions in the data set. Eigenvalues are values that represent variation explained by the reduced dimensions and are therefore statistics, just as a "mean" is a statistic that attempts to quantify central tendency. So even though no hypothesis testing takes place and no inferences are drawn in the probabilistic sense, we are still dealing with estimates of parameters (i.e., statistics). Therefore, "statistical significance" we think in the end is still valid terminology.

So, the rationale for the use of the eigenvalue of $\geq 1.5$ for "significance" in choosing and interpreting principal components is the following. If a principal component explains as much variation equivalent to at least 1.5 original variables then it must be a "significant" (e.g., meaningful) new variable in summarizing the variation latent in the host of original variables and therefore worthy of retaining and interpreting. It has been suggested (McCune 
and Grace 2002) that a value of 1.0, which many researchers use as a cutoff, is not conservative enough (i.e., the cutoff should be higher). Although where this cutoff is drawn is debated, ultimately and practically for our results it is meaningless because the variation explained by the first two axes as represented in eigenvalues was much greater than unity.

Along the same lines, if an original variable "loads" onto any principal component with a value of greater than $|0.5|$ then that value is 'practically' significant (Hair et al. 1995) because it means that the principal component explains or captures $25 \%$ (i.e., $0.5 * 0.5 * 100$ ) of the variance of that single original variable (i.e., factor loading $=$ correlation coefficient of the original variable with the new extracted factor). In fact, it has been shown that with a sample size of $\geq 350$ cases (ours was 375 , i.e., R-type components analysis) that a factor loading of greater than only $|0.3|$ is statistically significant (Hair et al. 1995) in the sense that the original variable is being associated positively or negatively with the new factor greater than that expected simply from chance alone. Therefore, all of the original variables that we used to interpret the first two principal components (e.g. Figure 2 and factor loadings $\geq|0.5|$ ) are indeed statistically significant values (alpha level 0.05) in the classic sense.

Although we think "statistical significance" is fully appropriate based on the above, we are revising the text to remove the "statistical" part of "statistical significance", but we are retaining the "significance" part. Changes took place on line number 162 of the revised manuscript.

Otherwise, this manuscript was a pleasure to read. The authors point out both the strengths and limitations of the approach, and raise a number of interesting questions stemming from the work. This is a solid piece of work.

\section{Reviewer \#2 (Comments for the Author(s)):}

General: This paper reports the results of the analyses of water quality samples representing sites affected to differing degrees by acid mine drainage (AMD) in two adjacent 
watersheds. The purpose of the study was to determine whether waters could be typed on the basis of their chemical composition as a guide to potential remediation. Samples were collected three times from each site, analyzed chemically for routine water quality parameters and major and trace elements. Several multivariate statistical procedures were employed to determine whether the sites were related in terms of their water quality. The conclusion, based on the results of the chemical and statistical analyses, was that the waters were of six types: reference, soft, hard, transitional, moderate AMD, and severe AMD. The authors further concluded that their results"...also suggest that human related stressors superimposed on geology are responsible for producing distinct water quality types in this region as opposed to more continuous variation..." Unfortunately, the details of the study design are so vaguely identified that it is impossible to judge the validity of the results and conclusions. The streams in these watersheds are obviously related, both hydrologically (by virtue of upstream/downstream and, possibly, groundwater connections) and geochemically (due to shared geology, etc.). However, no information on the spatial/hydrologic relationships among/between the sites is offered; even the map fails to identify the streams that were sampled. As such, the paper has not accounted for the potential contributions of spatial autocorrelation to the groupings (see Peterson et al. 2006, Environ Monit Assess 121:571), and the observed patterns may have resulted at least in part from the way the sites were selected.

We have added the streams layer to the map in Figure 1 so that sampling locations are related spatially within and among each watershed. In the methods on lines 115-116 we have added a statement that clarifies the sampling design. We address the issue of autocorrelation below in comment No. 4 and on lines 382-388 in the discussion of revised manuscript.

In addition no evidence is presented to indicate that factors other than AMD (municipal/industrial discharges, impoundments, etc.) were accounted for in the design. 
Intuitively, one would expect streams in this region not influenced by AMD to be hard, soft, somewhere in between (reference), and perhaps differing in organic content depending on geology, soils, wetlands, impoundments (many of these in the watershed), and other watershed-scale factors. These waters would then be affected by inter-mixing and interactions with rocks, soils, etc. with transit downstream, and be affected to differing degrees by AMD at various points in their respective networks. The expectation would therefore be a continuum of acidification and elemental enrichment that represents the net sum of the basic water quality + watershed factors + AMD. One might also expect soft waters to be more likely to progress to severe AMD than hard or transitional. Such gradients are somewhat evident in Fig. 2. However since none of the previously identified spatial variables has been accounted for, one cannot rule out the possibility that the observed patterns are artifacts of site selection. The descriptions of the field procedures and chemical methods also lack sufficient detail to judge their adequacy.

This concern is similar to the above concern. We have added statements about field procedures and chemical methods between lines 131 and 146 of the revised manuscript. We also added a statement about other factors influencing water chemistry below in comment No. 4 and on lines 116-118 in the methods section of the revised manuscript.

Additional detailed comments follow.

Key:

No. Page (original manuscript) Line(s) (original manuscript) Question or comment 1. 4 37-38 Statistically validated? How defined? Even if true, the statement is not necessary in the abstract.

We agree and so have revised this to read "... a statistically supported stream classification system..." rather than "validated" (see lines 36-37 of revised manuscript). 
Classification tree analysis, however, does employ a 10-fold cross-validation procedure. 2. 4 39-41 Alternative explanations are also possible.

The reviewer comments that alternative explanations for the emergence of groups from the expected pattern of continuous variation is possible, but does not offer any of those possibilities. Therefore, we can not return a response on those alternative explanations or interpretations.

3. 7 93-94 Grammatically incorrect; the rivers are tributaries, but not the basins.

We have corrected this grammatical error on line 91 of the revised manuscript.

4. 7 113-117 Were the 123 sites hydrologically related (i.e., some downstream of others), or were they selected to be independent of each other? Were they selected such that factors other than coal mining (municipal and industrial discharges, impoundments, etc.) were eliminated? Inspection of Appendix Fig. 1 suggests that the sites were hydrologically connected, but it's hard to tell; the map doesn't show streams, only watershed boundaries and sites.

We have included streams on the figure in Appendix Figure 1. The sites were selected to minimize interdependence and to capture the broad range of water quality present in the watersheds. We know from other studies that water chemistry in this region is influenced predominantly by acid rain and acid mine drainage (Petty and Barker 2004, Petty and Thorne 2005, Freund and Petty 2007, Merovich and Petty 2007). Therefore, we focused our sampling and analytical efforts to explain the variation in water chemistry due to these factors rather than from nutrients, industrial discharge, etc. We have added some statements in the methods to clarify how sites were selected. These statements are in the revised manuscript on lines 115-118.

It is true that some of the sites are "hydrologically related" in the upstreamdownstream sense, possibly by underground connections, and by coarse-scale factors beyond 
watershed boundaries (e.g., Peterson et al. 2006). Our intension for the analyses was to explain the variation in water chemistry and to categorize it, if possible. The intention was neither to examine how spatial location within drainages relates to water chemistry of (adjacent) sites, nor was it to find what explanatory variable(s) might determine a water sample's chemical constellation or categorical type, in which case autocorrelation would have to be controlled. It is not hard to imagine why and how the variation in water chemistry between two sites might be correlated depending on 1) how close they are, 2) if they drain the same geology, 3) if they are in the same drainage, and even if they are hydrologically connected between drainage divides, 4) if a sampling site is downstream of another, etc. Some of our sites were hydrologically related specifically because one was downstream of the other, but this represents real world conditions, and should not necessarily be excluded from an analysis that is meant to find and describe groups. We have added statements to the discussion of the revised manuscript that address this issue and we specifically cite the paper (Peterson et al. 2006) that was referred to by the reviewer in the context of the question (lines 382-388 of the revised manuscript).

5. 8 120-123 A brief description of these methods is more important than who's they are. If the agency has a written procedure that is generally available, it should also be cited.

Between lines 131 and 146, we added a revised description of our methods.

6. 8128 More details needed: Filter pore size? Cleaning methods? Sample storage conditions? Holding times? Etc., etc., etc...?

As above. We added these details on lines $131-141$ of the revised manuscript.

7. 8129 Were the ionic forms measured? If not, most of these (all except chloride) are major and trace elements, not ions (or exclusively metals). See also next. 
These questions are answered in the brief description of our methods on lines 135 142 of the revised manuscript.

8. 8 132-133 Who did the analyses is irrelevant. More importantly, how were they analyzed? By what method (s)? Detection limits? QA?

As above as well. However, we summarized information about detection limits (with analytical methods) in a new appendix table (Appendix Table 1) of the manuscript as referred to by lines 141-142 of the revised manuscript. We did not want to risk the methods becoming too cumbersome with these details. QA was addressed on lines 145-146 of the revised manuscript.

9. 8 It is likely that the zero alkalinity values co-occur, which creates a situation where all the values for a site could be $=1.0$ and the variance $=0$. Problem for parametric analyses? (see also Table 1).

All the values for alkalinity for a site could be 0 , with variance $=0$, but there were more than just one site in the severe AMD group. In other words, the variance for alkalinity in the severe AMD group was not 0 , because some sites that classified as severe AMD type had at least some alkalinity. See more explanation below in Table 1 for parametric analyses. 10. 9 What is the significance (figuratively and statistically) of the 1.5 value? I.e., where did it come from? Why selected? Likewise for the 0.5 value attributed to ref. [22]?

This question is nearly the same as the concern from reviewer \#1. Please see our response under reviewer \#1. Changes took place on line number 162 of the revised manuscript with regards to the issue of statistical significance.

11. 9157 The concentrations of $\mathrm{Ba}, \mathrm{Cd}$, and $\mathrm{Cr}$ should be presented (in Table 1). Even thought they added no value to the multivariate analyses, it is potentially useful information for others. 
We have made this change by adding the data to Table 1 in the revised manuscript. 12. $10 \quad 163-170$ Why were only PC1 and PC2 tested, and not the individual water quality parameters? Don't we need to know which parameters differ significantly (or not) among the types of sites? Also, were any of the concentrations censored (i.e., <LOD)? If so, how were these values used (or not) in the statistical analyses?

PCA reduces variation contained in a set of variables into new variables that are linear combinations of the original variables, thereby summarizing important gradients in a few tractable dimensions. In essence, we describe two important dimensions in the data set, and these are examined for differences between water types determined by cluster analysis. We did this rather than using all the variables and getting overwhelmed with a bunch of univariate tests that would need adjustment of type 1 error rates. Yes it is valuable to know which variables are different among water types, but this approach of multiple ANOVAs was not the approach we decided to take. This information is captured in PC space and in the ANOVAs on PC scores of the first two dimensions instead. For example, from Table 1 we can tell that water types $\mathrm{A}, \mathrm{T}, \mathrm{M}, \mathrm{H}$, and $\mathrm{R}$ and $\mathrm{S}$ as a group are all statistically different with regard to the original variables that load highly on PC1 (in either the positive direction (metals, sulfate, conductivity) or the negative direction $(\mathrm{pH})$ ). Thus, the value of PCA in reducing a complex, multidimensional data set into its strongest components.

One half of the limit of detection for a particular chemical constituent was used whenever that constituent was reported as less than the method's limit of detection. Because these values and the variation within them are so low compared to the variation observed within other chemical constituents, using one-half of the LOD for constituents under these cases would not affect any statistical procedures or conclusions based on our objectives. If anything, this approach would only mask patterns occurring within unimpaired waters (our reference type), which would not affect our objectives of finding and describing differences 
in water quality types. Lines $142-144$ of the revised manuscript include a statement about how values less than the LOD were handled.

13. $12 \quad$ Spatial variability at what scale? I.e., relative to proximity of the sites to each other?

This should not read “...spatial variability...” but simply just “...variability...” The correction was made on line number 220 of the revised manuscript.

\section{4. $14 \quad 268$ Chloride?}

Yes, fixed on line 272 of the revised manuscript.

15. $18 \quad 345-347 \quad$ As indicated previously, continuous variation is expected among hydrologically related sites, yes? (if they were in fact related, which can't be determined because the study design is not presented).

Same concern as above. See response to question No. 4 above.

16. Table 1 Sig. of individual variables? Numbers of each type? Any censored $(<$ LOD) values? For alkalinity, number of zero values in each type? Note that for the sever AMD group the mean $=0.5$; if 1.0 was substituted for 0 values, half the observations must have been zeros. Assumptions of statistical methods?

Sig. of individual variables? This question is the same as the comment above. See our response above in comment No. 12 to the question about the significance of individual variables across the water quality types.

Numbers of each type? We added the numbers of samples classifying into each water quality type in Table 1 . This description occurs on the table caption and the data occur in the table's first row in the revised manuscript.

Any censored values? This is the same as above in comments 8 and 12, and it is addressed on lines 142-144 of the revised manuscript, including the new Appendix Table 1. 
Zero value in each type? Soft type had 6 alkalinity values at 0 , and moderate type had 7. Severe AMD had 30 values of 0 for alkalinity...

Assumptions of statistical methods? ...despite many zero values for alkalinity under severe AMD, PCA is robust to violations of the assumption of linearity. However, it does do better at redistributing variation and representing gradients when variables have linear relationships. We assume this to hold true for the PC scores when we used ANOVA (robust to minor violations as well) to test for differences among water types.

17. A.F. $1 \quad$ Map contains no streams?

Map now contains streams.

\section{Literature Cited}

Freund, J. G., and J. T. Petty. 2007. Response of fish and macroinvertebrate bioindices to specific stressor levels in a mined Appalachian watershed. Environmental Management In Press.

Hair, J. F., Jr., R. E. Anderson, R. L. Tatham, and W. C. Black. 1995. Multivariate data analysis with readings. 4th edition. Prentice Hall, Upper Saddle River, NJ.

McCune, B., and J. B. Grace. 2002. Analysis of ecological communities. MjM Software Design, Gleneden Beach, OR.

Merovich, G. T., Jr., and J. T. Petty. 2007. Interactive effects of multiple stressors and restoration priorities in a mined Appalachian watershed. Hydrobiologia 575:13-31.

Peterson, E. E., A. A. Merton, D. M. Theobald, and N. S. Urquhart. 2006. Patterns of spatial autocorrelation in stream water chemistry. Environ Monit Assess 121:571-596.

Petty, J. T., and J. Barker. 2004. Water quality variability in tributaries of the Cheat River, a mined Appalachian watershed. Pages 1484-1504 in 2004 National Meeting of the American Society of Mining and Reclamation and the 25th West Virginia Surface 
Mine Drainage Task Force. American Society of Mining and Reclamation, Morgantown, WV.

Petty, J. T., and D. Thorne. 2005. An ecologically based approach to identifying restoration priorities in an acid-impacted watershed. Restor Ecol 13:348-357. 


\section{Appendix 2: Submission of Chapter 4 to Hydrobiologia- Submission Cover Letter, Reviewers' Comments, and Response to Comments}

\section{Cover Letter Accompanying Submission}

Dear Editor Hydrobiologia:

J. Todd Petty and I would like to have the enclosed manuscript "INTERACTIVE EFFECTS OF MULTIPLE STRESSORS AND RESTORATION PRIORITIES IN A MINED APPALACHIAN WATERSHED” considered for publication in Hydrobiologia.

These data are not contained in any other manuscript. In this manuscript, we detail the results of a field study of the Cheat River, WV, USA. To our knowledge, it is the first to document the severe, interactive effects of diffuse levels of acid mine drainage and thermal effluent on benthic macroinvertebrate communities.

Thank you for your consideration. I can be reached easily via email (gmerovic@mix.wvu.edu) or phone (304-293-2941 ext. 2318).

George T. Merovich, Jr., Corresponding Author

Reviewer Comments on HYDR 1646 (Merovich and Petty 2007)

Ref Reviewer 1 : Reject

This is a solidly written paper with adequate analysis. I had a few minor editorial changes that will be caught by an editor. A clear impact on community health is demonstrated downstream of an acid mine drainage input as well as below a heated effluent. Furthermore, an interaction between these two stressors is observed. The main problem I have with this manuscript is that I'm not convinced of the utility of examining the benthic macroinvertebrate community data in three different ways. This is a rather long paper, and so much time is spent between the methods, results and discussion in explaining the data using these three approaches, but really, all three methods essentially tell the same story. There maybe be some different bumps and details in the various figures, but essentially, all three methods suggest that the AMD impacted communities were different from the reference sites, 
as were the heat impacted sites, and there appeared to be an interaction between the two. The authors have not entirely sold me, either, on the uniqueness of this study. I think that the EU approach was interesting and could be expanded on somewhat, and I was especially interested in the discussion of the "stress-induced community sensitivity model". Perhaps these data could be further examined as a test of this model. In summary, I think this is a well done study and a well written paper, but I feel the authors need to frame their story in a way that makes it sound more unique.

\section{Ref. Reviewer 2: Revisions}

This is a well written paper describing the macroinvertebrate communities and water quality of the Cheat River in WV, USA. I believe the readers of Hydrobiologia will find the paper of interest. I have a few comments and concerns, which I list below.

No information on in-stream habitat is provided, leaving the reader to assume that all changes in macroinvertebrate community structure are driven by water chemistry and temperature. Over the length of the study reach, about $60 \mathrm{~km}$, are there changes in sediment characteristics, algal productivity, depth, velocity, or other factors that could contribute to changes in macroinvertebrate community structure independently of AMD or temperature? If quantitative data are not available, even a qualitative description of the in-stream conditions would be helpful.

Why are EU's presented as area (ha) rather than length? This seems to make the calculation (and description) more complicated than needed. The calculation appears to use the same river width in both fall and spring (equal surface area of 544 ha), despite lower flow during the fall and presumable smaller wetted width.

I would expect smaller surface area, and thus lower expected EUs, during periods of low flow. By using a constant width, any value in expressing EU's as area appears to be lost, unless I am missing something. 
I suggest moving the justification for using family level taxonomic resolution from the top of page 9 to the end of the section on Benthic Macroinvertebrates (top of page 8), where taxonomic resolution is first mentioned.

On page 10, it states: "Expected EUs were calculated as the surface area of each river segment multiplied by 1.0" What is the point in multiplying by 1? It does nothing. In general, the description of the EU calculation is complicated, and any re-wording that could make that section clearer would be good.

On page 11 it is stated that heat impacts were not present in spring 2003. Was the power plant not operating or operating at reduced capacity? A more detailed description of the inputs from the power plant in the site description section would be useful.

I suggest using $\mathrm{m} 3 / \mathrm{s}$ rather than $\mathrm{cms}$ (p. 13, Fig. 3)

I think the data in Fig. 3a could easily be put into Table 2.

For clarity, consider making Fig. $3 b$ into two graphs with a common $x$-axis. This would allow the y-axis for temperature to be expanded and the differences between sites more readily seen.

\section{Associate Editor's Comments: Major Revisions}

Even though one reviewer has recommended rejection I believe with the appropriate revisions that this manuscript could be acceptable. The manuscript is well written and conclusions are supported by a wealth of data, however one reviewer feels that the study lacks uniqueness. The authors should focus on addressing this point and and I am encouraging them to revise accordingly

Response to "Comments for the Author" on HYDR 1646 (Merovich and Petty 2007)

We appreciate your consideration of our manuscript "Interactive effects of multiple stressors and restoration priorities in a mined Appalachian watershed" for publication in Hydrobiologia. 
We believe this paper detailing our research is unique, and that it contains important findings on the effects of multiple, interacting stressors in pollution ecology and restoration ecology. For example, in the Discussion section (p. 20 original submission), we highlight that, as far as we know, there are no other field studies that have examined the potential for interactive effects of acid mine drainage and thermal pollution specifically, and that studies on potential interactive effects of multiple stressors in general are rare. In addition, we are unaware of any data other than ours that suggest that diffuse levels of multiple stressors may result in greater ecological damage than severe local impacts from single stressors (p. 21 original submission). We also employed a technique that combined the use of an IBI and similarity analysis that we believe is useful and important, but that has not been attempted by others (p. 23 original submission).

Therefore, we believe that our study and approaches are unique, but we also agree with the "Comments for the Author" that the unique aspects are probably not as clearly and demonstrably portrayed as they need to be, especially in the Introduction. Consequently, we made major revisions corresponding to the suggestions in the "Comments for the Author" in the following ways:

\section{Issues of Uniqueness and Paper Length}

First, we revised the Abstract so that it stresses the uniqueness of our research and so that it highlights our biggest findings. These findings include those associated with the interactive effects of thermal effluent and acid mine drainage compared to the effects of stressors in isolation.

Secondly, we shortened, reorganized, and revised the introduction so as to focus on multiple, interacting stressors rather than having so much focus on general bioassessment concepts, which is rather commonplace. Specifically, paragraphs 1, 2, and 4 (p. 3-4 revised 
submission) of the Introduction were most heavily revised to highlight the focus of multiple, interacting stressors. A few additional citations were added in relation to this.

Another major revision dealing with uniqueness was addressed in the Discussion. The first two paragraphs of the Discussion were shortened, reorganized, and revised to bring to the forefront the evidence of the effects of multiple, interacting stressors, specifically AMD and thermal effluent, on benthic communities. This emphasizes one big conclusion we wanted to make that the interacting stressors brought extensive impairment to the river, while ecological condition improved rather rapidly downstream of single stressor inputs.

We kept intact our statements about our study being one of the first to document interactive effects of AMD and heat, and that such field studies in general are rare (p. 18 revised submission). Also, we believe our field data is the first to provide some evidence of Vinebrook's et al. (2004) stress induced community sensitivity model, and that the diffuse levels of multiple stressors AMD and heat are responsible for more extensive impairment than intensive levels of single stressors from which communities recover from rapidly, because organism's tolerances are negatively correlated to differing stressors, and because it is impossible to have a stress induced sensitivity from the presence of only one major anthropogenic stressor (p. 19 revised submission). We also gave another possible explanation (on p. 19 of the revised submission) for the widespread impairment associated with the co-occurrence of AMD and thermal effluent.

These findings are so important because diffuse levels of multiples stressors are probably more common and widespread in the environmental than acute inputs of single stressors (top p. 20 end of half-paragraph revised submission).

The Influence of Habitat

We appreciate the comment concerning the possible influence of habitat on these benthic communities. Therefore, we addressed the possibility of habitat structuring 
macroinvertebrates in the Cheat River with a paragraph and a few additional citations (end $\mathrm{p}$. 21 revised submission).

Other Specific Changes to Address Paper Length

We also made other edits to specifically address the issue of manuscript length. We deleted Figure 2 of the original submission, because the data are already in Table 2. We shortened the Methods and Results sections each by about $1 / 2$ of a page, by deleting material that was non-essential. For example, in the first sentence of the Methods section of the original submission we deleted the information about the tributaries that combine to form the Cheat River at Parsons, WV. As another example, we deleted from the original submission the comment that reference Region 1 in the upper Cheat River basin is a productive smallmouth bass (Micropterus dolomieu Lacepède) fishery. These edits reduced the paper length from 42 manuscript pages in the original submission to 40 manuscript pages in the revised submission.

\section{Conclusion}

Finally, in conclusion, we believe we have significant findings reported in our paper, and we would like to have the opportunity to show these data to the readership of Hydrobiologia. We hope our revisions are received favorably.

Our Best Regards.

George T. Merovich, Jr., Corresponding Author

J. Todd Petty

\section{Literature Cited}

Merovich, G. T., Jr., and J. T. Petty. 2007. Interactive effects of multiple stressors and restoration priorities in a mined Appalachian watershed. Hydrobiologia 575:13-31. 
Vinebrooke, R. D., K. L. Cottingham, J. Norberg, M. Scheffer, S. I. Dodson, S. C. Maberly, and U. Sommer. 2004. Impacts of multiple stressors on biodiversity and ecosystem functioning: the role of species co-tolerance. Oikos 104:451-457. 


\section{George T. Merovich, Jr.}

Address: $\quad$ Division of Forestry \& Natural Resources

Wildlife and Fisheries Resources

West Virginia University

P.O. Box 6125

Morgantown, WV 26506

Telephone: (304) 293-2941 ext.2318 (office)

Internet: gmerovic@mix.wvu.edu, http://www.stat.wvu.edu/ gmerovic

Personal: $\quad$ Born Camp Hill, PA, June 15, 1971

Hometown Dillsburg, PA

Married to Catherine E. Merovich

Daughter Emily A. Merovich (August 26, 2001)

\section{Academic History and Professional Experience:}

1994 BS, The University of Arizona, magna cum laude, Wildlife \& Fisheries Sciences

1994-1996 Teaching Assistant, Frostburg State University, Department of Biology

1996 Contractual Instructor, Frostburg State University, Department of Biology

1998 MS, Frostburg State University, Applied Ecology and Conservation Biology

1998-2002 Instructor, Department of Biological Sciences, Western Michigan University

1998-2001 Researcher at Kalamazoo Nature Center

2002-present PhD Student and Research Assistant, Division of Forestry \& Natural Resources, West Virginia University

2006-present Instructor Department of Biology, West Virginia University

$2007 \quad \mathrm{PhD}$, West Virginia University, Forestry and Natural Resources, Expected August 2007

\section{Awards and Recognition:}

Academic scholarships (The University of Arizona)

Golden Key National Honors Society invitation

Mortor Board invitation (a national senior honors society)

Dean's List for 7 semesters (The University of Arizona)

Dean's List with Distinction honors for 2 semesters (The University of Arizona)

Teaching Assistantship (Frostburg State University)

Who's Who Among America's Teachers (Western Michigan University)

$\mathrm{PhD}$ Research Assistantship (West Virginia University)

Hoyt PhD Teaching Assistantship (West Virginia University 2005)

Gamma Sigma Delta Honor Society of Agriculture (West Virginia University 2006) 


\section{Certifications:}

First Aid

Adult CPR

Electrofishing safety

Smith System Advanced Drivers Training

\section{$\underline{\text { Research Interests: }}$}

Ichthyology, benthic macroinvertebrates, aquatic ecology, stream ecology, fluvial geomorphology, ecology and evolution of North American freshwater fishes, fisheries management, conservation of native North American fishes, teaching biological sciences. I have a broad interest in aquatic ecology, particularly the ecology, evolution, and conservation of native North American freshwater fishes, and stream ecosystem health. I am especially interested in how community level factors such as interactions with exotic species influence the distribution and ecology of indigenous stream fishes. I am also interested in the relationship between riparian zone quality and the health of aquatic ecosystems, the effects of riparian zone reparation on stream communities, how other artificial or natural landscape disturbances shape aquatic communities. For my PhD research, I studied stream invertebrate communities in watersheds where coal mining, acid mine drainage, and acid rain are important sources of impairment that, in part, define discrete water quality types. I use many new and old multivariate modeling techniques in the $\mathrm{R}$ language and environment for statistical computing to test patterns in these communities, and how they correspond with various elements of the abiotic environment ranging in scale from local water quality types to large scale landscape features. I am currently working on models that predict reach-scale water quality types and reach-scale ecological condition from watershed-scale landscape attributes. I'm also working on quantifying functional processes in streams, such as organic matter decomposition rates, and determining how this is influenced by water quality. The outcomes of this research help us identify stream restoration opportunities as well as stream protection and restoration priorities at the reach and watershed scales from both structural and functional integrity perspectives. In my free time I like to hike along streams. I also like smallmouth bass fishing, spring gobbler hunting, and fall archery season. I have a webpage at http://www.stat.wvu.edu/ gmerovic.

\section{Teaching}

Frostburg State University

1994 Biol 201 Human Anatomy and Physiology Lab

1995 Biol 109 Human Biology and the Environment Lab

1995-1996 Biol 149 Introduction to Biology Lab

1996 Biol 330 Wildlife Techniques Lab/Lecture (with Dr. Lisa Shipley)

Biol 450/550 Ecology and Management of Wildlife Populations Lecture (with Dr. Lisa Shipley)

Western Michigan University

1998-9, 2002 Bios 110 Biological Sciences Lab 
1998-2002 Bios 105 Environmental Biology, Bios 112 Principles of Biology

1999-2001 Bios 234 Outdoor Science

$2000 \quad$ Bios 211 Human Anatomy

2000-2005 Bios 105 Environmental Biology Self-Instructional

Web Page http://vms.cc.wmich.edu/ merovichg/

West Virginia University

2003 and 06 WMAN 493 Stream Ecosystem Assessment

2004-7 BIOL 362/WMAN 446 Limnology Lab

2005, 07 WMAN 445 Introduction to Fish Management

2006 BIOL 102 General Biology

2007 BIOL 341/WMAN 493 Ichthyology Lab

$2007 \quad$ WMAN 633 Quantitative Ecology

Web Page http://www.stat.wvu.edu/ gmerovic/

\section{Memberships:}

Gamma Sigma Delta

Golden Key National Honors Society

The Native Fish Conservancy

North American Native Fishes Association

American Fisheries Society

American Society of Ichthyologists and Herpetologists

North American Benthological Society

Ecological Society of America

\section{Professional Service:}

1999 Textbook reviewer for The New Biology (Introductory and Cell Biology Units), a new issues-oriented non-majors biology text by Joe Levine and Ken Miller.

2001 Textbook reviewer for New Designs for Bio-Explorations, a new inquiry-based biology lab manual by Janet Lanza.

2002 Textbook reviewer for The New Biology (Ecology Unit), an issues-oriented nonmajors biology text by Joe Levine and Ken Miller.

2002 Textbook reviewer for Biology $\left(7^{\text {th }}\right.$ ed.) by Sylvia S. Mader.

2004 Volunteer instructor Aquatic Ecology section 2004 Canon Envirothon (National Competition), West Virginia Wildlife Center, French Creek, WV.

2004 Reviewer for Proc. Annu. Conf. Southeast. Assoc. Fish and Wildl. Agencies Manuscript Number: SE(F)-04-31-01

2005 Reviewer for Proc. Annu. Conf. Southeast. Assoc. Fish and Wildl. Agencies Manuscript Number SE(F)-05-07-03

2005-present Volunteer with Friends of Deckers Creek 


\section{University Service:}

1999-2001 Consultant for Western Michigan University's website on environmental health.

\section{Past Students and Letters of Recommendation:}

1998

1999

2000

2000

2001

2002

2007
Anthony Majewski (field assistant); graduate applicant to the Psychology Department at Western Michigan University

Trisha Benson (field assistant); Western Michigan University student and Kalamazoo Nature Center field researcher

Cari Delong; Accepted to Western Michigan University's Lee Honors College October 2000

Michael A. Fair; Michigan National Bank Detroit Urban League Scholarship.

Nathan Peplinski; Accepted to graduate program in the Department of Biology at Western Michigan University

Rae Immekus; scholarship from the Society of Exploration Geophysicists Jessica Carper; application to WVU Medical Technology Program

\section{$\underline{\text { Research: }}$}

Merovich, Jr., G. T. 1998. Plant germination and growth in strip mine overburden spoil amended with fluidized bed ash. Master's Thesis. Frostburg State University, Frostburg, MD.

Merovich, Jr., G. T. 1999. Fishes of Schippers' Crossing. Pages 21-25, 62 in D. Powless. 1999. A Floristic and Natural Features Inventory of Schippers' Crossing, Kalamazoo, Michigan, 1998. Kalamazoo Nature Center, Kalamazoo, MI.

Merovich, Jr., G. T. 1999. Distribution and relative abundance of fishes in Trout Run at the Kalamazoo Nature Center. Kalamazoo Nature Center Report for the Michigan Department of Natural Resources.

Merovich, Jr., G. T., and J. T. Petty. 2007. Interactive effects of multiple stressors and restoration priorities in a mined Appalachian watershed. Hydrobiologia 575:13-31.

Merovich, Jr., G. T., J. M. Stiles, J. T. Petty, J. Fulton, and P. F. Ziemkiewicz. 2007. Water chemistry based classification of streams and implications for restoring mined Appalachian watersheds. Environmental Toxicology and Chemistry 26:1361-1369.

Merovich, Jr., G. T. 2007. Stream water quality and benthic macroinvertebrate ecology in coalmining, acid-sensitive region. PhD Dissertation. West Virginia University, Morgantown, WV. 
Merovich, Jr., G. T., and J. T. Petty. In Prep. Correspondence between stream macroinvertebrates and a discrete disturbance gradient: consequences for diagnosing stressors. Ecological Applications.

\section{$\underline{\text { Presentations }}$}

George Merovich. 2004. Benthic macroinvertebrate communities along a continuum of the Cheat River: an impact assessment of the Albright Power Station. Presented at graduate student seminar, Wildlife and Fisheries Program, West Virginia University, February 25, 2004.

George Merovich* and J. Todd Petty. 2004. Assessing the impact of multiple stressors on benthic macroinvertebrate communities in the Cheat River. Eighth Annual Davis College Graduate Student Conference, Blue/Gold Rooms of Towers, Evansdale Campus, West Virginia University, Morgantown, West Virginia, April 08, 2004

George Merovich. 2005. Assigning levels of ecological impairment to multiple interacting stressors in the lower Cheat River Basin. Presented at graduate student seminar, Wildlife and Fisheries Program, West Virginia University, March 2, 2005.

George Merovich* and J. Todd Petty. 2005. Assigning levels of ecological impairment to multiple interacting stressors in the lower Cheat River, WV. Ninth Annual Davis College Graduate Student Conference, Blue/Gold Rooms of Towers, Evansdale Campus, West Virginia University, Morgantown, West Virginia, April 14, 2005.

George Merovich. 2007. Water quality patterns among streams in the mountains of North Central West Virginia and consequences to benthic macroinvertebrate communities. Invited presentation to student subsection of American Fisheries Society, West Virginia University.

George Merovich* and J. Todd Petty. 2007. Interactive effects of multiple stressors on riverine macroinvertebrate communities and implications towards prioritizing restoration efforts. 2007 WV-PA Joint AFS Chapter Meeting. March 9th-10th Ramada Inn, Morgantown, WV.

George Merovich* and J. Todd Petty. 2007. Water chemistry based classification of streams and the correspondence with benthic macroinvertebrate communities in mined watersheds. Eleventh Annual Davis College Graduate Student Conference, Blue/Gold Rooms of Towers, Evansdale Campus, West Virginia University, Morgantown, West Virginia, April 19, 2007.

George Merovich* and J. Todd Petty. 2007. Scheduled: Correspondence of benthic macroinvertebrate communities with a water chemistry based classification of streams in a mining influenced region. Virginia / West Virginia Water Research Symposium, The Inn at Virginia Tech and Skelton Conference Center, Virginia Tech, Blacksburg, Virginia, November 28-29, 2007. 


\section{References:}

Dr. William J. Pegg, Major advisor, Frostburg State University, (301) 687-4343

Dr. Lisa Shipley, Washington State University, (509) 335-9182

Dr. Alexander Enyedi, Western Michigan University, (269) 387- 5600

Dr. J. Todd Petty, Major advisor, West Virginia University, (304) 293-2941 x 2417

Dr. Kyle J. Hartman, PhD committee member

Dr. Stuart Welsh, PhD committee member

Dr. Jeffrey Skousen, PhD committee member

Dr. Paul Ziemkiewicz, PhD committee member 